\title{
METALLHORTE DER JÜNGEREN UND SPÄTEN RÖMISCHEN KAISERZEIT IN BÖHMEN
}

\author{
Rastislav Korený - Petra Jánská - Jiří Hošek ${ }^{\circledR}$ - Jan Jílek ${ }^{\circledR}$
}

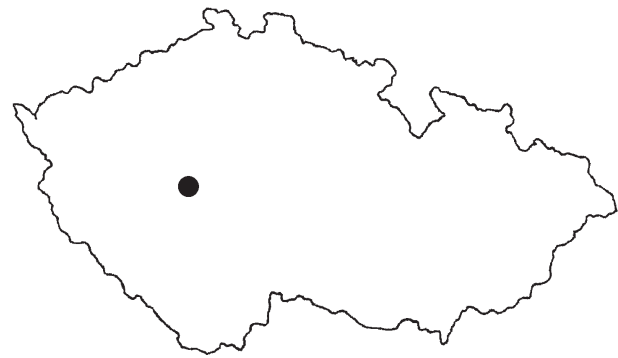

DOI: https://doi.org/10.31577/szausav.2021.68.13

Keywords: Bohemia, chronology, $3^{\text {rd }}-4^{\text {th }}$ century AD, functional replicas, archeometalurgical analysis, hoards

\section{Hoards of metal objects dated to the $3^{\text {rd }}-4^{\text {th }}$ century AD in Bohemia}

This paper refers to three hoards of metal objects. Recent one from Rosovice and two older (but originally incorrectly dated) from Lety near Dobřichovice and Benátky nad Jizerou in central Bohemia region. The analysis confirmed that all three hoards were buried during $3^{\text {rd }}-4^{\text {th }}$ century AD. The paper also includes the results of the archeometalurgical analysis of scythes found in Rosovice and description of making functional replicas.

\section{EINLEITUNG \\ (R. Korený)}

Das Thema der Studie umfasst zum Teil neue und zum Teil schon früher freigelegte, aber bisher nicht detailliert ausgewertete Hortfunde der römischen Kaiserzeit aus Mittelböhmen. ${ }^{1}$ In die erstere Gruppe gehört der Depotfund aus Rosovice (Bez. Př́bram). Dieser Hort verhalf auf eine bedeutende Weise zum Verständnis und anschließend zur Umwertung und Neudatierung des älteren Befundes aus Lety u Dobřichovic (Bez. Beroun), der irrtümlich ins 6.-7. Jh. eingesetzt wurde; dasselbe gilt auch für den in die Latènezeit datierten Depotfund aus Benátky nad Jizerou (Bez. Mladá Boleslav). Der Beitrag enthält

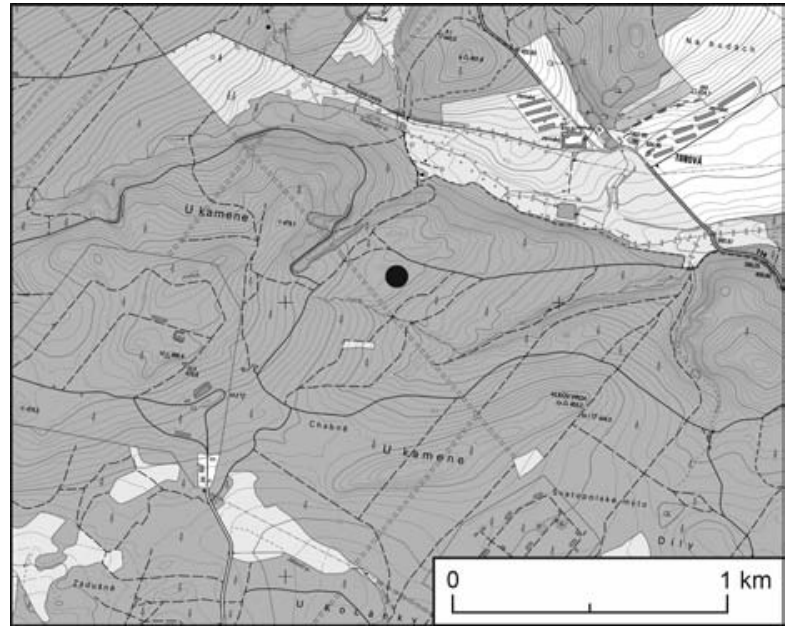

Abb. 1. Rosovice. Fundstelle des Hortes. Hergestellt von P. Čechák und R. Korený. auch die archäometallurgische Analyse der Sensen aus Rosovice und Dokumentation ihrer experimentellen Herstellung.

\section{ROSOVICE, BEZ. PŘÍBRAM \\ Fundumstände und Fundstelle}

Die Sensen entdeckte man mit Hilfe eines Metalldetektors am 2. Mai 2015 im Waldbestand auf einem leicht gewellten Plateau, in der Gabelung zweier namenloser rechter Zuflüsse des Trnovský-Bachs (heutzutage eher trocken) an der Katastergrenze zwischen Rosovice und Dobřís (Abb. 1). Die Koordinaten sind $49^{\circ} 47^{\prime} 21.00^{\prime \prime} \mathrm{N}$, $14^{\circ} 07^{\prime} 22.81^{\prime \prime} \mathrm{E}$, die Höhe über dem Meeresspiegel beträgt $442 \mathrm{~m}$ und die Entfernung vom Wasserlauf ist $100 \mathrm{~m}$. Die Sensen befanden sich in einer

1 Der archäologische Teil der Studie wurde in den Jahren 2015-2017 verfasst, kürzere Zusätze dann noch in den Jahren 2018-2021. Die Herstellung von Repliken, Konservierung (im Archäologischen Institut in Prag durchgeführt) und archäometallurgische Analyse wurden aus internen Quellen des Bergbaumuseums in Př́ibram finanziert. 


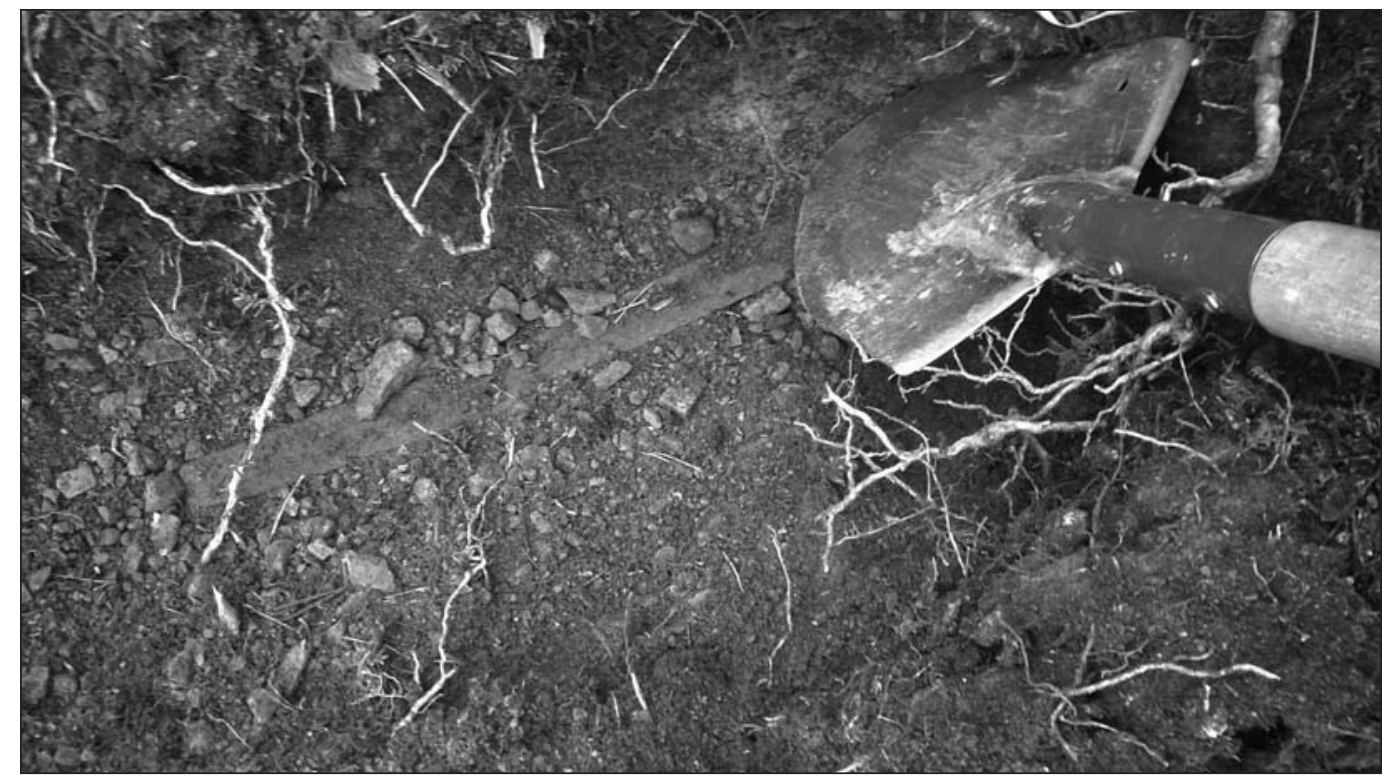

Abb. 2. Rosovice. Das Depot im Moment der Freilegung der zweiten Sense (Foto des Finders).

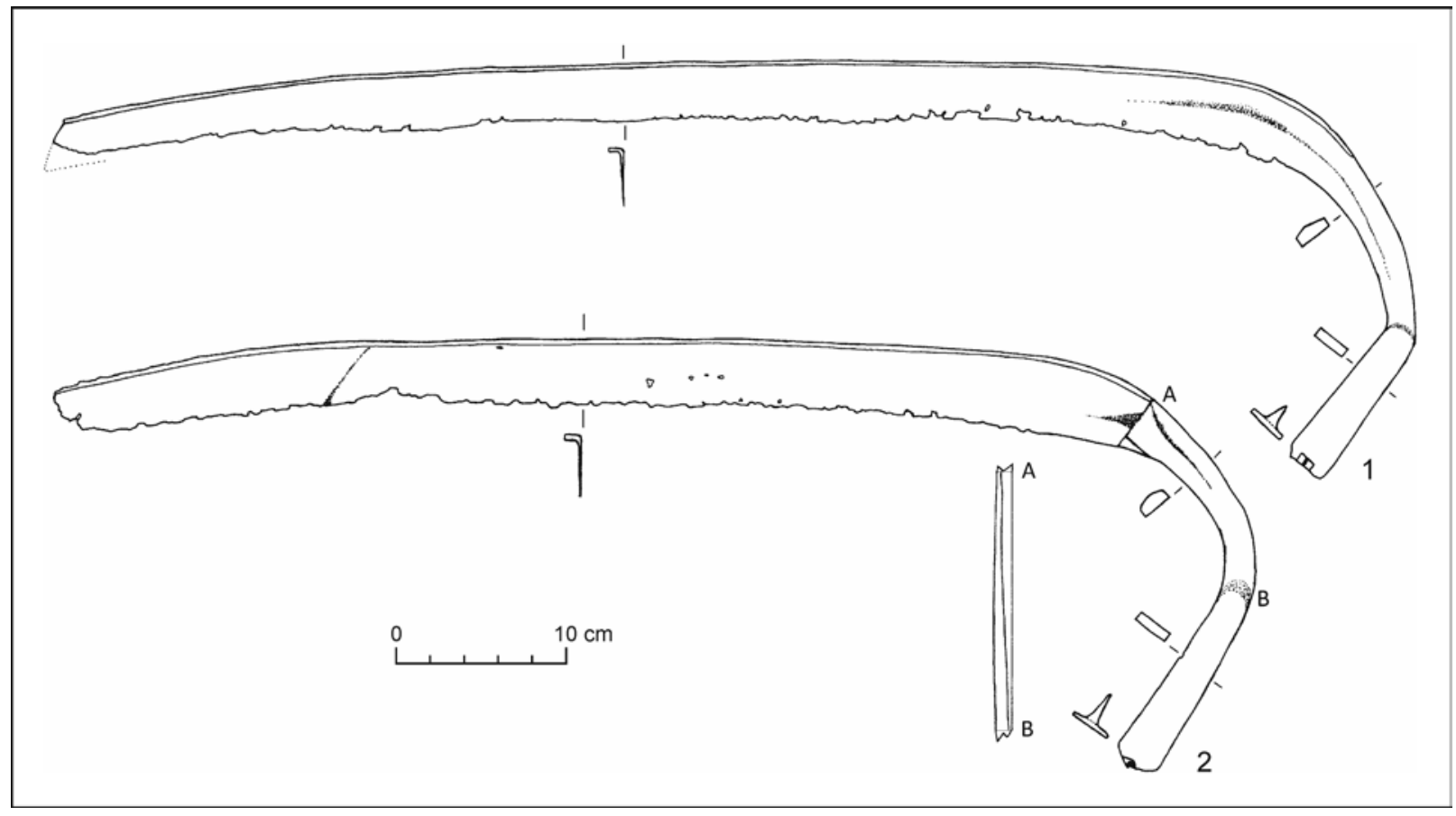

Abb. 3. Rosovice. Hortfund. Zeichnung R. Korený.

Grube mit den Ausmaßen von ungefähr $80 \times 30 \mathrm{~cm}$, sie lagen 10 und $25 \mathrm{~cm}$ tief und waren in Richtung NO-SW orientiert. Eine der Sensen lag flach, ihre Spitze befand sich in einer Tiefe von $10 \mathrm{~cm}$ und die Schneide war der anderen Sense zugewandt. Die zweite Sense war mit der Schneide nach oben gedreht. Die Fundsituation wurde von dem Finder im Moment der Freilegung der zweiten Sense fotografisch dokumentiert (Abb. 2). Anhand der vom Finder bereitgestellten Beschreibung der Fundumstände lässt sich annehmen, dass die Sensen ursprünglich in einem Behälter aus organischem Material deponiert wurden (z. B. in einem Stoff- oder Lederbeutel). Auf den Sensen wurden jedoch keine organischen Residuen festgestellt. 


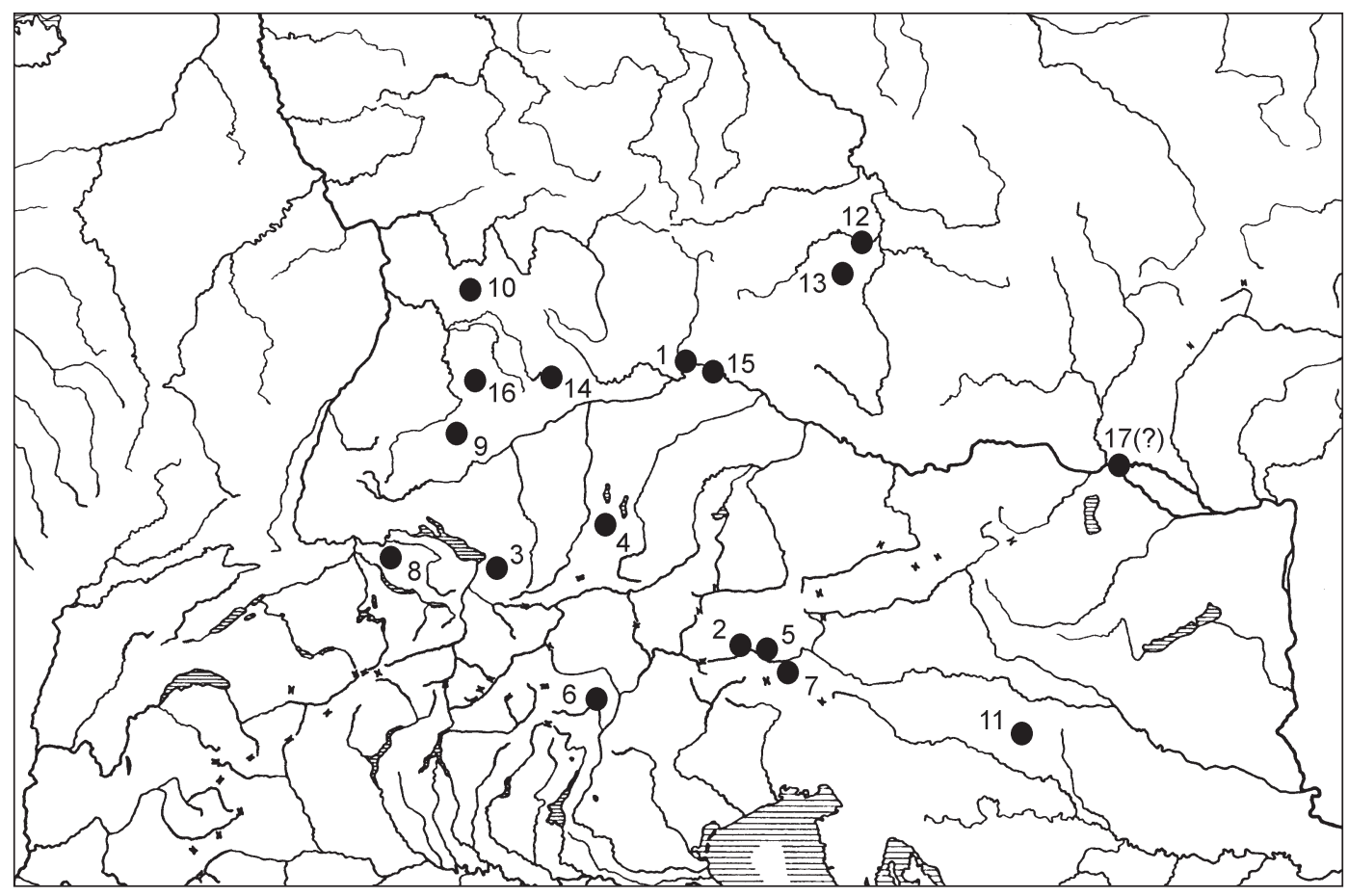

Abb. 4. Die Fundkarte von Sensen des 4. Typs. 1 - Regensburg-Kumpfmühl; 2 - Lienz; 3 - Bregenz; 4 - Monatshausen; 5 - Stein; 6 - Sanzeno; 7 - Dellach-Gurina; 8 - Benken; 9 - Bad Urach - Runder Berg; 10 - Osterburken; 11 - Loka pri Žusmu; 12 - Lety u Dobřichovic; 13 - Rosovice; 14 - Rainau-Buch; 15 - Regensburg-Harting; 16 - Weißenburg; 17(?) - Bratislava-Rusovce.

\section{Fundbeschreibung}

1. Lange eiserne Sense von brauner Färbung, die Spitze ist (teilweise?) abgebrochen. Durch die Basis des Sensenblatts und einen Teil der Hamme geht ein Grat von leicht dachförmigem Profil durch. Die Hamme ist aus zwei Teilen zusammengesetzt. Der erste, bogenförmige Teil setzt fließend an das Blatt an, der zweite Teil mit einer Länge von $88 \mathrm{~mm}$ ist unter einem stumpfen Winkel von $115^{\circ}$ geknickt. Erhaltene Länge 750 mm, Breite des Blatts 34 mm, Gewicht 651 g (Abb. 3: 1). Aufbewahrungsort: Bergbaumuseum Př́bram, Zuwachs-Nr. 5/2015, Inv.-Nr. 38247.

2. Lange eiserne Sense von schwarzer Färbung, die Spitze ist zum Großteil abgebrochen, der letzte Teil des Blattbogens in einer Länge von $15 \mathrm{~cm}$ ist leicht aufgebogen (Abb. 3: 2). Die Schneide befindet sich nicht entlang der ganzen Länge des Blatts, sondern endet etwa $5 \mathrm{~cm}$ vor dem Ansatz der Hamme, von der sie vermutlich etwa $2 \mathrm{~mm}$ abgesetzt war. Zwischen der Hamme und dem Sensenblatt befindet sich am Ansatz der Schneide eine Lücke, die darauf verweist, dass die Hamme und das Blatt aus zwei Teilen zusammengeschweißt wurden (Abb. 3: 2A). In der Biegung der Hamme wurde in einer Länge von ungefähr $13 \mathrm{~cm}$ ein weiterer Metallstreifen mit einer ungleichmäßigen Breite von 2-5 mm angeschmiedet (Abb. 3: 2A-B). Die Verschweißung der beiden Blättchen wurde nicht sorgfältig gemacht, an der Außenseite des Bogens ist zwischen ihnen eine deutliche Lücke zu sehen. Die Sense wurde also vermutlich aus drei Teilen hergestellt. Ein Teil der Hamme hat ein leicht dachförmiges Profil. Der Hammendorn mit einer Höhe von $23 \mathrm{~mm}$ ist asymmetrisch eingesetzt. Erhaltene Länge $670 \mathrm{~mm}$, Breite des Blatts $39 \mathrm{~mm}$, Gewicht 617 g. Aufbewahrungsort: Bergbaumuseum Př́ibram, Zuwachs-Nr. 5/2015, Inv.-Nr. 38248.

\section{Übersicht der bisherigen Funde, deren Typologie und Datierung}

Die Form der Sensen aus Rosovice entspricht den Langsensen vom Typ 3c nach der Klassifikation von M. Pietsch (1983, 69), dem Typ "mit langem Baum und gebogener Hamme“ nach R. Pohanka (1986, 155), dem oberdonauländischen Typ nach J. Henning $(1985,581,582)$ und dem Typ 4 nach der Klassifikation von B. Hanemann, auf die wir uns im weiteren Text noch berufen werden (Hanemann 2014, 193, Abb. 171). 
Tab. 1. Sense vom Typ 4, ihre Parameter und Fundkontexte.

\begin{tabular}{|c|c|c|c|c|c|}
\hline Fundstelle/Nr. & Kontext & Länge & Blattbreite & $\begin{array}{l}\text { Erhaltungszustand } \\
\text { der Sense }\end{array}$ & $\begin{array}{l}\text { Datierung des Fundes/ } \\
\text { Deponiereung des Depots }\end{array}$ \\
\hline Regensburg-Kumpfmühl & Kastell & 515 & - & komplett & $79 / 81-130$ \\
\hline Bregenz & Depotfund? & - & 41 & $\begin{array}{l}\text { Fragment, gebrochen, } \\
\text { Reparatur }\end{array}$ & 2.-4. Jh.? Depotfund 4.Jh.? \\
\hline Lienz & Kontext unbekannt & - & 34 & Bruchstück, kleiner Ring & 2.-4. Jh.? \\
\hline Rosovice/1 & Wald/Depotfund & 750 & 34 & beschädigt & 2.-3. Jh., Depotfund 4. Jh. \\
\hline Rosovice/2 & Wald/Depotfund & 670 & 39 & $\begin{array}{l}\text { beschädigt, Stück der Leiste } \\
\text { fehlt, Reparatur? }\end{array}$ & Dtto \\
\hline Benken & Grabhügel/Depotfund & 825 & 35 & komplett & Depotfund 3. Jh. \\
\hline Monatshausen & Moor/Depotfund? & $\min 790$ & - & fast komplett & vor der Mitte des 3. Jh. \\
\hline Stein & Kontext unbekannt & 700 & 35 & komplett & 2.-3. Jh.? \\
\hline Sanzeno & Höhensielung & 620 & 42 & komplett & 2.-3. Jh.? \\
\hline Dellach-G./1 & Síedlung & 920 & 44 & komplett, zwei kleine Ringe & 2.-3. Jh.? \\
\hline Dellach-G./2 & Síedlung & 808 & 40 & komplett, zwei kleine Ringe & Dtto \\
\hline Dellach-G./3 & Síedlung & 872 & 42 & komplett, zwei kleine Ringe & Dtto \\
\hline \multirow[t]{2}{*}{ Runder Berg } & \multirow[t]{2}{*}{ Höhensiedlung/Depotfund } & \multirow[t]{2}{*}{765} & \multirow[t]{2}{*}{34} & $\begin{array}{l}\text { beschädigt, } 2 x \text { gebrochen, } \\
\text { Reparatur }\end{array}$ & $\begin{array}{l}\text { 2.-3. Jh., Depotfund, erst um } \\
500(?)\end{array}$ \\
\hline & & & & Amboss, Hammer $(2 x)$ & \\
\hline Loka pri Žusmu & Höhensiedlung/Depotfund & - & - & $\begin{array}{l}\text { Bruchstück, zwei kleine } \\
\text { Ringe, Funktion: als Sichel? } \\
\text { Satz-Wetzstein, Amboss, } \\
\text { Hammer }\end{array}$ & $\begin{array}{l}\text { 2.-3. Jh., Depotfund 2. Hälfte } \\
\text { des 4. Jh. }\end{array}$ \\
\hline Lety u Dobřichovic & Siedlung?/Depotfund & - & 39 & $\begin{array}{l}\text { Bruchstück, Reparatur, dann } \\
\text { als Sichel verwendet? }\end{array}$ & 2.-3. Jh., Depotfund 4. Jh. \\
\hline Osterburken/1 & Kastell/Depotfund & 745 & - & $\begin{array}{l}\text { komplett, Nagel, Reparatur. } \\
\text { Satz-Wetzstein, Amboss, } \\
\text { Hammer }\end{array}$ & $\begin{array}{l}\text { 2.-3. Jh., Depotfund 2. Hälfte } \\
\text { des 4. Jh./Anfang des 5. Jh.? }\end{array}$ \\
\hline Osterburken/2 & Kastell/Depotfund & 733 & - & komplett, Nagel, Reparatur & Dtto \\
\hline Osterburken/3 & Kastell/Depotfund & 675 & - & komplett, Nagel & Dtto \\
\hline Weißenburg 1 & Kastell/Keller & 930 & - & fast komplett & $90-$ vor $251 / 253$ \\
\hline Weißenburg 2 & Kastell/Depotfund? & 1300 & - & komplett & Dtto \\
\hline Rainau-Buch/1 & Kastell/Brunnen 7/Depotfund & 1135 & - & komplett & vor 254 \\
\hline Rainau-Buch/2 & Kastell/Brunnen 7/Depotfund & 1185 & - & komplett & Dtto \\
\hline Rainau-Buch/3 & Kastell/Brunnen 9/Depotfund & 1200 & - & komplett & Dtto \\
\hline Regensburg-Harting/1 & Villa/Brunnen/Opfergabe & - & - & komplett & 232-Mitte des 3. Jh. \\
\hline Regensburg-Harting/2 & Villa/Brunnen/Opfergabe & - & - & komplett & Dtto \\
\hline Regensburg-Harting/3 & Villa/Brunnen/Opfergabe & - & - & komplett & Dtto \\
\hline Bratislava-Rusovce & Siedlung & 111 & - & Griffbruchstück & 1. Hälfte des 5 . Jh. \\
\hline
\end{tabular}

In diese heute bereits relativ heterogene Gruppe gehören 26 Exemplare aus 16 Fundstellen. Sie unterscheiden sich voneinander durch die verschiedenartige Krümmung der Hamme (doppelte bis ovale), die Präsenz/Absenz der Rückenleiste und das Loch in der Hamme für einen Sicherungsnagel, den Winkel zwischen der Hamme und der anschließenden Klinge und den flachen oder dachförmigen Teil der Hamme (Übersicht Abb. 4; Tab. 1). In der nachfolgenden Zusammenfassung werden wir uns mit den unten erwähnten Funden ausführlicher beschäftigen: 


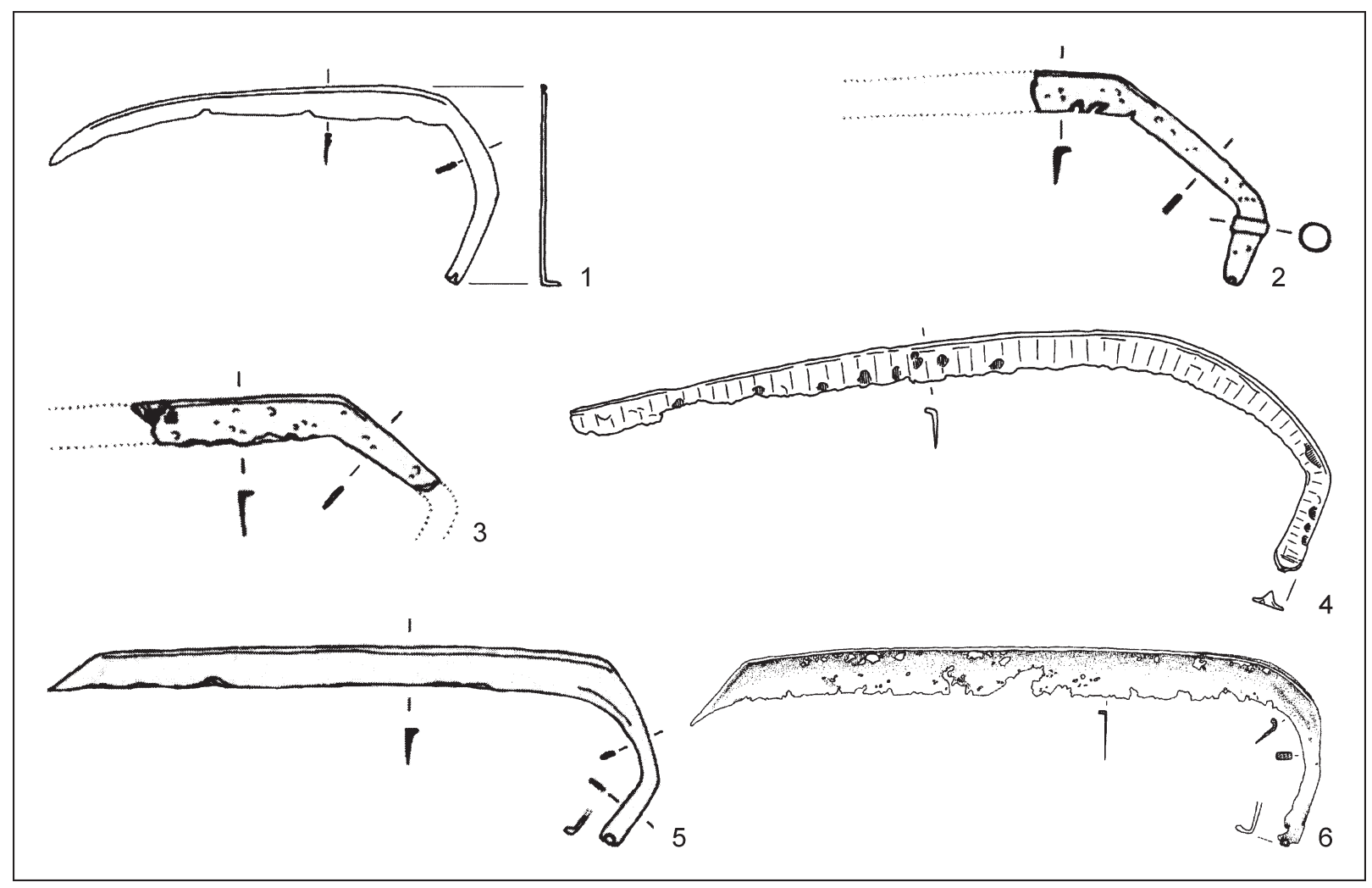

Abb. 5. Sensen des 4. Typs. 1 - Regensburg-Kumpfmühl; 2 - Lienz; 3 - Bregenz; 4 - Monatshausen; 5 - Stein; 6 - Sanzeno (nach Garbsch 1993; Henning 1991a; Nothdurfter 1979; Pohanka 1986). Verschiedene Maßstäbe.

Die Sensen aus Lienz und Bregenz von ähnlicher Form blieben nur in Fragmenten erhalten und nur die erstere von ihnen besitzt eine vollständig erhaltene Hamme (Abb. 5: 2; Pohanka 1986, 156, 360, Taf. 32: 121, 122). Bei der Sense aus Lienz kennen wir nicht die Fundumstände und sie lässt sich nur allgemein in die römische Kaiserzeit datieren. Die Sense aus Bregenz hängt vermutlich mit dem im Jahr 1857 beim Stadtgefängnis gefundenen Hort zusammen (Frohnveste; siehe Henning 1985, 594, Nr. 27; Pollak 2006, 40, Nr. 31). ${ }^{2}$ In dem Befund aus Monatshausen, Ldkr. Starnberg, der als möglicher Hort betrachtet wird, erhielt sich ein Exemplar der Sense mit flacher Griffplatte. Der angebliche Depotfund ist in die Mitte des 3. Jhs. datiert (Abb. 5: 4; Garbsch 2003, Abb. 6: 10).

Die Sense aus Sanzeno, Prov. Trentino-Südtirol, stammt aus älteren Ausgrabungen, die an der Fundstelle im 19. Jh. durchgeführt wurden (Abb. 5: 6; Nothdurfter 1979, 46, 126, Taf. 22: 329; Zeitlinger 1944, Taf. 5: 4). A. Bartoli $(2017,331)$ datiert die Sense neu ins 4.-5. Jh., aber für eine so späte Datierung fehlt es an direkten Belegen.

Die Sense aus Benken, Kt. Zürich, wird in der Literatur als Grabfund erwähnt (Abb. 6: 4; Keller 1846-1847, 20, Taf. 3; Tschumi 1930, 133, Abb. 2; Ulrich/Heizmann 1890, 136, Nr. 3874). Es kann sich jedoch um einen Hort handeln, der nachträglich in einem vorgeschichtlichen Grabhügel deponiert wurde (obwohl Langsensen in Gräbern dieser Zeit tatsächlich vorkommen; Henning 1987, 130, Nr. 256). Der Fund wird ins 3. Jh. datiert.

Weitere Sensen dieser Variante erhielten sich in einem beschädigten oder fragmentarischen Zustand. Die Sense aus dem Runden Berg bei Bad Urach, Ldkr. Reutlingen, war in drei Teile gebrochen (Abb. 6: 5; Koch 1988; 1991, 15, 23, Taf. 5; Willmy 2008, Abb. 119). U. Koch (1991, 23, 24) datierte die Sense deswegen ins 1.-3. Jh. und die Deponierung des Hortes selbst dann in die Zeit um das Jahr 500. ${ }^{3}$

2 Die Annahme über eine gemeinsame Herkunft könnte auch dadurch unterstützt werden, dass in der Zahlenreihe des Inventars des örtlichen Museums die Sense gleich hinter die Pflugscharen und Pflugmesser des gegebenen Hortes eingereiht wurde (Pohanka 1986, 156, 340, Nr. 17-19; 342, Nr. 29, 30).

3 Trotzdem bezogen einige Autoren die Datierung der Sense erst auf das vermutliche „Datum“ ante quem, d. h. auf die Deponierung des Hortes in der Zeit um das Jahr 500 (oder am Anfang des 6. Jhs., z. B. Bartoli 2017, 323; Beranová 2005, 26-27, Abb. 24; 


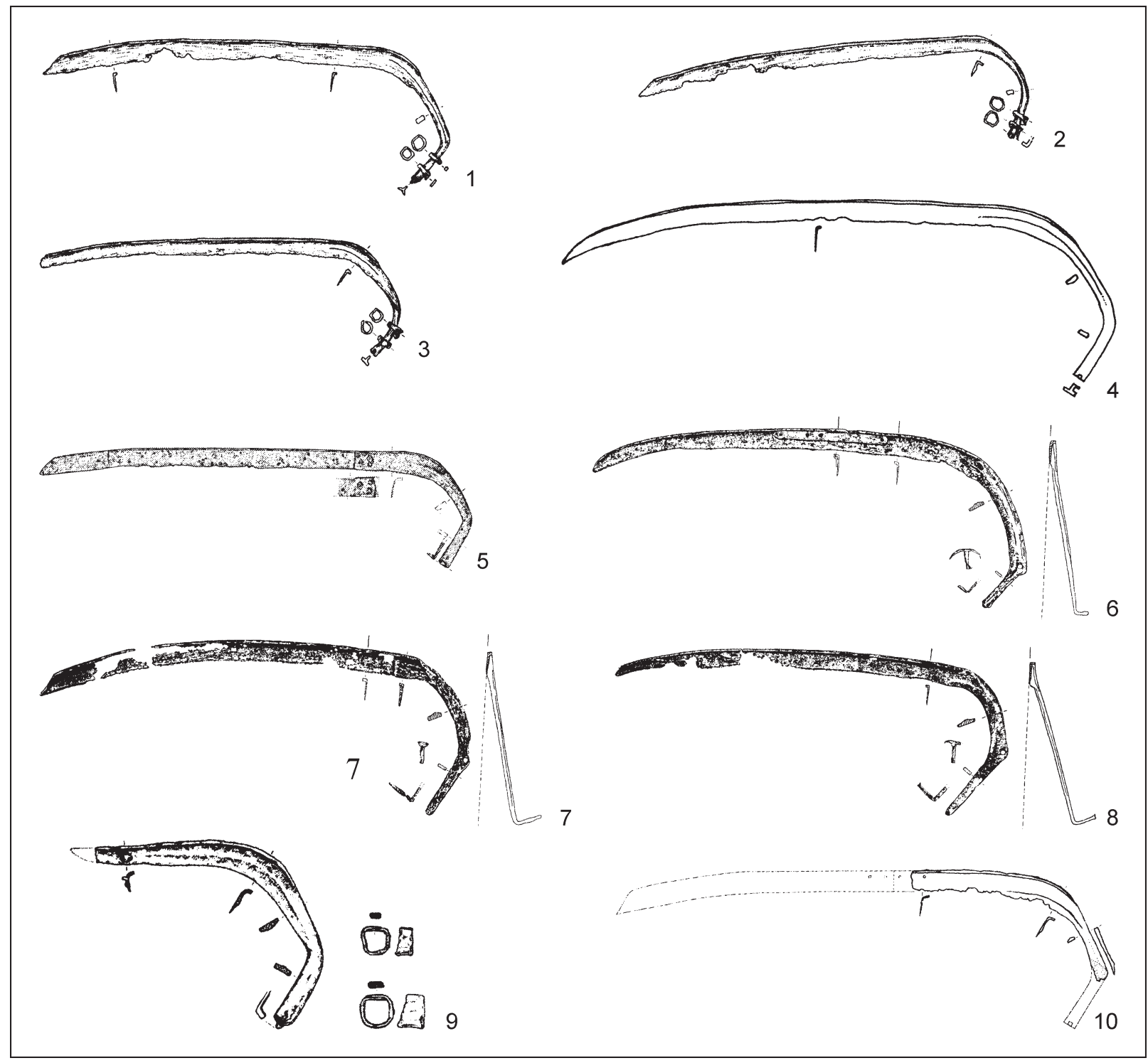

Abb. 6. Sensen des 4. Typs. 1-3 - Dellach-Gurina; 4 - Benken; 5 - Bad Urach - Runder Berg; 6-8 - Osterburken; 9 - Loka pri Žusmu; 10 - Lety u Dobřichovic (nach Ciglenečki 2000; Henning 1985; Jablonka 2001; Keller 1846-1847; Koch 1991; Ulrich/Heizmann 1890 - bearbeitet). Verschiedene Maßstäbe.

Drei Sensen dieses Typs gehörten zum Inhalt des Hortes von Osterburken, Ldkr. Neckar-OdenwaldKreis (Abb. 6: 6-8; Wagner 1897, 325; Wagner/Haug 1911, 437). Von den anderen Sensen unterscheiden sie sich nur durch das Loch für den Sicherungsdorn am Gipfel der Hamme. Die Hamme hat ein dachförmiges Profil mit den Neigungswinkeln von $10^{\circ}, 11^{\circ}$ und $15^{\circ}$. Insgesamt waren in dem Hort sechs Exemplare deponiert ${ }^{4}$, die anderen drei Sensen gehören jedoch dem Typ 3B an. ${ }^{5}$ Es ist ebenfalls bemerkenswert,

Beranová/Kubačák 2010, 163, 165; Henning 1996, 775, Abb. 631: 9; 2004, 401; 2007, Taf. 2: 8, vgl. jedoch S. 23 , Anm. 87 - hier 4./5. Jh.; Spors-Gröger 2005, 215, Abb. 88 -6 Jh.). Es ist nicht ohne Bedeutung, denn z. B. J. Henning hält diese in Wirklichkeit römische Sense langzeitig für einen sicheren Vertreter der frühmittelalterlichen Langsensen in Westeuropa (z. B. Henning 1991a, Abb. 3: B; 2005, Abb. 1.5A1; 1.6) und gleichzeitig für ein „Verbindungsglied“ zwischen den römerzeitlichen und frühmittelalterlichen Sensen (z. B. Henning 1991a; 1991b).

4 In dem ursprünglichen Fundbericht von Wagner werden sieben Sensen erwähnt.

5 B. Hanemann hat die Klassifikation der Sensen aus Osterburken von J. Henning $(1985,582)$ übernommen. Ihrem Typ 4 ordnet sie vier Exemplare zu (Hanemann 2014, 192, Anm. 445; Henning 1985, Abb. 2: 1-3, 3: 1), dem Typ 3B dann zwei Sensen (Hanemann 2014, 192, Anm. 441; Henning 1985, Abb. 3: 2, 3). Wir glauben, dass diese Klassifikation nicht genau ist, denn bei der Sense 4 fehlt der erste Teil der Hamme mit dachförmigem Profil und die ganze Hamme ist im Profil daher oval, genauso 
dass die ersteren drei Sensen des Typs 4 in einem schlechteren technischen Zustand erhalten blieben. Zwei von ihnen waren gebrochen und anschließend repariert und die dritte Sense weist ebenfalls deutliche Gebrauchsspuren auf (Henning 1985, 577, Abb. 2). Diese Feststellungen könnten schließlich (aber nicht unbedingt) auch auf ihr höheres Alter im Vergleich zu den anderen drei Sensen verweisen. Die Deponierung des Hortes wird ins Intervall von der Wende des 4./5. Jhs. bis zur zweiten Hälfte des 5. Jhs. datiert (Bartoli 2017, 331; Henning 1985). J. Henning stützte die Datierung des Hortes z. B. auf die Breite zweier Schwertklingen $(65$ und $75 \mathrm{~mm}){ }^{6}$ Diese Klingen entsprechen den Typen Osterburken-Vrasselt (Biborski/Ilkjaer 2006, 271-279, Abb. 164; Taf. 45 - Osterburken: 4. Jh.) und Osterburken-Kemathen nach der Klassifikation von Ch. Miks (2007, 132, 133, Vortf. 7; Taf. 137-142). Die gegenwärtige Forschung einigt sich über das Optimum deren Vorkommens von der Mitte des 4. bis zur Mitte des 5. Jhs. Ch. Miks (2007, 132, 133) hat richtig auf die formalen Ähnlichkeiten mit älteren Schwertern des Typs Lauriacum-Hromówka aufmerksam gemacht und schloss somit nicht aus, dass die Spathae des Typs Osterburken-Kemathen von diesen Vorlagen ausgehen. Auf diese Tatsache verweist möglicherweise indirekt auch die Feststellung, dass die Breiten der Schwertklingen aus dem Hort von Osterburken auf keinerlei Weise von den metrischen Angaben der römischen Langschwerter seit dem Ende des 3. und im Verlauf des 4. Jhs. abweichen (z. B. Böhme 1974; Künzl 1993, 75-80; Schulze-Dörrlamm 1985; Ulbert 1974). In die zweite Hälfte des 4. Jhs. datieren nämlich die Gräber mit Schwertern, deren Klingenbreite sogar 7 bis $8,5 \mathrm{~cm}$ betrug: Abbeville- Homblières, Monceau-le-Neuf, Grab 1 und Frankfurt-Praunheim (Biborski/Ilkjaer 2006, Tab. 45, 46; Schulze-Dörrlamm 1985, 566, Nr. 35-37). Auch weitere Komponenten des Hortes von Osterburken (z. B. Viehglocken, Äxte, Kreuzhauen, Seche, Dengelhammer, Säge, Löffelbohrer, Webschwert) weisen ein massenhaftes Vorkommen entweder während der ganzen römischen Kaiserzeit oder nur in der jüngeren/späten römischen Kaiserzeit auf (Fries 1995, 61, 65 - Seche; Hanemann 2014). Wenn wir noch den fragmentarischen Erhaltungszustand eines Teiles der Gegenstände in Betracht ziehen, können wir also konstatieren, dass sie schon während des 4. Jhs. deponiert gewesen sein konnten (obwohl Schwerter der obengenannten Parameter angeblich vereinzelt auch am Anfang des 5. Jhs. vorgekommen sind).

Ein Teil der gebrochenen Schneide einer Langsense mit Hamme von dachförmigem Profil, die in eine Sichel (?) umgewandelt wurde, stammt aus Loka pri Žusmu (Tinje) in der Region Savinjska in Slowenien (Abb. 6: 9). ${ }^{7}$ Die Sense gehörte zu einem Hort, der anhand der Fragmente von "langobardischer" Keramik aus Befund 4 (unter welchem der Hort deponiert war) ursprünglich ins 6. Jh. datiert wurde (Božičl Ciglenečki 1995, 259, 260; Ciglenečki 1983, Taf. II: 6; 2000, 56, Taf. 3: 1; 39: 7; Henning 2004, 401, Anm. 10). D. Božič hat später die Datierung des Hortes einer Kritik unterworfen und ins Intervall von dem 4. bis zur ersten Hälfte des 5. Jhs. verschoben (Bartoli 2017, 325; Bitenc/Knific 2015, 104, Anm. 2; Božič 2005, 335, 336). ${ }^{8}$ Die ursprünglich lange Sense ist deswegen höchstwahrscheinlich noch älter als das 4 . Jh.

Ein anderes fragmentarisch erhaltenes Exemplar befand sich in dem Hort von Lety u Dobřichovic, Bez. Prag-Westen, dessen Deponierung traditionell ins 6., bzw. 7. Jh. datiert wird (Abb. 6: 10; Beranovál Lutovský 2009, 123; Friedrich 1946). Zu diesem Depotfund und zu der Sense selbst werden wir noch im Teil des Beitrags zurückkehren (Teil „Lety u Dobřichovic“). Hier sei nur soviel erwähnt, dass der Hort vermutlich während des 4 . Jhs. im Boden deponiert wurde.

Sensen, die den obengenannten Exemplaren ähneln, aber eine längere Klinge und Hamme mit flachem Profil haben, kennen wir aus dem römischen Kastell Rainau-Buch, Ldkr. Ostalbkreis, wo im Brunnen 7 zwei und im Brunnen 9 ein Exemplar zum Vorschein gekommen sind. Die Brunnen wurden nach dem Untergang des Vicus im J. 254 zugeschüttet (Abb. 7: 1-3; Greiner 2002; 2010, 186, 187, Taf. 73: 35; 140: 91, 92 - der Autor klassifiziert die Sensen als Zwischentyp Pietsch 3b-c; Planck 1983, 147, Abb. 105). Drei weitere Sensen desselben (Zwischen-)Typs stammen aus der römischen Villa in Regensburg-Harting, wo sie in einem vor der Mitte des 3. Jhs. zugeschütteten Holzbrunnen gefunden wurden (Abb. 7: 4-6; Osterhaus 1985, Abb. 80; Rieckhoff 1997, 500, Abb. 3: 1-3). Zwei Sensen dieses Typs entdeckte man auch im Kastell Weißenburg (Abb. 7: 7, 8), das irgendwann im J. 251-253 untergegangen ist (gegründet

wie bei den Sensen 5 und 6. Bei diesen drei Sensen ist zudem der Übergang zwischen der Klinge und der Hamme anders ausgeführt, sie besitzen breitere Klingen und sind mehr gekrümmt. Die Autorin übernimmt gleichzeitig von F. Unruh eine sehr späte Datierung der Deponierung dieses Hortes in die Zeit um das Jahr 500 oder in die frühmerowingische Zeit (Hanemann 2014, 193, Anm. 462 - mit Verweis auf die Arbeit von F. Unruh - vgl. Gralfs 1992).

6 Im ursprünglichen Fundbericht sind auch Fragmente eines weiteren Schwertes erwähnt (Wagner 1897, 325).

7 Die Umwandlung eines Fragments der Sensenklinge in eine Sichel ist auch im Hort von Heilbronn-Böckingen belegt (Schönberger 1967, 150, Abb. 9: 12).

8 Die Frage ist, ob eine solche Umwertung auch im Fall der Datierung des Hortes vom Runden Berg möglich wäre. 


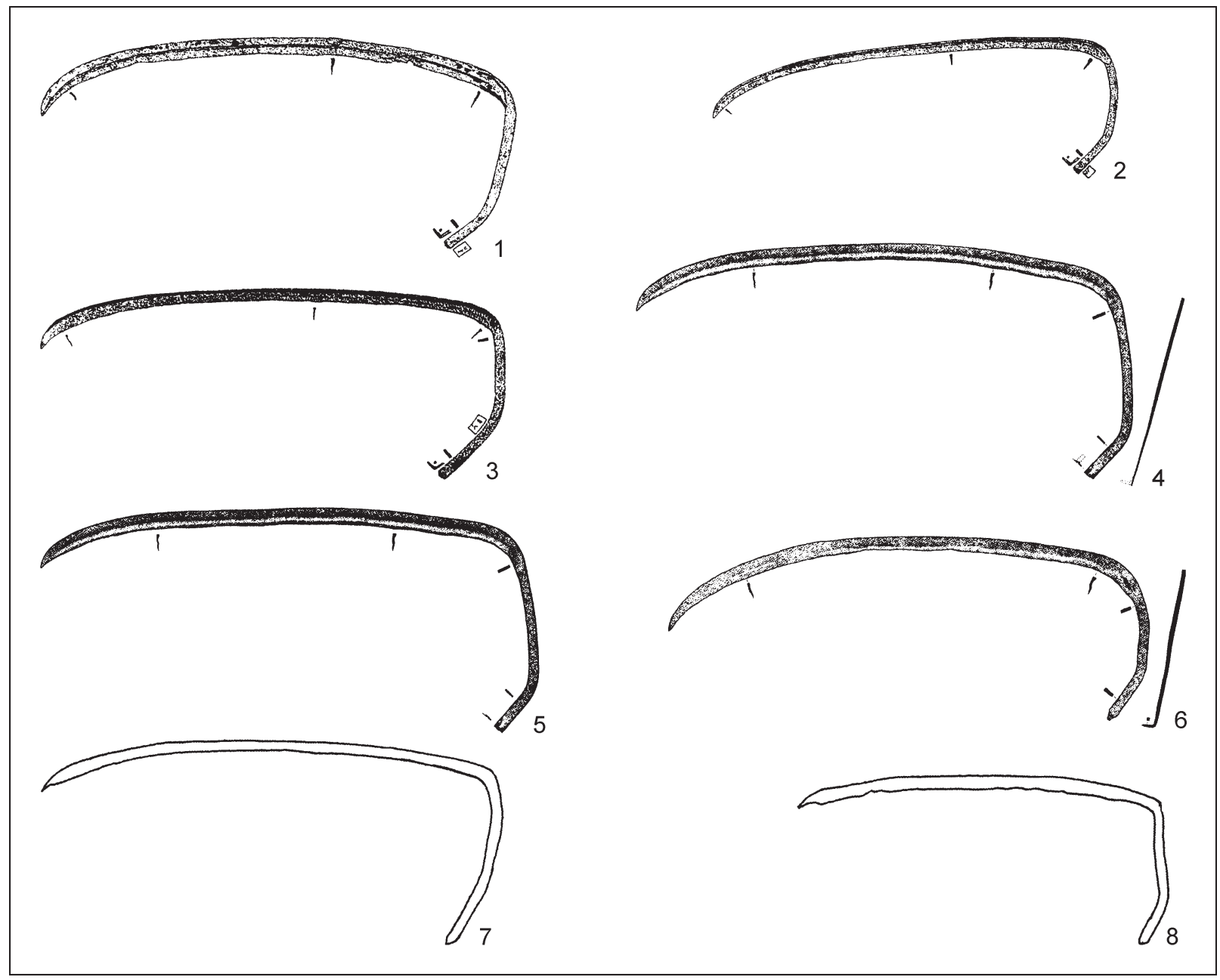

Abb. 7. Sensen des 4. Typs. 1-3 - Rainau-Buch; 4-6 - Regensburg-Harting; 7, 8 - Weißenburg (Greiner 2010; Rieckhoff 1997; Schwarz 1967 - bearbeitet). Verschiedene Maßstäbe.

140-150/160; Fabricius 1914, 41, Nr. 30; Taf. X: 1; Grönke 1997, 102, Anm. 734; vgl. Schwarz 1967, 159, Abb. 11 bildet zwei Exemplare dieses Typs ab).

Fragment der Hamme einer Sense von unbestimmbarer Variante entdeckte man im Grubenhaus 15/03 in Bratislava-Rusovce, das in die 1. Hälfte des 5. Jhs. datiert ist. In dem Grubenhaus befand sich auch ein Zugmesser, ebenfalls beschädigt. Es handelt sich höchstwahrscheinlich um deutlich älteres Material (bzw. Schrott), das in der unweiten römerzeitlichen Siedlung aufgesammelt wurde (Bazovský 2008, 135, Abb. 4: 5).

\section{Physischer Zustand und Datierung der Sensenfunde}

Zuletzt beschäftigte sich mit einigen Sensen dieses Typs A. Bartoli, die sie im Einklang mit J. Henning ins 4. bis 5. Jh. datiert (Bartoli 2017, 325, Anm. 5; Henning 2007, 23, Anm. 87; Taf. 2: 8). Dies ist, wie wir im Weiteren noch sehen werden, unter Berücksichtigung der gegenwärtigen Kenntnis nicht real. Im Gegenteil, es spiegelt die Situation wider, wenn die Sensen dieses Typs nicht nur schon außer Gebrauch gekommen sind, sondern fast alle bekannten Stücke bereits im Boden deponiert waren.

Werfen wir also einen Blick auf die Tabellendaten (Tab. 1), vor allem auf die Spalten in Bezug auf den physischen Zustand der Sensen im Moment deren Freilegung und auf die Datierung. Das älteste Exemplar, das gleichzeitig den vermutlichen Anfang der Produktion dieses Typs innerhalb des Intervalls von der Wende des 1./2. Jhs. bis zum J. 130 n. Chr. belegt, ist eine vollständige Sense aus dem Kas- 


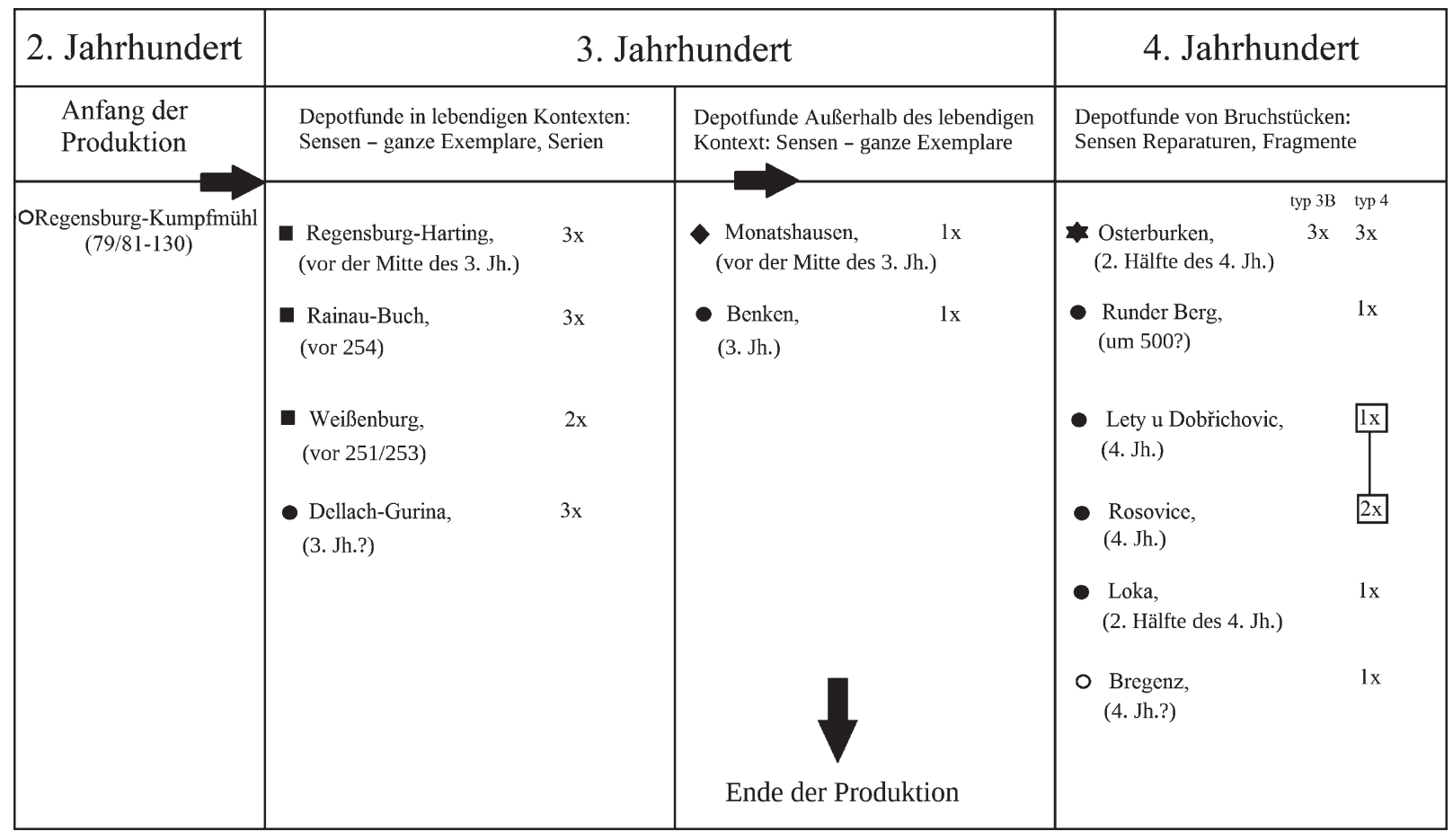

Abb. 8. Sensen des 4. Typs und deren Vorkommen während des 1.-4. Jhs.

tell Regensburg-Kumpfmühl (Abb. 5: 1; Faber 1994, 299, 301, Abb. 24: 15; Henning 1991a, Abb. 3: 1; 1991b, Abb. 3a) aus dem Kastell/Vicus in Rainau-Buch, der Villa in Regensburg-Harting und dem Kastell in Weißenburg stammen insgesamt acht ganze, unbeschädigte Sensen. In dem erstgenannten Fall wurde der Untergangshorizont der beiden Brunnen, in denen die Sensen deponiert waren, dendrochronologisch zum J. 254 datiert, an der zweiten Fundstelle wurde der Holzbrunnen im J. 232 ausgeschachtet und in der Mitte des 3. Jhs. zugeschüttet, und das Kastell in Weißenburg ist im J. 251/253 untergegangen. Bedeutend ist, dass die Sensen in den ersten zwei Fällen zur Ausstattung des gegebenen Gehöfts gehörten (oder im „lebendigen Kontext“ befindlich waren) und dort auch in einem spezifischen Moment deponiert wurden - zusammen mit z. B. Küchenausstattung, Teilen der Handwaschgarnituren oder des Hauslarariums und der Werkzeugsätze. Die beiden Depots konservierten damit, natürlich nur zu einem gewissen Maß, ein authentisches Bild der Ausstattung der Gehöfte, darunter auch einige Beispiele für das ältere Inventar des 1. und 2. Jhs. (Brunnen 7: z. B. Kannen E 125 und Ra 71 usw.; Greiner 2008, 68-74), einschließlich der Anzahl und des technischen Zustandes von Sensen. Diese Daten deuten gleichzeitig an, dass die Sensen dieses Typs mit großer Wahrscheinlichkeit erst seit dem 2. Jh. hergestellt worden sind. Ihre Produktion endete dann in diesem Abschnitt des Grenzgebietes spätestens im 3. Jh., vielleicht nach dem Untergang des Obergermanisch-Rätischen Limes im J. 260 und der anschließenden Räumung von Agri decumates. Weitere chronologische Stützen umfassen das Depot/ Grab von Benken, dessen Deponierung ins 3. Jh. eingesetzt wird, und das Depot (?) von Monatshausen aus der ersten Hälfte des 3. Jhs. Diese Fundverbände wurden jedoch schon außerhalb der Siedlung (d. h. des "lebendigen Kontextes") und in einer ziemlich reduzierten Zusammensetzung (die Auswahl von einigen Exemplaren des Kochgeschirrs, einige Werkzeuge) deponiert. Dies betrifft auch die Anzahl von Sensen - nur je ein Stück, obwohl es sich immer noch um ganze, oder fast vollständige Exemplare, wieder ohne Befestigungsringe handelt. In weiteren Horten waren die Sensen schon mehr oder weniger beschädigt, repariert, oder in einem fragmentarischen, bzw. reutilisierten Zustand - auf dem Runden Berg (die bisher angenommene Deponierungszeit erst um das J. 500), in Loka pri Žusmu (zweite Hälfte des 4. Jhs.), Lety u Dobřichovic (4. Jh.) und in dem vermutlichen Hort von Bregenz (etwa 4. Jh.). Eine Ausnahme bildet der Hort von Osterburken mit sechs teilweise beschädigten, reparierten und fragmentarisch erhaltenen Sensen, der vermutlich in der zweiten Hälfte des 4. (oder am Amfang des 5.?) Jhs. im Boden deponiert wurde. Die angeführten Daten können wir in dem nachfolgenden Schema des „Lebenszyklus“ von Sensen des 4. Typs zusammenfassen (Abb. 8). 
Tab. 2. Übersicht der Sensenfunde (verschiedene Typen) mit Ambossen, Hämmern von Typen 3 und 2 (nach Hanemann 2014) und Wetzsteinen (Abkürzungen: $\mathrm{D}=$ Depotfund).

\begin{tabular}{|c|c|c|c|c|}
\hline Fundstelle/Kontext & Sensen/Stücke & Amboss & Hammer/Typ & Wetzstein \\
\hline Neupotz/D & 6 (2 Sets $\times 3$ Stck) & $1+1$ & $5 \times$ Typ 2 & $1+1$ \\
\hline Osterburken/D & 6 (2 Sets $\times 3$ Stck) & $1+-$ & 1 x Typ 3 & $1+-$ \\
\hline Augsburg-Ober. & 1 & 3 & 1 x Typ 2,1 x Typ 3 & - \\
\hline Dormagen & 4 & 1 & - & - \\
\hline Feldberg & $1+$ & 1 & - & 2 \\
\hline Compiégne & 2 & 2 & 1 x Typ 3 & - \\
\hline G. Chesterford/D & 12 & 5 & $5 \times$ Typ 2 & - \\
\hline Herzberg/D & 1 & 1 & 1 x Typ 2 & 1 \\
\hline Newstead & 4 & 1 & 2 x Typ 2 & 1 \\
\hline Pforzheim/D & 1 & 2 & 1 x Typ 3 & - \\
\hline Saalburg & $3+$ & 1 & 1 x Typ 2 & $2+$ \\
\hline Seeb & 3 & 1 & - & - \\
\hline Stockstadt & 1 & 1 & $2 \times$ Typ 2 & 4 \\
\hline Weißenburg & 2 & - & - & 7 \\
\hline Xanten-Wardt/D & 1 & - & 1 x Typ 2 & - \\
\hline Zugmantel & $4+$ & 4 & 2 x Typ 2 & 1 \\
\hline Oberaden & 3 & - & 1 x Typ 2 & - \\
\hline Urach/D/1981 & 1 & 1 & 1 x Tyр 3,1 x Тyр 2 & - \\
\hline Kreimbach/D & 3 & 1 & 1 x Typ 3, 2 x Typ 2 & - \\
\hline Waldfischbach/D & 1 & 1 & 1 x Typ 3, 2 x Typ 2 & 3 \\
\hline Heilbronn-Böck./D & $1+1$ (reutilisiert als Sichel) & Amboss & 1 x Tyр 3,1 x Тур 2 & - \\
\hline Dellach-Gurina & 3/Hortfund & - & 1 x Typ 2 & - \\
\hline Loka/D & 1 (reutilisiert als Sichel) & 1 & 1 x Typ 3 & 1 \\
\hline
\end{tabular}

\section{Sensen, Ambosse, Hämmer und Wetzsteine}

Die Langsensen waren nur für eine kurze Zeit funktionsfähig. Einen unentbehrlichen Teil der Ausstattung bildeten deswegen neben den Sensen auch Einsteckambosse, Dengelhämmer und Wetzsteine (Tab. 2; Henning 1991b, 52, Abb. 4). Die Verwendung dieser Werkzeugsätze ist in Hortfunden belegt. Deren Basis bildete eine Sense, ein Einsteckamboss, 1-3 Dengelhämmer und 1-2 Wetzsteine (Herzberg, Urach, Waldfischbach, Loka; Božič 2005; Hanemann 2014; Koch 1991; Pietsch 1983). Interessant sind dabei die Verhältnisse zwischen einzelnen Geräten in den Horten von Neupotz (Künzl 1993) und Osterburken (Henning 1985). In jedem von ihnen befanden sich sechs Sensen und eine entsprechende Anzahl von Hilfsgeräten, so dass sie jeweils einen Satz von drei Sensen, einem Einsteckamboss, 1-3 Hämmern und einem Wetzstein bildeten. Im Fall des Hortes von Osterburken bildeten dann den ganzen Werkzeugsatz offenbar nur die Sensen 4-6, während die Sensen 1-3 zur Zeit der Deponierung des Hortes schon eine gewisse Zeit außer Gebrauch gewesen sind und deswegen keine dazugehörende Ausstattung hatten.

\section{Metallographische Analyse der Sensen aus Rosovice} (J. Hošek)

Die beiden Sensen wurden einer metallographischen Untersuchung unterzogen, um die Art ihrer Herstellung und Pflege zu verdeutlichen. 


\section{Analytische Methoden}

Die Proben für metallographische Analyse wurden aus den Gegenständen mit Hilfe einer Rotationssäge mit Diamantscheibe herausgetrennt und danach unter Anwendung der Standardverfahren vorbereitet (im Acrylharz eingebettet, auf einem Satz von Schleifpapieren nassgeschliffen, mit Hilfe von Diamantsuspensionen nachpoliert). Bewertet wurden sie zunächst im ungeätzten Zustand (verfolgt wurden dabei die Einschlüsse und Schweißnähte) und dann nach der Mikroätzung mit 3 \%-igem Nital (Charakter und Verteilung der Grundstrukturen) und Makroätzung mit der Oberhoffer-Lösung (verfolgt wurden die Schweißnähte und die Verteilung von phosphorreichen und phosphorarmen Bereichen). Die Metallreinheit wurde nach der Tradition des Laboratoriums des Instituts für Archäologie in Prag anhand der Jernkontoret-Norm bewertet, die Korngröße dann anhand der ASTM E112-Norm. Die Struktur beobachtete und dokumentierte man mit dem Mikroskop Olympus BX 60 mit digitaler Bildaufnahme mit Hilfe der Digitalkamera Olympus E-410. Die Härte wurde unter Anwendung der Vickers-Methode mit dem Härteprüfgerät Wilson Wolpert 401MVD bei einer Prüflast von 0,2 kg gemessen.

\section{Erste Sense}

Die Proben wurden in den Entfernungen von 197,220 und 845 mm von dem Klingenbruch entnommen.

\section{Metallographische Beschreibung (Abb. 3: 1; 9-11)}

- Probe A (Schneide): Metallmatrix der Probe ist relativ rein (Stufe 2-3 nach Jernkontoret). Es überwiegen kleine Einschlüsse meistens länglicher Form. Nach dem Ätzen wurden Strukturbereiche dokumentiert, deren räumliche Verteilung auf Abb. 9: 2 abgebildet ist. Im Bereich I befindet sich perlitische, stark verformte Struktur mit einer Härte von rund 290 HV0,2 (aufgrund einer Messung). Im Bereich II befindet sich perlitisch-zementitische, leicht übereutektoide Struktur. Bereich III, der die meiste Fläche der Probe einnimmt, ist perlitisch, stellenweise mit ein wenig Ferrit. Die Härte erreicht $236 \pm 15$ HV0,2. Nach der Ätzung mit Oberhoffer sieht man gut die zeilenverteilte Struktur sowie einen Teil der länglichen Schweißnaht. Im Bereich IV befindet sich ferritisch-perlitische Struktur mit ca. 0,35 \% Kohlenstoff, Korngröße von 9 bis 10 ASTM und Härte von $165 \pm 5$ HV0,2. In der Probe identifizierte man keine Schweißnähte, die auf eine mehrteilige Konstruktion des Sensenblatts verweisen würden.

- Probe B (Rücken): Matrix der Probe ist relativ rein (Stufe 2-3 nach Jernkontoret). Durchsetzt ist sie vor allem mit groben Einschlüssen. Nach dem Ätzen erschien auf der meisten Fläche der Probe, im Bereich I, perlitische Struktur (stellenweise mit ein wenig Ferrit) mit einer Härte von $281 \pm 45$ HV0,2. Im Bereich II befindet sich perlitischferritische Struktur, deren Kohlenstoffgehalt rund 0,6\% erreicht.

- Probe C (Hamme): Matrix der Probe ist auf der meisten Fläche relativ rein (Stufe 2-3 nach Jernkontoret), wenn auch stellenweise mit ziemlich unreinen Zonen von sehr feinen Einschlüssen (4-5 Jern.) durchsetzt. Das Ätzen hat eine ziemlich heterogene Struktur bloßgelegt. Im Bereich I ist sie ferritisch, mit einer Korngröße von ASTM 6 und Härte von $91 \pm 6$ HV0,2. Im Bereich III befindet sich perlitische Struktur, die Härte erreicht $254 \pm 13$ HV0,2. Bereich II stellt eine Übergangszone zwischen Bereichen I und III dar. Im Bereich IV sind die Perlitkörner von Ferrit umgeben, der mit einem sekundären Zementitnetz an der Grenze der ursprünglichen austenitischen Körner durchsetzt ist. Der Kohlenstoffgehalt beträgt wenigstens 1,2 \% C.

\section{Auswertung}

Das Sensenblatt wurde aus leicht heterogenem Stahl mit vorwiegend eutektoidem Kohlenstoffgehalt geschmiedet. Die Schneide wurde kaltgedengelt. Die Hamme wurde vermutlich aus unsortiertem, sehr heterogenem Material geschmiedet, das sich vom Eisen bis in einen übereutektoiden Stahl ändert.

\section{Zweite Sense}

Die Proben wurden in den Entfernungen von 87 und $650 \mathrm{~mm}$ von dem Klingenbruch entnommen.

\section{Metallographische Beschreibung (Abb. 3: 2; 12; 13)}

- Probe A (Schneide): Metallmatrix der Probe ist mit feinen sowie groben Einschlüssen durchsetzt, die Reinheit schwankt zwischen den Stufen 2 und 3 nach Jernkontoret. Nach dem Ätzen erschien auf der ganzen Fläche der Probe feine perlitische Struktur. Im Bereich II hat sie eine Härte von $315 \pm 33$ HV0,2. Im Bereich I, wo der feine Perlit offenbar auch mit bainitischen Körnern durchsetzt ist, erreicht sie eine Härte von $378 \pm 7$ HV0,2. In der Probe wurden keine Schweißnähte identifiziert. 


\section{B}

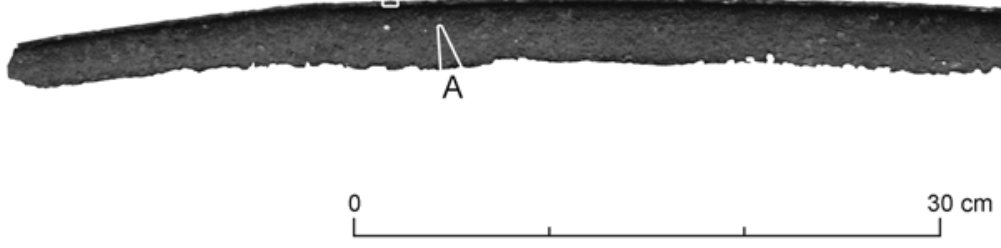

B

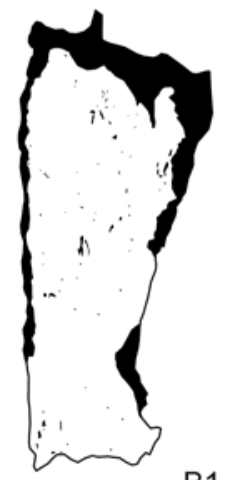

B1

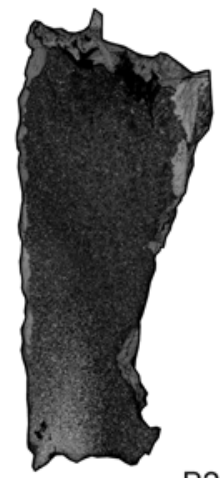

B2

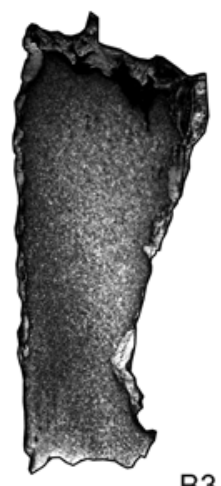

B3
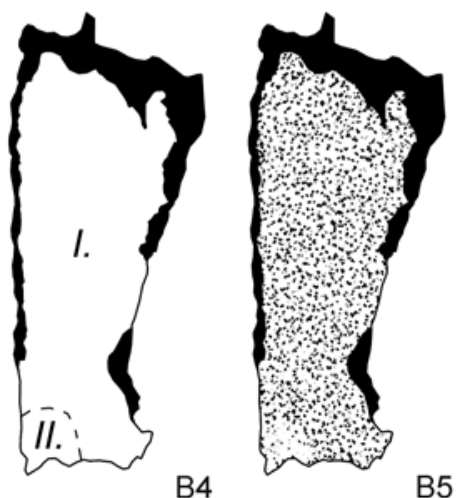

B5
A

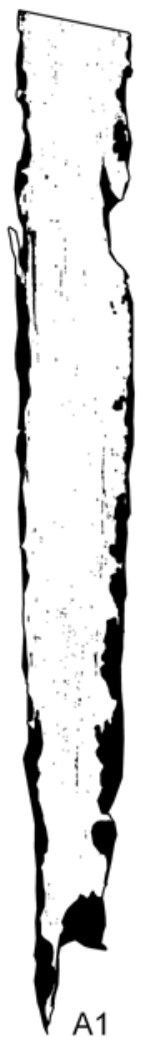

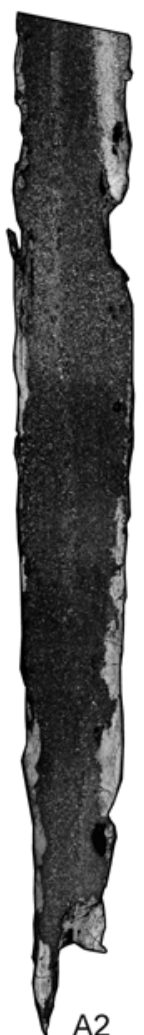
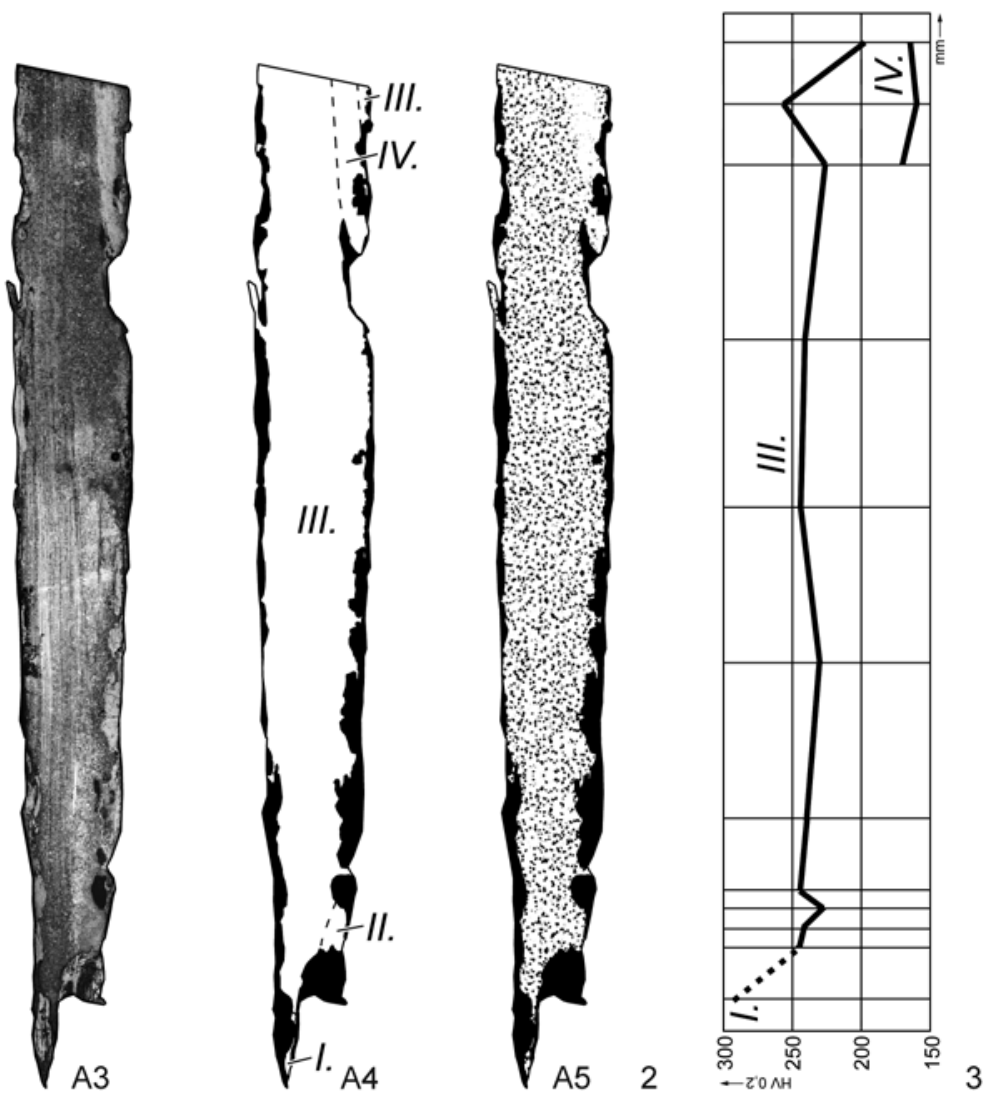

Abb. 9. Erste Sense. 1 - untersuchter Gegenstand und Methodik der Probenentnahme; 2 - schematische Zeichnungen der Proben (A1, B1 - ungeätzter Zustand; A2 B2 - geätzt mit Nital; A3, B3 - geätzt mit Oberhoffer; A4, B4 - Verteilung der beschriebenen Strukturbereiche; A5, B5 - Bezeichnung der wichtigsten Schweißnähte und der identifizierten Strukturbereiche); 3 - Diagramm des Härteverlaufs. Foto J. Hošek. 


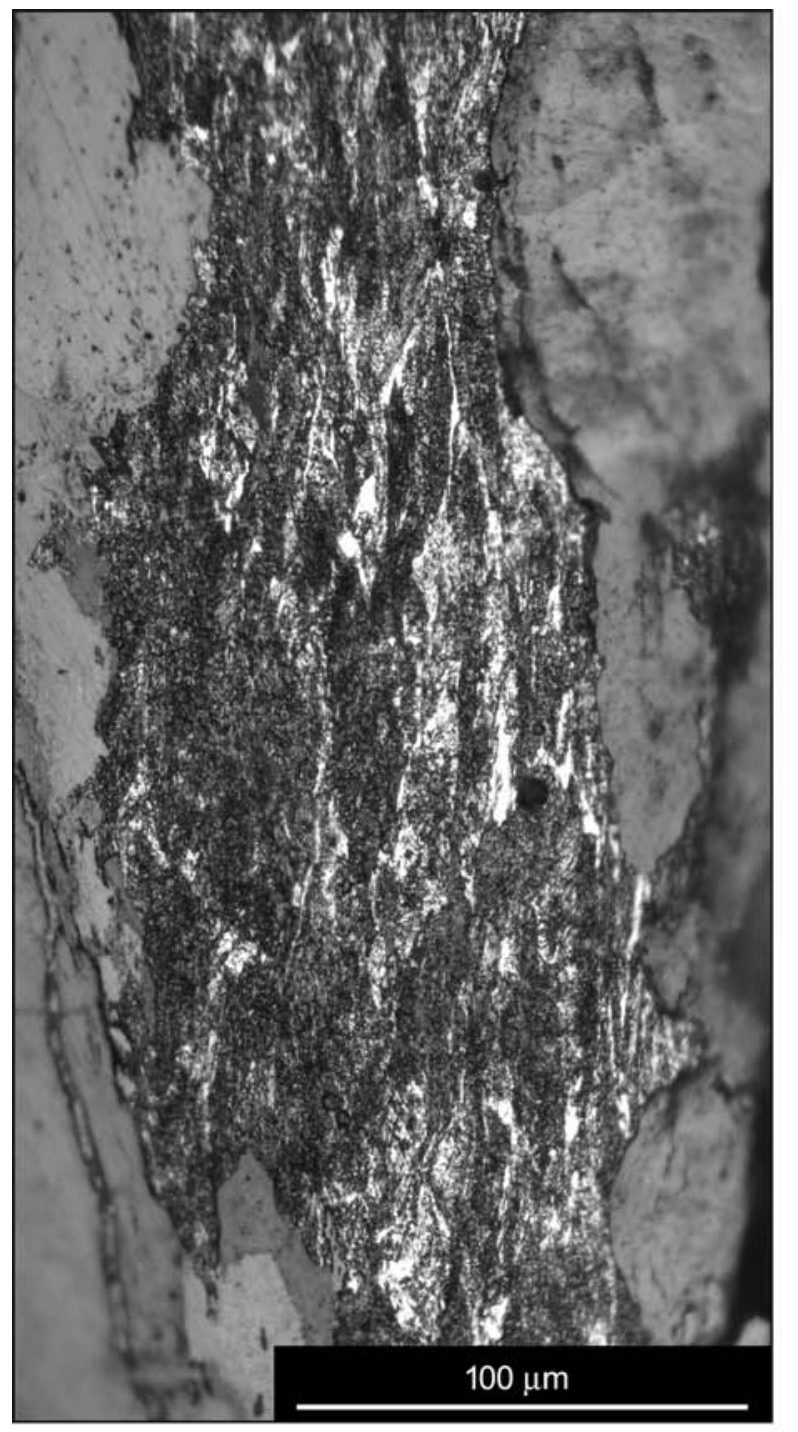

a

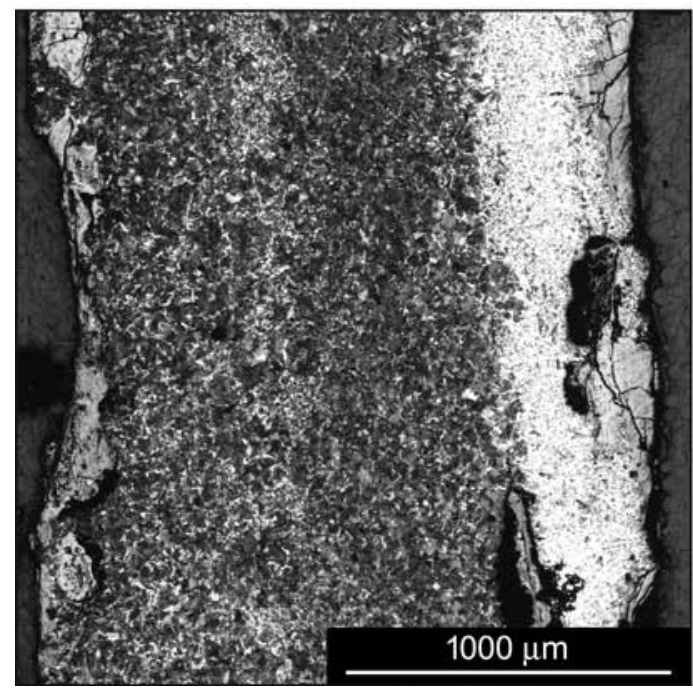

d
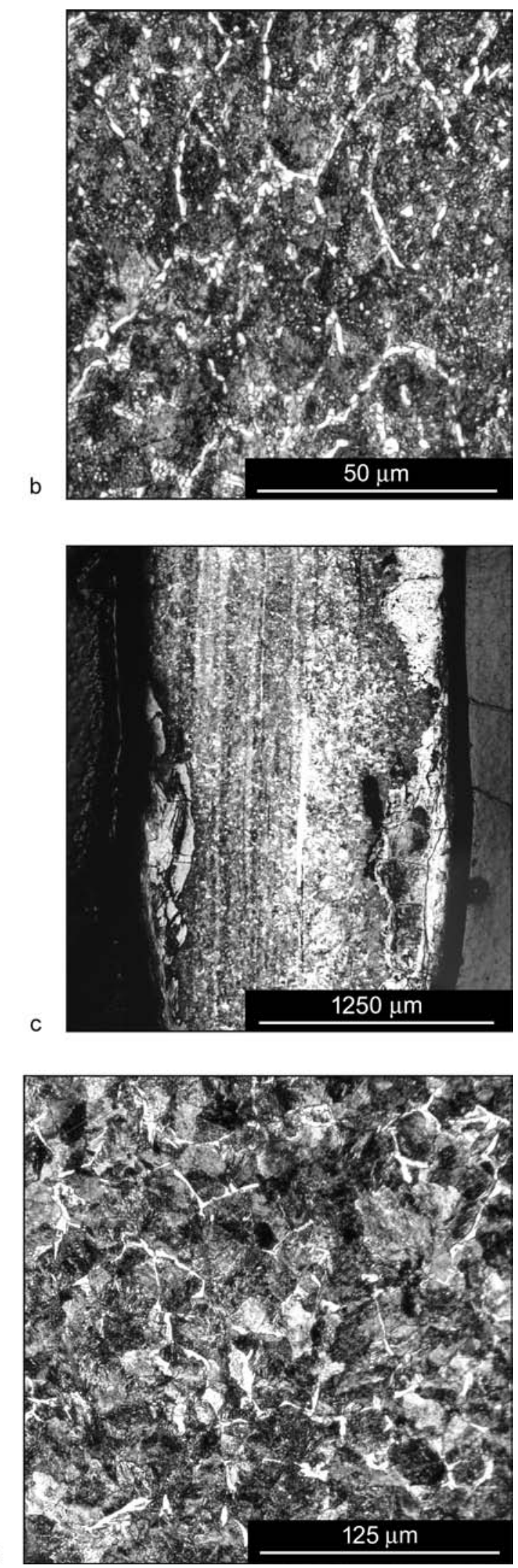

Abb. 10. Erste Sense. a - kaltumgeformte perlitische Struktur der Probe A, Bereich I; b - leicht übereutektoide perlitischzementitische Struktur der Probe A, Bereich II; c - zeilenverteilte Struktur und ein Teil der länglichen Schweißnaht, Probe A, Bereich III; d - Bereiche III und IV in der Probe A; e - perlitische Struktur mit ein wenig Ferrit, Probe B, Bereich I. a, b, d, e - Geätzt mit Nital; c - Geätzt mit Oberhoffer. Foto J. Hošek. 

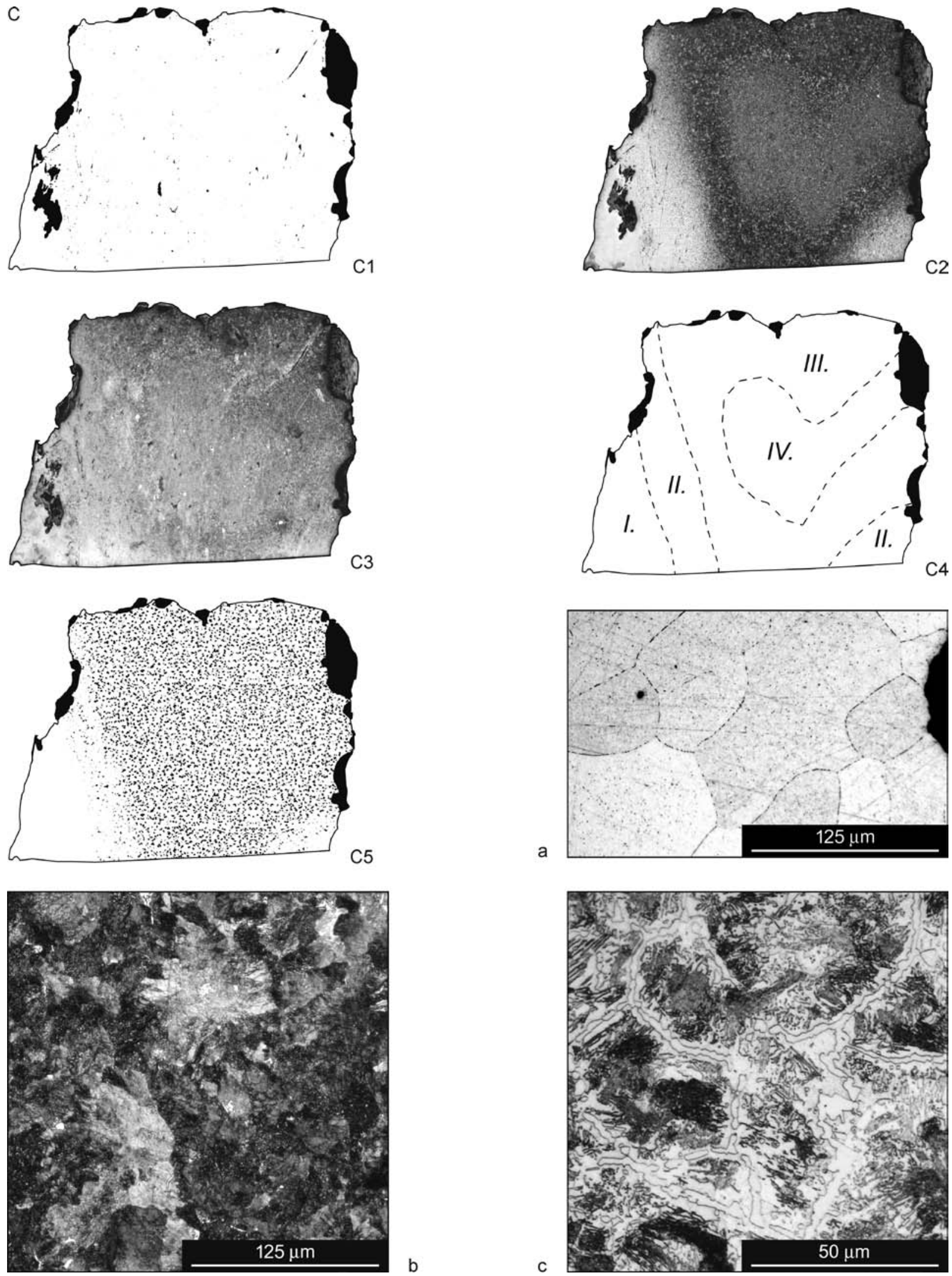

Abb. 11. Erste Sense. Schematische Zeichnungen der Probe C (C1 - ungeätzter Zustand; C2 - geätzt mit Nital; C3 - geätzt mit Oberhoffer; C4 - Verteilung der beschriebenen Strukturbereiche; C5 - Bezeichnung der wichtigsten Schweißnähte und der identifizierten Strukturbereiche); a - ferritische Struktur im Bereich I; b - perlitische Struktur im Bereich III; c - übereutektoide perlitisch-zementitische Struktur im Bereich IV. Geätzt mit Nital. Foto J. Hošek. 


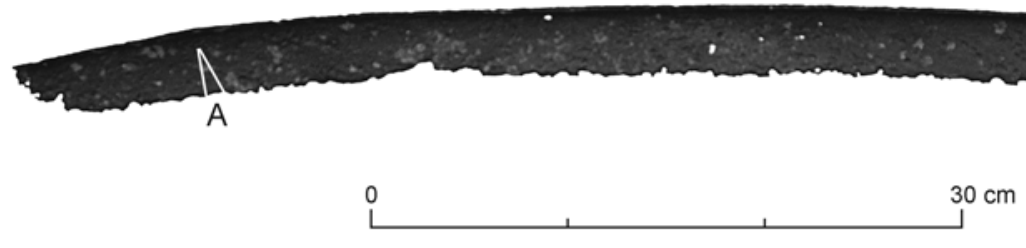

A

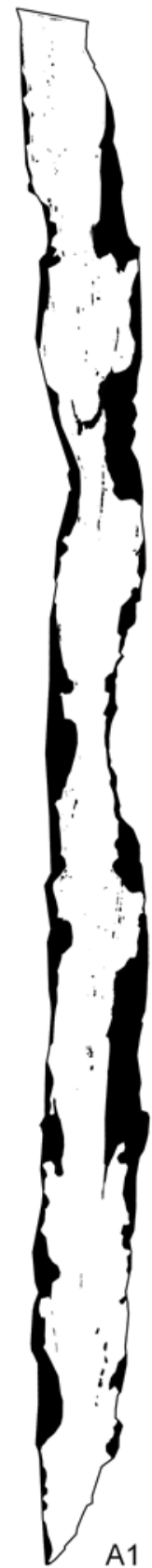

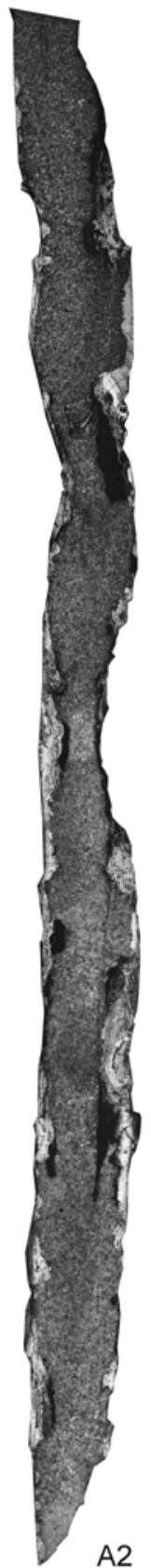
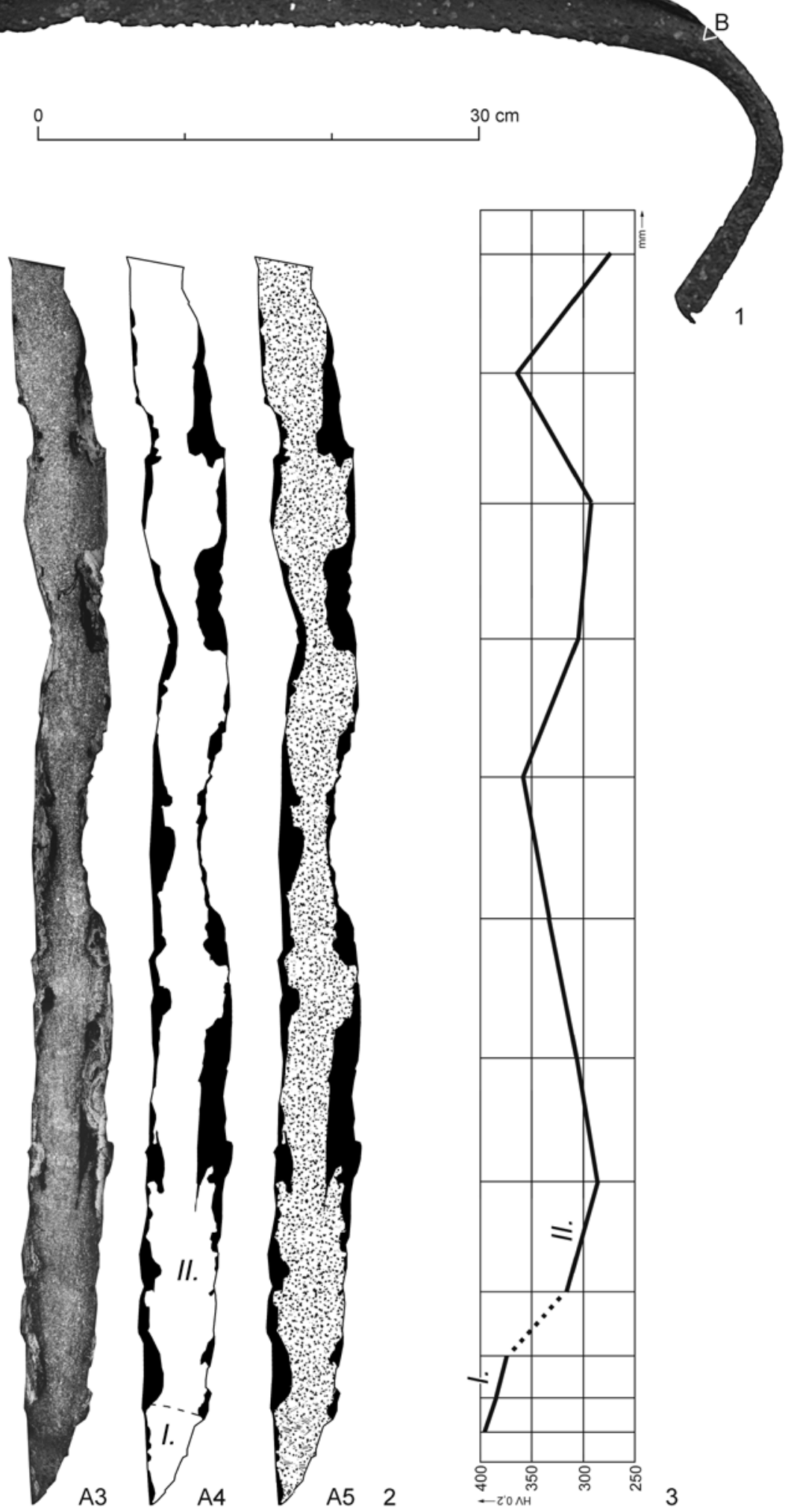

Abb. 12. Zweite Sense. 1 - untersuchter Gegenstand und Methodik der Probenentnahme; 2 - schematische Zeichnungen der Probe A (A1 - ungeätzter Zustand, geätzt mit Nital; A2 - geätzt mit Oberhoffer; A3 - Verteilung der beschriebenen Strukturbereiche; A4 - Bezeichnung der wichtigsten Schweißnähte und der identifizierten Strukturbereiche; A5 - Diagramm des Härteverlaufs). Foto J. Hošek. 

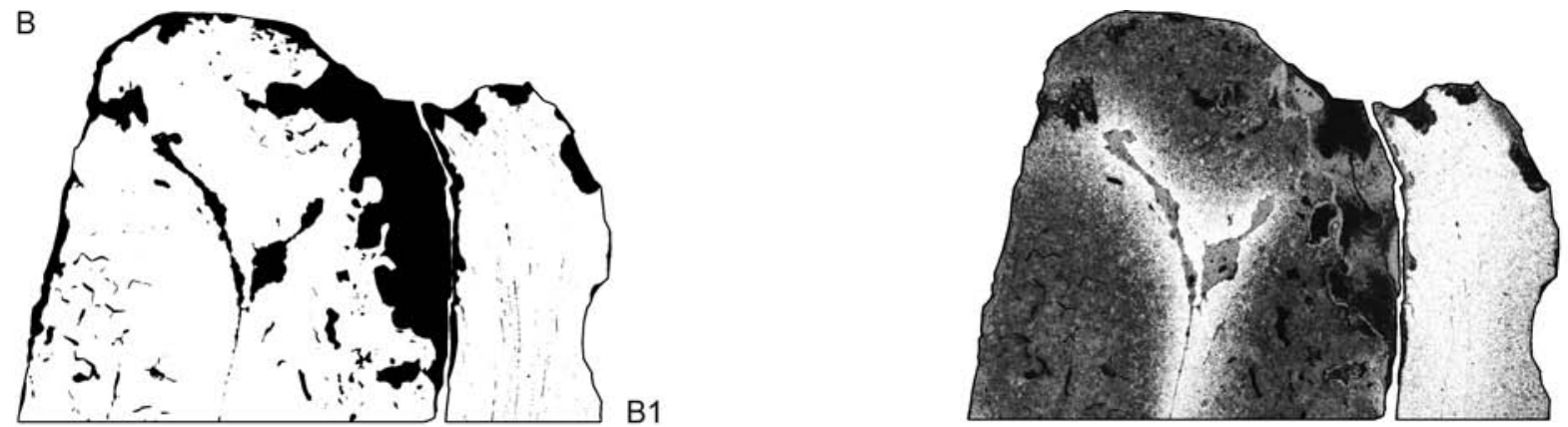

B2
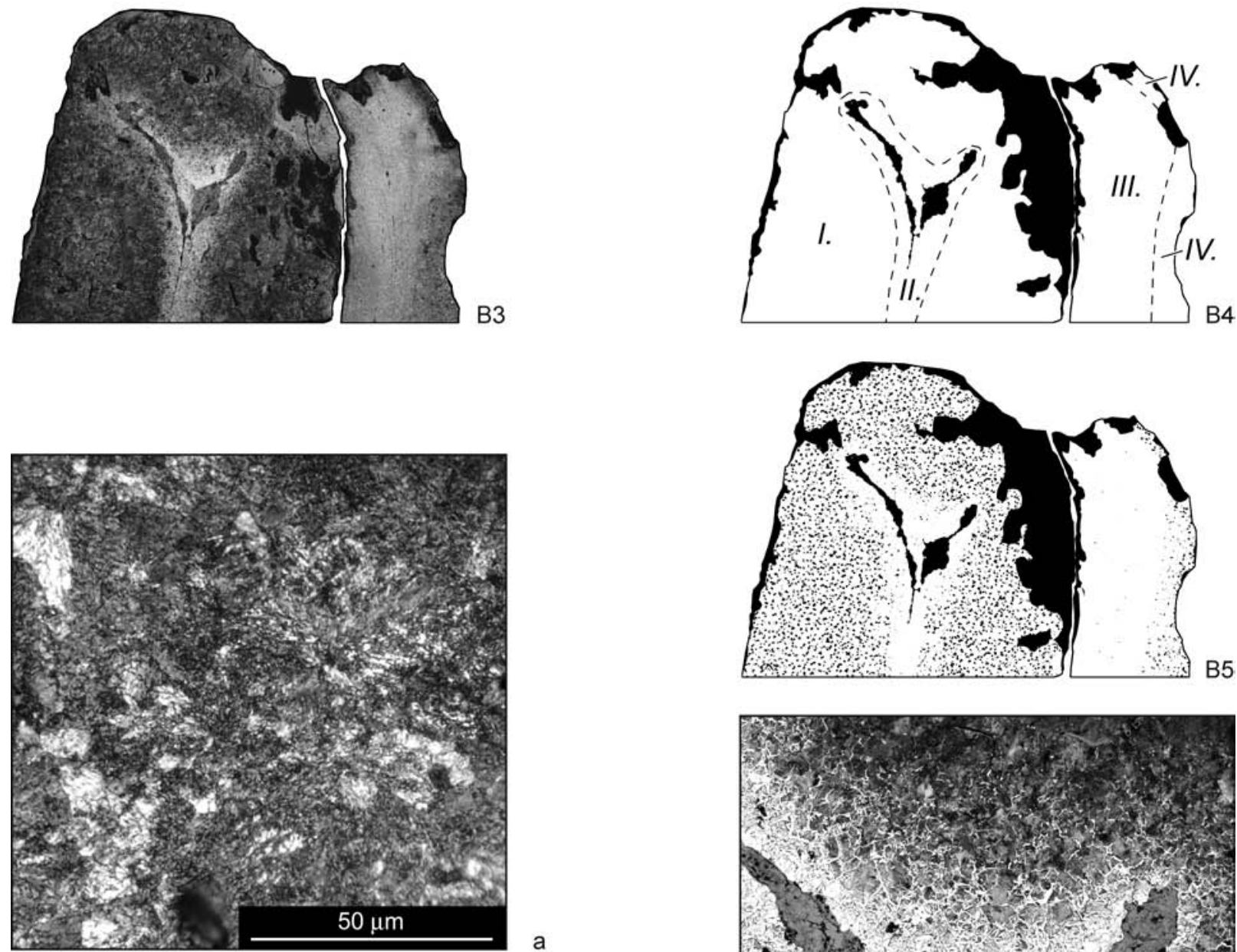

a

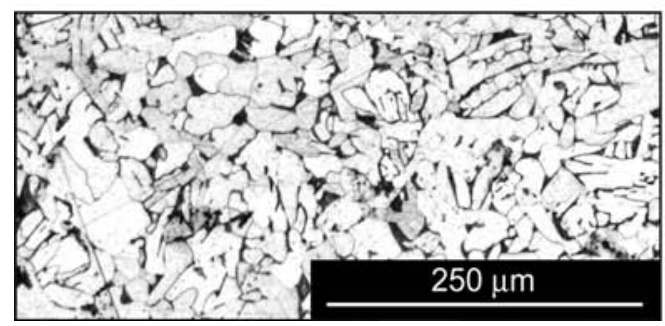

b
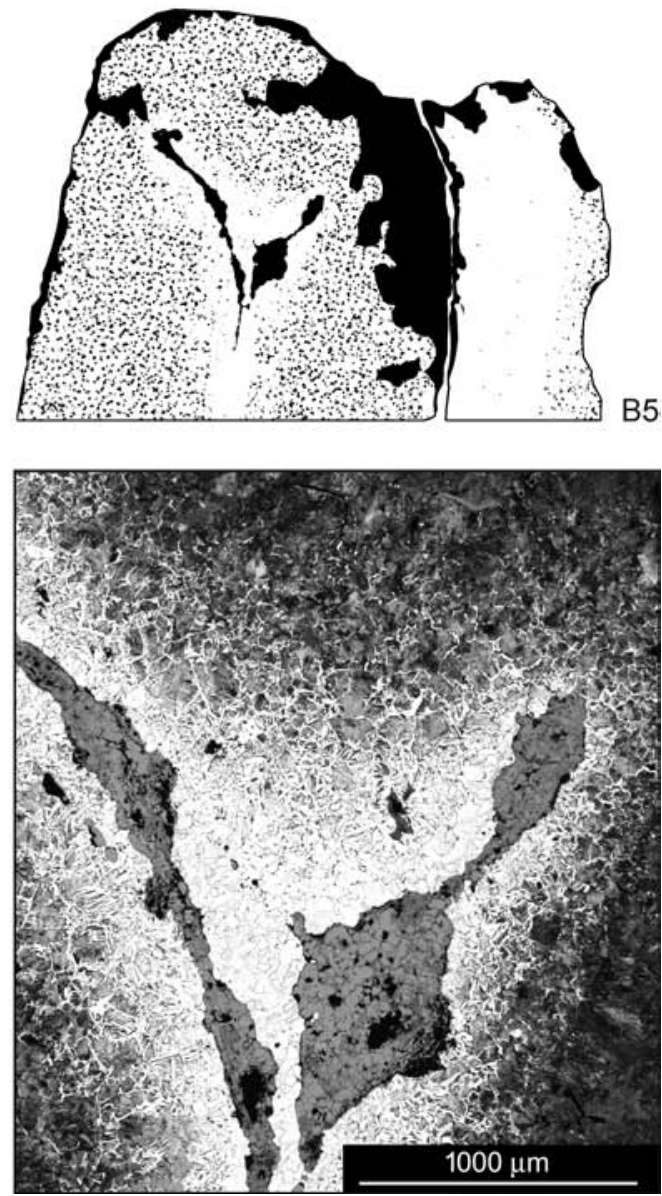

Abb. 13. Zweite Sense. Schematische Zeichnungen der Probe B. B1 - ungeätzter Zustand; B2 - geätzt mit Nital; B3 - geätzt mit Oberhoffer; B4 - Verteilung der beschriebenen Strukturbereiche; B5 - Bezeichnung der wichtigsten Schweißnähte und der identifizierten Strukturbereiche. $a$ - perlitische Struktur der Probe A, Bereich II; $b$ - ferritisch-perlitische Struktur der Probe B, Bereich III; c - Makroaufnahme der Probe B, Bereich II ist von Bereich I umgeben. Geätzt mit Nital (a, c, d). Foto J. Hošek. 
- Probe B (Hamme): Matrix im linken Teil der Probe ist relativ rein (Stufe 2-3 nach Jernkontoret), der rechte Teil der Probe ist jedoch mit vielen sehr groben Einschlüssen durchsetzt und die Metallreinheit entspricht den Stufen 4 bis 5 nach Jernkontoret. Nach dem Ätzen wurden Strukturbereiche dokumentiert, deren Verteilung über die Fläche der Probe auf Abb. 13: b abgebildet ist. Im Bereich I befindet sich perlitische Struktur mit einer Härte von $234 \pm 33$ HV0,2. Im Bereich II befindet sich ferritische Struktur mit einer Korngröße von ASTM 8 und Härte von $93 \pm 5$ HV0,2. Der Übergang zwischen diesen zwei Bereichen ist allmählich. Im Bereich III befindet sich feinkörnige (ASTM 8) ferritisch-perlitische Struktur mit einem Kohlenstoffgehalt von 0,1 bis 0,2 \% und einer Härte von $109 \pm 13$ HV0,2. Im Bereich IV befindet sich ferritisch-perlitische Struktur mit 0,5\% C. Der Übergang zwischen den Bereichen III und IV ist allmählich. In der Probe B ließen sich keine Schweißnähte identifizieren, obwohl es ersichtlich ist, dass der linke Teil (Bereiche I und II) nicht sehr sorgfältig mit dem rechten Teil (Bereiche III und IV) verschweißt wurde.

\section{Auswertung}

Das Sensenblatt wurde aus Stahl von anscheinend eutektoider Zusammensetzung hergestellt, die Hamme wurde aus etwas heterogenem Eisen geschmiedet. Die Verschweißung der Klinge und der Hamme war an einigen Stellen unsorgfältig ausgeführt. Die Sense wurde von den Schmiedetemperaturen ziemlich schnell abgekühlt, aber die gezielte Warmumformung ist schwer nachzuweisen (genauso wie auch auszuschließen). Die Spuren von Kaltumformung wurden auf der erhaltenen Schneide nicht identifiziert.

\section{Nachmachung der Sense}

(P. Jánská)

Für die Nachmachung der Sensen aus Rosovice gab es mehrere Gründe:

1. Der Zustand der Originalstücke, der selbst nach einer sorgfältigen Konservierung keine große Hoffnung auf ihre dauerhafte Erhaltung in der Zukunft gab. Aus diesem Grund ist es daher erwünscht, die Originalstücke (wenn möglich) dauerhaft in einem Depositorium zu lagern und zur Präsentation ihre Repliken oder Kopien zu nutzen.

2. Experimentelle Überprüfung des zur Herstellung einer Sense nötigen Arbeits- und Zeitaufwands.

3. Geplante funktionelle Überprüfung und Bewertung der Arbeit mit dem genannten Typ der Sensen. ${ }^{9}$

\section{Materialauswahl}

Für die Herstellung der Repliken wurden folgende Halbfabrikate von rechteckigem Querschnitt benutzt: Sense 1 - Stahl CSN 12050 (0,42-0,50\% C), $10 \times 20$ mm; Sense 2 - Stahl ČSN 11523 (max. 0,2 \% C), $10 \times 30 \mathrm{~mm}$. Als Brennstoff benutzte man während des Arbeitsvorgangs die Holzkohle.

Die nachfolgende Arbeitsbeschreibung betrifft die Sense 1, dasselbe gilt jedoch auch für die Herstellung der Sense 2.

Das Material wurde über die gesamte Blattlänge mit einem Hammer parallel zur Kante in die Breite flach ausgeschmiedet (Abb. 14: 1).

Danach wurde der Querschnitt eingeebnet und gleichzeitig keilförmig zugerichtet, nur die Schneide wurde nicht scharf, sondern zu einer Stärke von rund $1 \mathrm{~mm}$ ausgezogen, um beim erneuten Aufheizen nicht zu verbrennen. Anschließend wurde allmählich eine ungefähr rechtwinklige Beugung mit rechteckigem Profil geformt (Abb. 14: 2).

Durch die nachfolgende Umformung mit einem runden Hammer von innen und mit flachem Hammer von draußen zu dem gewünschten Profil in der Beugung hat sich der Winkel der Umbiegung vergrößert (Abb. 14: 3).

Der scharfe Übergang zur Hamme wurde umgebogen und die Hamme wurde abgeflacht (Abb. 14: 4).

Auf der Ambosskante wurde ein Dorn für die Stielbefestigung geschmiedet. Über die gesamte Blattlänge wurde der Rücken umgebogen und gleichzeitig die Krümmung der Klinge geformt (Abb. 14: 5).

Die überschüssigen Teile wurden beseitigt, die Schneide wurde ausgezogen, die Oberfläche geschliffen, die Schneide gedengelt und nachgeschärft (Abb. 14: 6).

9 Das Mähen wurde nur am Gras und nur versuchsweise ausprobiert. Analytische Versuche mit dem Mähen verschiedener Typen der Pflanzenbestände sind noch geplant. 

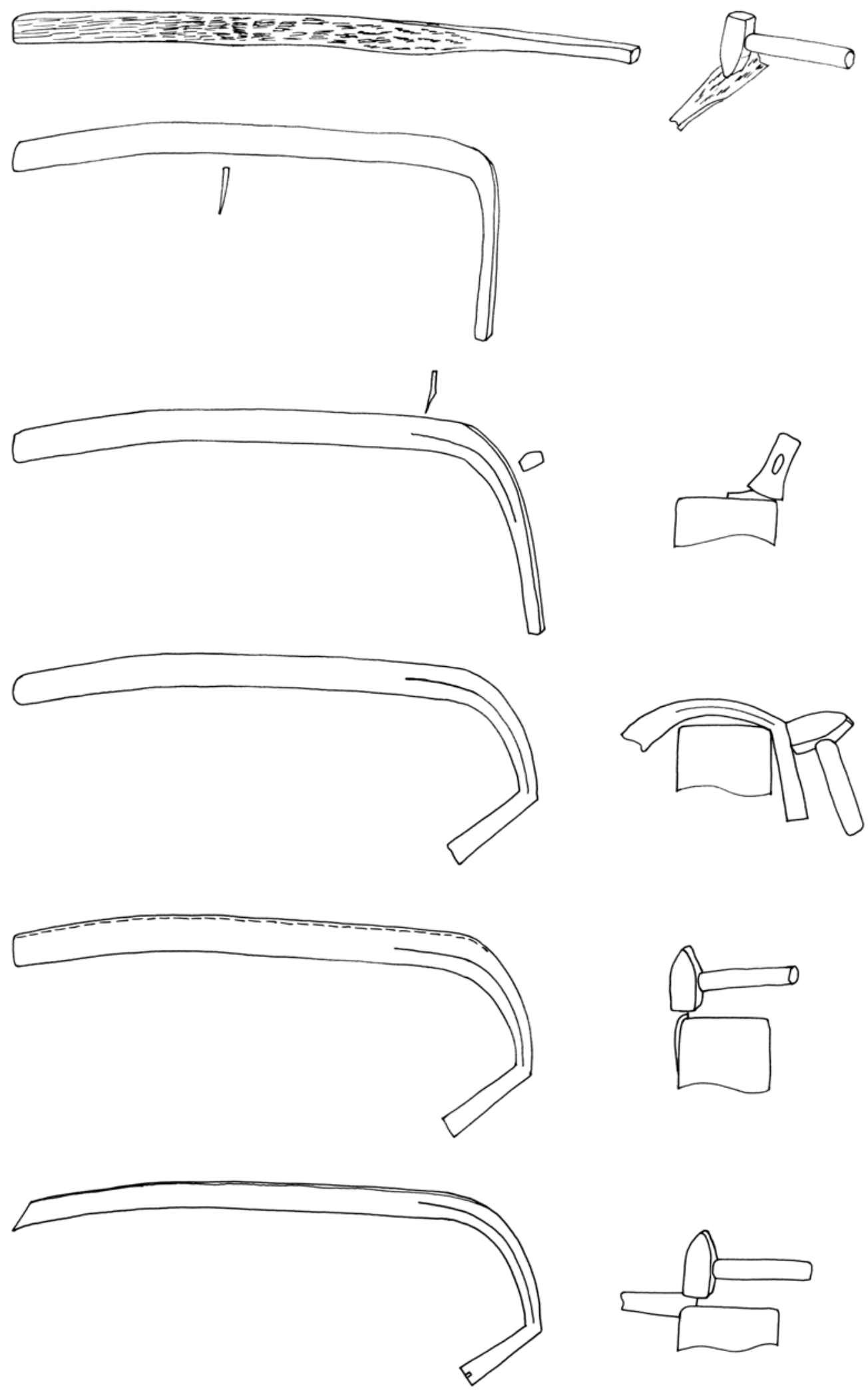

Abb. 14. Arbeitsvorgang bei der Herstellung der Replik einer Sense. Zeichnung P. Jánská. 
Die Ringe für die Stielbefestigung wurden in unserem Fall durch das Durchschlagen des Endes einer Stange von rechteckigem Querschnitt geschmiedet, danach wurde der erforderliche Teil abgehauen und zu einer regelmäßigen Form nachgeformt. Vor dem Aufsetzen auf den Stiel wurden die Ringe aufgeheizt und warm auf die Sense aufgezogen. Die Sense wurde auf den Stiel aufgesetzt und bei durchlaufender Kühlung sind die Ringe allmählich auf den konischen Teil des Stiels aufgesteckt worden.

Die Fertigung einer Sense dauerte ungefähr 30 Stunden. Hinsichtlich der Praxis handelte es sich um die ersten hergestellten Sensen. Es ist daher sehr wahrscheinlich, dass die Fertigung einer Sense in der römischen Kaiserzeit eine kürzere Zeit erforderte; wir können sie auf 20 Stunden schätzen.

\section{Fertigung und Pflege von Sensen}

(J. Hošek)

Wie es aus den Ergebnissen der metallographischen Untersuchung hervorgeht, sind die beiden Sensenblätter aus qualitätsvollem Stahl mit einem etwa eutektoiden Kohlenstoffgehalt hergestellt. Sie wurden nicht gehärtet, obwohl die Abkühlung von den Schmiedetemperaturen relativ schnell gewesen sein könnte. Da die Schneide einer der Sensen Spuren einer intensiven Kaltumformung trägt, ist es offensichtlich, dass die hohe Schärfe dieser Sensen durch zeitweiliges Dengeln mit einem Dengelhammer und häufiges Nachschärfen mit einem Wetzstein erreicht wurde. Die Klingen wurden an Hammen angeschweißt, deren Material offensichtlich einer nicht so strengen Selektion unterlag. Es lässt sich konstatieren, dass die Sensen aus Rosovice dieselbe Pflege erforderten wie die heutigen Sensen. Dies ist vermutlich auch dadurch gegeben, dass die Sensenblätter aus Rosovice relativ dünn sind. Die Dünnwandigkeit der Klingen ermöglichte es, ein akzeptables Verhältnis zwischen Gewicht und Länge zu erzielen. Die ausreichende Steifheit der Sensen wurde durch das Hochziehen der Rückenkante unter einem rechten Winkel in die Form einer einfachen Randstrebe (Rippe) erzielt. Die heutigen Sensen sind zwar gehärtet, aber aus einem viel dünneren Blech hergestellt, so dass das Dengeln der Schneide, selbst nach deren Härtung, keine Probleme macht; im Fall der Sensen aus Rosovice könnte eine höhere Härte von Stahl mit Rücksicht auf das Dengeln schon ungewünscht sein. Die Absenz von Härtung muss daher nicht unbedingt einen deutlicheren technologischen Mangel bedeuten. Das Dengeln selbst ist durch den Bedarf an Verdünnung der Schneide gegeben, und zwar bis zu einer Ebene, wo man mit dem Wetzstein eine sehr scharfe Kante formen kann; diese ermöglicht dann das Mähen feiner Halme (Gras). Das Dengeln erhöht gleichzeitig die Härte der Schneide, denn die partielle plastische Kaltumformung verursacht gewisse Erschöpfung der Plastizität des Materials, die von der steigenden Härte und Festigkeit begleitet wird. Auf diese Weise kann man die Absenz von Härtung zu einem gewissen Maß kompensieren.

Eine sehr nahe Analogie im Hinblick auf die Herstellungstechnologie bildet das Fragment einer Sense aus Hradisko bei Mušov, das ursprünglich als Sichel interpretiert wurde (Beran 2012, 35). Der Fund stammt aus dem Areal des handwerklichen Bezirks der römischen Militärfestung. Er lässt sich in die 2. Hälfte des 2. Jhs. datieren und dem Typ Henning I6 zuordnen. Der Erhaltungszustand macht es nicht möglich, das ursprüngliche Profil der Klinge zuverlässig zu bestimmen, sie war jedoch sicherlich dünnwandig. Auch diese Klinge wurde aus vorwiegend eutektoidem Stahl geschmiedet und weist keine zuverlässigen Spuren des ursprünglichen Härtens auf (Beran 2012, 48, 49, 74, 75). Genauso wie die Sensen aus Rosovice wurde auch diese Sense vermutlich mit Hilfe des Dengelns und häufigeren Nachschärfens in einem voll funktionsfähigen Zustand gehalten. Eine andere Vergleichsmöglichkeit bietet sich im Fall zweier Sensen aus dem 2. bis 3. Jh., die unweit des ehemaligen Legionslagers Lauriacum (Enns, Österreich) gefunden wurden. Es handelt sich um die Sense aus Pichling und das Sensenfragment aus Wels. Die beiden Funde hatten massivere Blätter mit dreieckigem Profil (Breite ungefähr $3 \mathrm{~cm}$ und Höchststärke rund $1 \mathrm{~cm}$ ), die aus kohlenstoffreichem Stahl geschmiedet wurden (Pribyl/Schmidt 1944; Zeitlinger 1944, 156, 157). Im Fall der Sense aus Pichling handelt es sich um eine Stahlklinge mit nachträglich auf den Kohlenstoffgehalt von ca. $1 \%$ aufgekohlter Schneide, die Sense aus Wels wurde aus übereutektoidem Stahl mit 1,3\% C geschmiedet (das Zementitnetz um die Perlitkörner beeinflusste negativ die Zähigkeit von solchem Stahl, was am Ende zum Klingenbruch führte). Die Härtung und Kaltumformung wurden bei keiner der Klingen nachgewiesen. Ins 2. und 3. Jh. datiert man auch das Fragment einer Sense, das an der Stelle des römischen Kastells Feldberg (Deutschland) gefunden und von R. Maddin und anderen analysiert wurde (Maddin/Hauptmann/Baatz 1991). Die metallographische Untersuchung deckte auf, dass die Klinge einen eisernen Rücken und angeschweißte Stahlschneide hat. Der Stahl war nicht gehärtet (die Struktur von sphäroidisiertem Perlit) und seine Härte war relativ niedrig. Die letzte Sense aus dem 2. bis 3. Jh., die metallographisch untersucht wurde, ist eine ungewöhnlich lange $(1,25 \mathrm{~m})$ und schwere $(5 \mathrm{~kg})$ Sense, die an der Stelle des römischen Kastells 
Durnomagus (Deutschland; Willer 2005) gefunden wurde. Sie gehört zu einer Gruppe von vier stark korrodierten und vielfach gebrochenen Sensen. Die Details von den metallographischen Analysen wurden nicht veröffentlicht, die untersuchte Klinge wurde angeblich aus Eisen hergestellt. Ob man bei der Interpretation auf den schlechten Erhaltungszustand des Fundsatzes Rücksicht nahm, wissen wir nicht. Theoretisch lässt es sich also nicht ausschließen, dass die Klinge ursprünglich mit einer Stahlschneide versehen war. Das experimentelle Mähen mit dieser Sense hat gezeigt, dass sie wegen ihres hohen Gewichts zum Grasmähen nicht geeignet, aber beim Schilfmähen gut brauchbar ist (Schilf wurde als Dacheindeckung verwendet). Die spezifische Funktion des Gerätes lässt daher auch die Möglichkeit einer ursprünglichen eisernen Schneide zu, obwohl dies nicht wahrscheinlich zu sein scheint. Erwähnen kann man auch eine Sense vom Ende des 4. Jhs. aus dem römischen Kastell Poundbury (Großbritannien). Sie hatte ein dünnwandiges Blatt mit einfacher Randstrebe, dessen Rücken aus weichem Eisen geschmiedet war. Die Schneide wurde mit einem dünnen Mantel aus ungehärtetem Stahl versehen, heutzutage ist sie jedoch stark korrodiert, so dass ihre ursprüngliche Spitze nicht beurteilt werden kann (Tylecote/Gilmour 1986, 65).

Der ungehärtete Zustand „römischer" Sensen ist ein interessantes Phänomen, das eine eingehendere Untersuchung verdient. Wir wissen nämlich nicht, in welchem Verhältnis die ungehärteten und gehärteten Sensen in der Gesamtproduktion vertreten sein konnten, oder ob der ungehärtete Zustand irgendwie mit größerer Länge und der Gesamtform des Gerätes zusammenhängt. Zum Vergleich können wir erwähnen, dass die wenigen untersuchten latènezeitlichen Sensen (Piaskowski 1958; Pleiner 1962, 87; 1982; Schwab 2002) und die zahlreichen mittelalterlichen Sensen (z. B. Kolčin 1953, 95-99; Piaskowski 1959; Pleiner 1962, 147; Semykin 2015, 81, 82; Voznesens'ka/ Nedopako/Pan'kov 1986, 101-103; Zav'jalov/Rozanova/Terechova 2012, 323, 329, 330, 368) am meisten eiserne Rücken und an- oder eingeschweißte gehärtete Stahlschneiden hatten. Häufig zu finden sind auch gehärtete Ganzstahlexemplare.

\section{LETY U DOBŘICHOVIC, BEZ. PRAG-WESTEN \\ (R. Korený und J. Jílek)}

Die detaillierte Kenntnis dieses Hortes ist durch mehrere Faktoren beeinflusst: er wurde durch Zufall, ohne Anwesenheit eines Archäologen entdeckt. Wir kennen daher nicht genau seine Deponierungsstelle, den physischen Zustand und die Anzahl der Gegenstände im Moment seiner Freilegung, den Zustand der Gegenstände vor der von F. C. Friedrich durchgeführten Konservierung und den jetzigen Zustand. Gegenwärtig sind nämlich nur Bronzegefäße verfügbar. ${ }^{10}$ Die Eisengegenstände sind nicht mehr auffindbar und vermisst werden sie vermutlich seit 1967, als der Hort ins Nationalmuseum in Prag überführt wurde (Abb. 15; Lutovský 2005, 126; Lutovský/Slabina 2004, 30). ${ }^{11}$ Verfügbar für das Studium waren deswegen lediglich die erhaltenen Gefäße, einige zeitgenössische Fotos (die vermutlich noch F. C. Friedrich selbst gemacht hat), Zeichnungen der Eisengegenstände (welche jedoch die genannten Fotos kopieren) und eine heutzutage äußerst wertvolle Kollektion der Acrylharzabgüsse von elf Eisengegenständen (Ev.-K 988-998). Im Nationalmuseum in Prag werden gegenwärtig zwei Kessel, eine Schüssel und ein Teller (Zuwachs-7/67, Inv.-Nr. 352 564-352 567) aufbewahrt und registriert. ${ }^{12}$

\section{Fundumstände}

Der Hort wurde im Zusammenhang mit dem Bau einer neuen Brücke über den Fluss Berounka und der anschließenden Straße (heute Pražská-Straße) in den Jahren 1936-1937 freigelegt. Gefunden hat ihn angeblich der Bauleiter selbst beim Bau des Wegs zur neuen Brücke im Jahr 1936. Die Fundumstände erfasste F. C. Friedrich nur sehr flüchtig in seinem Tagebuch. Der genaue Fundort wurde jedoch nicht

10 Die Elementzusammensetzung des Metalls kennen wir nicht (es kann sich in allen, oder nur in einigen Fällen um Bronze oder Kupfer handeln).

11 Über die Deponierung des Hortes (bzw. der Pflugschar) im Nationalmuseum in Prag hat jedoch schon im J. 1961 F. Šach geschrieben (Šach 1961, 65).

12 Dank ihnen war es möglich, nicht nur die Ausmaße der bis dahin nur flüchtig beschriebenen Gegenstände wesentlich zu ergänzen, sondern einige von ihnen auch mit Rücksicht auf ihre Funktion identifizieren (z. B. Gerbereisen, Haareisen). Den erhaltenen Angaben zufolge wurden die Acrylharzkopien irgendwann nach dem Jahr 1967 für die Zwecke der Präsentation des Fundes in einer Dauerausstellung im Hauptgebäude des Nationalmuseums in Prag gefertigt - diese Serie stand für das Studium zur Verfügung. Später wurde noch ein weiterer Satz für die Dauerausstellung im Palais Lobkowitz auf der Prager Burg gefertigt. 


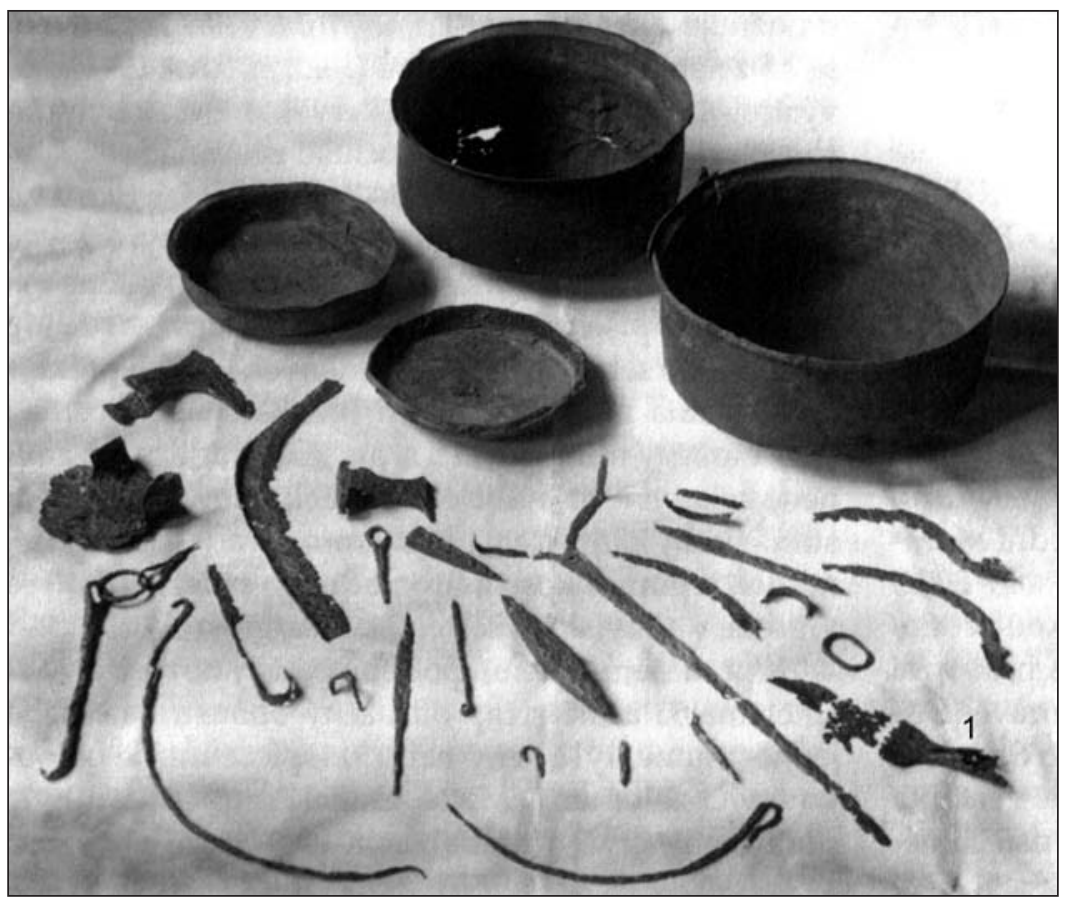

Abb. 15. Lety. Fotografie des Hortes, undatiert (1967?). 1 - Tüllenschar (?, nach Beranová/Lutovský 2009, bearbeitet).

aufgezeichnet. Der Hort befand sich vermutlich auf der Fläche einer Terrasse, die von den Pražská- und Řevnická-Straßen und einer namenslosen Quergasse umgrenzt war (Abb. 16). Gelagert war er „... in zwei ineinander gelegten Kupferkesseln. Der Fund lag in einer kesselförmigen steinverkleideten Grube mit Lehmfüllung ohne Scherben, 50-70 cm unter der Ackerkrume ${ }^{13}$, innerhalb einer sandigen Flussablagerung. Der größere Kupferkessel wurde in den kleineren eingelegt (ihre Eisenhenkel waren teilweise zerfallen) und die Eisengegenstände darin waren mit 2 Kupferschalen bedeckt, die mit dem Boden nach oben gedreht waren. Die Eisengegenstände... waren ziemlich stark verrostet und zerfielen an der Luft, denn sie waren relativ seicht in feuchtem Sand gelagert; durch eine sorgfältige Konservierung gelang es mir, sie zu erhalten“" (Friedrich 1946, 40). Falls bei der Beschreibung der Deponierungsweise der beiden Kessel kein Irrtum vorlag (der größere Kessel in den kleineren eingelegt), dann hat der größere Kessel höchstwahrscheinlich mit seinem Boden an den kleineren angesetzt; aus der Beschreibung „die Eisengegenstände darin“ ergibt sich dann, dass die Eisengegenstände in zwei Teile geteilt waren und jeder von ihnen noch mit einer Schale bedeckt war.

\section{Bisherige Datierung des Befundes}

Der Hort wurde als slawisch interpretiert und ins 6.-7. Jh. datiert (Eisner 1948; Friedrich 1946). Gegen diese Schlüsse gab es später mehrere Einwände bezüglich der Datierung und Provenienz einiger der Gegenstände; den deutlichsten Einwand erhob J. Bubeník, indem er eine Datierung in die römische Kaiserzeit und (oder eher) in die Völkerwanderungszeit aufgeworfen hat (Bubeník/Pleinerová/Profantová 1998, 128, mit Literatur). Die Andeutung eines Wandels in der Interpretation dieses Befundes wurde jedoch in den nachfolgenden Jahren von M. Beranová kategorisch abgelehnt (Beranová/Lutovský 2009, 123). ${ }^{14}$

13 Mit der Angabe „unter der Ackerkrume“ meint der Autor in seinem Tagebuch einmal die Tiefe unterhalb der Geländeoberfläche, ein anderes Mal aber die Tiefe unterhalb der unteren Kante der Ackerkrume; die Tiefe der Grube betrug damit vermutlich wenigstens $1 \mathrm{~m}$.

14 "Die Äxte darin sind typisch slawisch und konnten nicht der römischen Kaiserzeit oder den Germanen der Völkerwanderungszeit angehören...". Diese Behauptung kontrastiert mit ihrer Überzeugung vier Jahrzehnte früher: „Die Gegenstände darin sind nicht identisch mit typischen Werkzeugen der großmährischen Zeit und sind zweifellos älter. Nach Analogien und dem Ursprung muss man in nichtslawischen Kulturen suchen. Die Geräte... waren für die landwirtschaftliche Bevölkerung bestimmt, entweder die slawische oder die germanische, falls sich die Germanen damals in den tschechischen Ländern intensiver mit Landwirtschaft beschäftigt haben" (Beranová 1963, 472). 


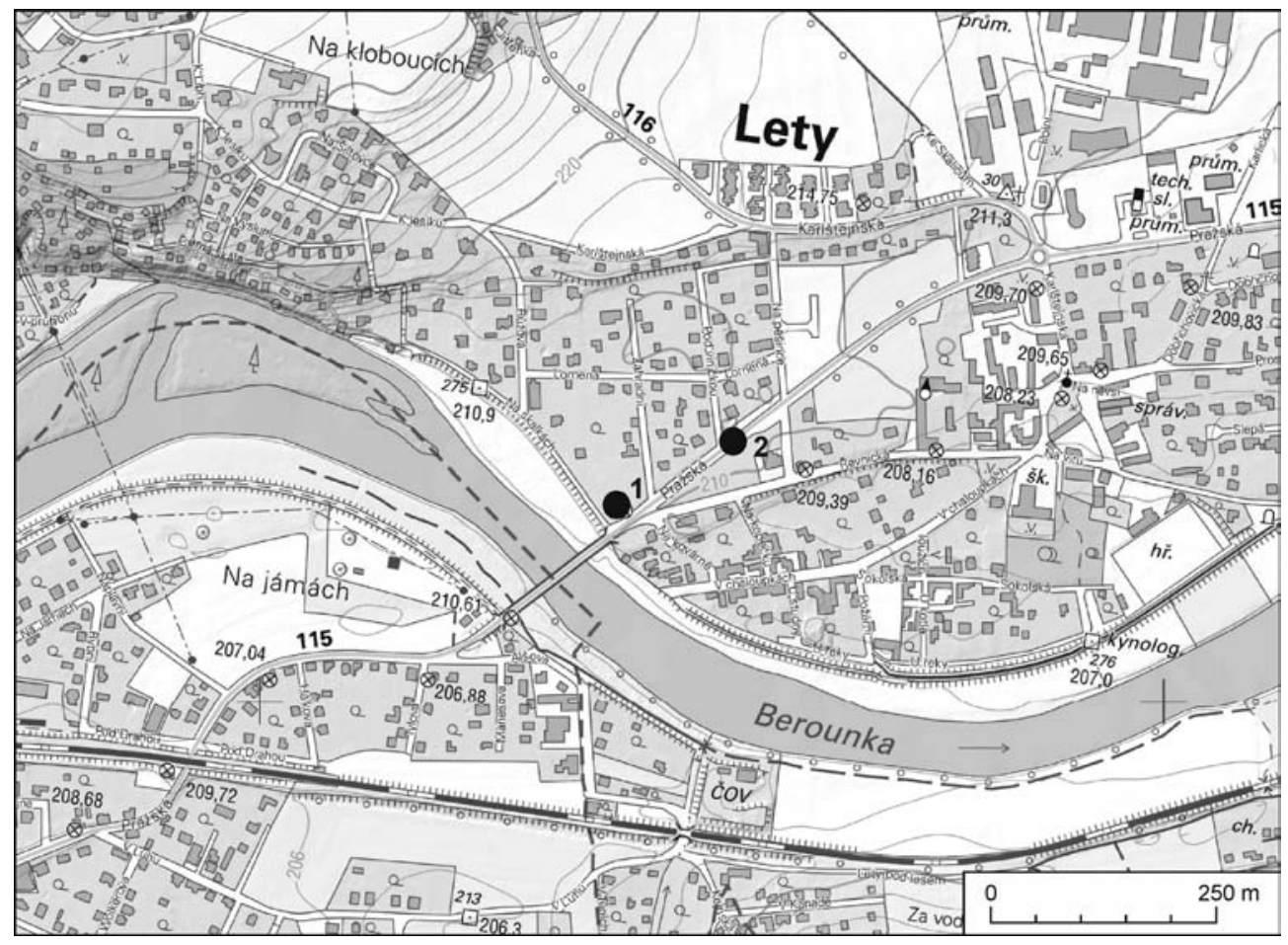

Abb. 16. Lety. 1 - Siedlung der älteren römischen Kaiserzeit; 2 - vermutliche Fundstelle des Hortes (nach Halama 2006, ergänzt). Hergestellt von P. Čechák und R. Korený.

\section{Analyse}

\section{Eimer vom Typ Eggers 43}

- Ausmaße: Höhe 20,4 cm, Mündungsdurchmesser 33,5 cm, maximale Bauchweite 32,7 cm, Durchmesser des Bodens 13,3 cm. Zu dem Eimer gehörte ein eiserner, fragmentarisch erhaltener Henkel (Abb. 17: 1; 19: 4; Bartošková 1986, Taf. III: 3; Beranová/Lutovský 2009, Abb. 25; 27; Friedrich 1946, Abb. 1: 3). Aufbewahrungsort: Ursprünglich die Sammlung von F. Friedrich, Nr. 730, seit 1967 das Nationalmuseum in Prag, Inv.-Nr. 352565.

Der Eimer nähert sich dem Typ E 43 - Variante Eskildstrup (Eggers 1951, Taf. 6: 43). Das Gefäß wurde durch Treiben hergestellt, wovon die ovalen, manchmal einander überlappenden Hammerspuren zeugen (vgl. Neupotz: Willer 2006, 176, Abb. 233). Von den verwandten Eimertypen E 41 und NE 13 unterscheidet er sich vor allem durch einen scharfen Wandknick (Künzl 1993, Typtaf. 16: NE 13). Der Kesselrand ist ausbiegend und die Art seiner Formung ist typisch für die tonnenförmigen Östland-Eimer. Die Eimer vom Typ E 43 stellen die Schlussform der tonnenförmigen Eimer dar, nach deren Ursprüngen schon in der frühen römischen Kaiserzeit gesucht wird. Dem heutigen Forschungsstand zufolge sind die Formen E 43 in die Zeitspanne von der Mitte des 2. Jhs. bis zum Ende des 3. Jhs. datiert (Koster 1997, 66, 67; Kunow 1983, 19; Lund Hansen 1987, 87). St. Berke nach (Berke 1990, 22) sollte man jedoch nach dem Ursprung dieses Typs schon in der Mitte des 1 . nachchristlichen Jhs. suchen. Die meisten Kontexte mit dem Vorkommen dieser Gefäße datieren aber ins 3. Jh. (Bienert 2007, 143; Lund Hansen 1987, 87; Werner 1938, Taf. 110: 1; 119: 7). An dieser Stelle ist es zu betonen, dass die Typen E 41, NE13 und E 43 zu verwandten Formen gehören und ihre Unterscheidung oftmals auf die ziemlich variable Art des Wandknicks im unteren Teil des Gefäßes gestützt ist. Diese Unterschiede könnten dann hypothetisch auf mehrere Produktionszentren im Rhein- sowie im Donaugebiet verweisen. Bei diesem Typ der Gebrauchsgefäße ist diese Überlegung begreiflich. Sehr nahe zu dem Eimer aus Lety steht der Fund eines Östland-Eimers aus dem Kastell Saalburg (Brunnen Nr. 48; Eggers 1955, 46, 48, Taf. 3: 6). Er unterscheidet sich jedoch durch die Art von Befestigung des Henkels, der mit Hilfe einer Eisenrute fixiert wurde, und durch die Absenz des eingewölbten Bodens. Bei der Bearbeitung der Bronzegefäße aus Saalburg bemerkte H. J. Eggers: „Kessel (!) vom Östlandtyp (eine im freien Germanien bisher noch nicht nachgewiesene Variante!)“. Das Gefäß 


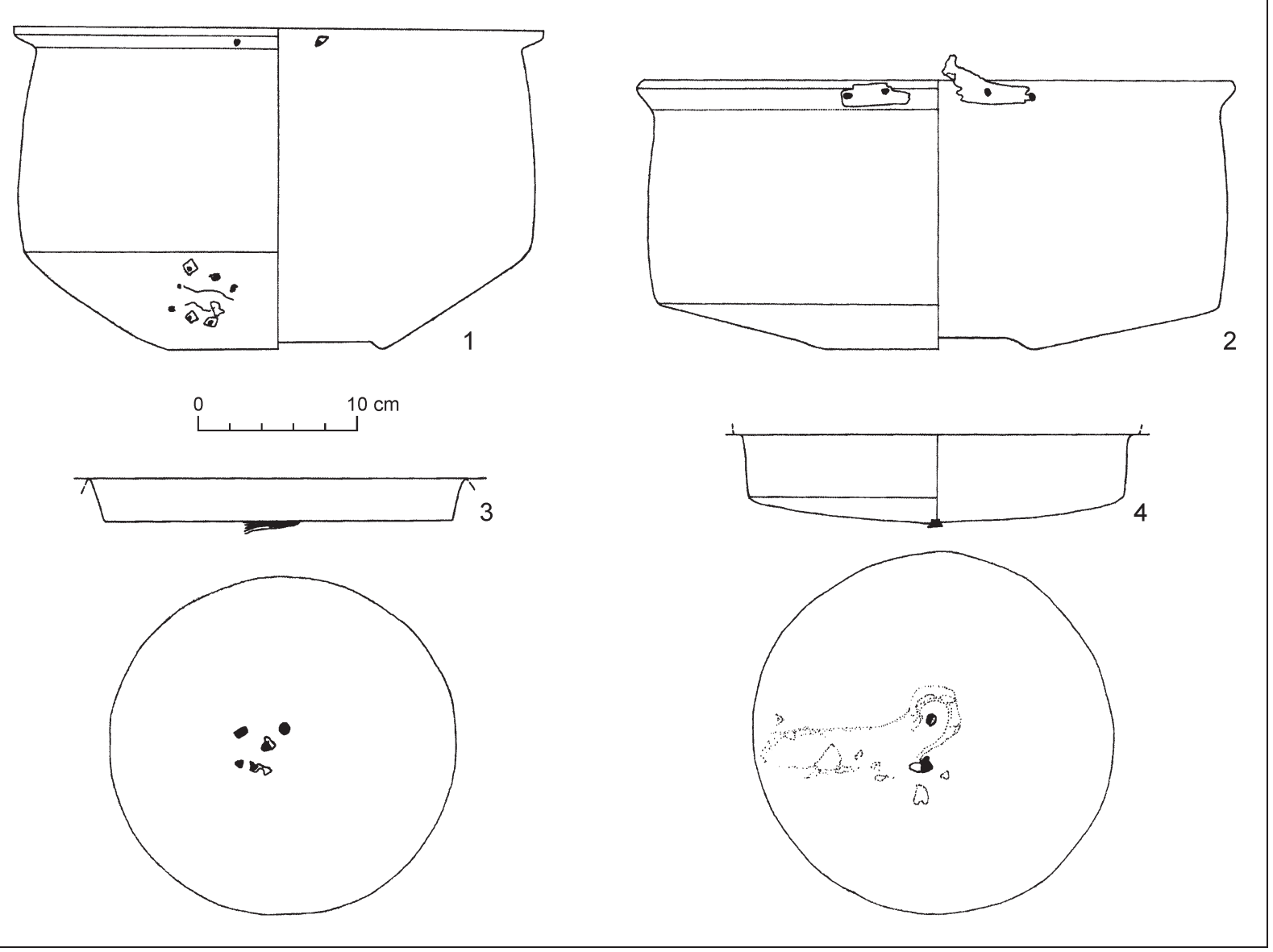

Abb. 17. Lety. Metallgefäße. Zeichnung R. Korený.

datierte er dann in den breiten Zeitabschnitt von der Mitte des 2. Jhs. bis zum Jahr 300 (Eggers 1955, 48). Aus römischem Umfeld lassen sich einige entferntere, nicht ganz identische Parallelen nennen, die in die jüngere - späte römische Kaiserzeit datiert sind (D'Andria 1974, 61, 63, Abb. 15; Cholakov/Atanasov 2007, 257, 259, Abb. 1; 2).

Im Rahmen des Barbarikums sind die Eimer vom Typ E 43 vor allem im nordischen Fundgut belegt (Lindeberg 1973, 43; Lund Hansen 1987, 87). Weniger häufig sind sie dann in mitteleuropäischen Kontexten (Berke 1990, 180; Dušek/Becker 2017, 106, Taf. 16: 3; XVII-13-13/1.1). Zu den neulich publizierten Exemplaren gehört der Eimer aus einem Hort in der Siedlung Strážnice I. Einen Teil des Befundes in der Kulturschicht bildete auch eine reparierte Schöpfkelle E 161 mit breitem ruderförmigem Griff. Gerade das gemeinsame Auftreten dieser Gefäße deutet auf die Datierung in die jüngere römische Kaiserzeit hin (Zeman u. a. 2017, 59, 291, Tab. 145; 146). Mit Rücksicht auf die Form ähneln den Eimern E 41 und E 43 auch einige Gefäße aus dem Mitteldonaugebiet (Jílek 2012,33). Damit meinen wir den Eimer aus dem Körpergrab II/1929 in Krakovany-Stráže (Klčo/Krupa 2008, 24, 26, Abb. 10, 24; Krupa/Klčo 2015, 82, 83; Neustupný 1936, 21, 22) und den Schöpfeimer aus der Siedlung der jüngeren römischen Kaiserzeit und der älteren Stufe der Völkerwanderungszeit in Štúrovo (Beljak 2009, 234, Taf. 2: 11). Diesen Beispielen nähert sich dann auch ein Eimer aus dem Depot im Befund 10 aus Mušov „U svatého Jana" (Trňáčková 1985, 279-284, Abb. 2). Die Eimer aus Großneuhausen, Strážnice I, Stráže, Štúrovo und Mušov unterscheiden sich jedoch von dem Exemplar aus Lety durch ihre kleineren Ausmaße. Diese Tatsache könnte auf eine breite Anwendungsskala der Gefäße verweisen, bzw. auf die Nutzung verschieden großer Gefäße beim Kochen, je nach der Menge der Zutaten. Bei dieser Überlegung muss man die breite Größenskala der Gefäße in römischen Küchen beachten (siehe z. B. Leconte 2013, 242, 243, Abb. 239).

Es ist sehr wahrscheinlich, dass die obenerwähnten Eimer provinzialrömische Erzeugnisse darstellen, die (vielleicht auch im Barbarikum) über eine längere Zeit in Gebrauch gewesen sind. Darauf 

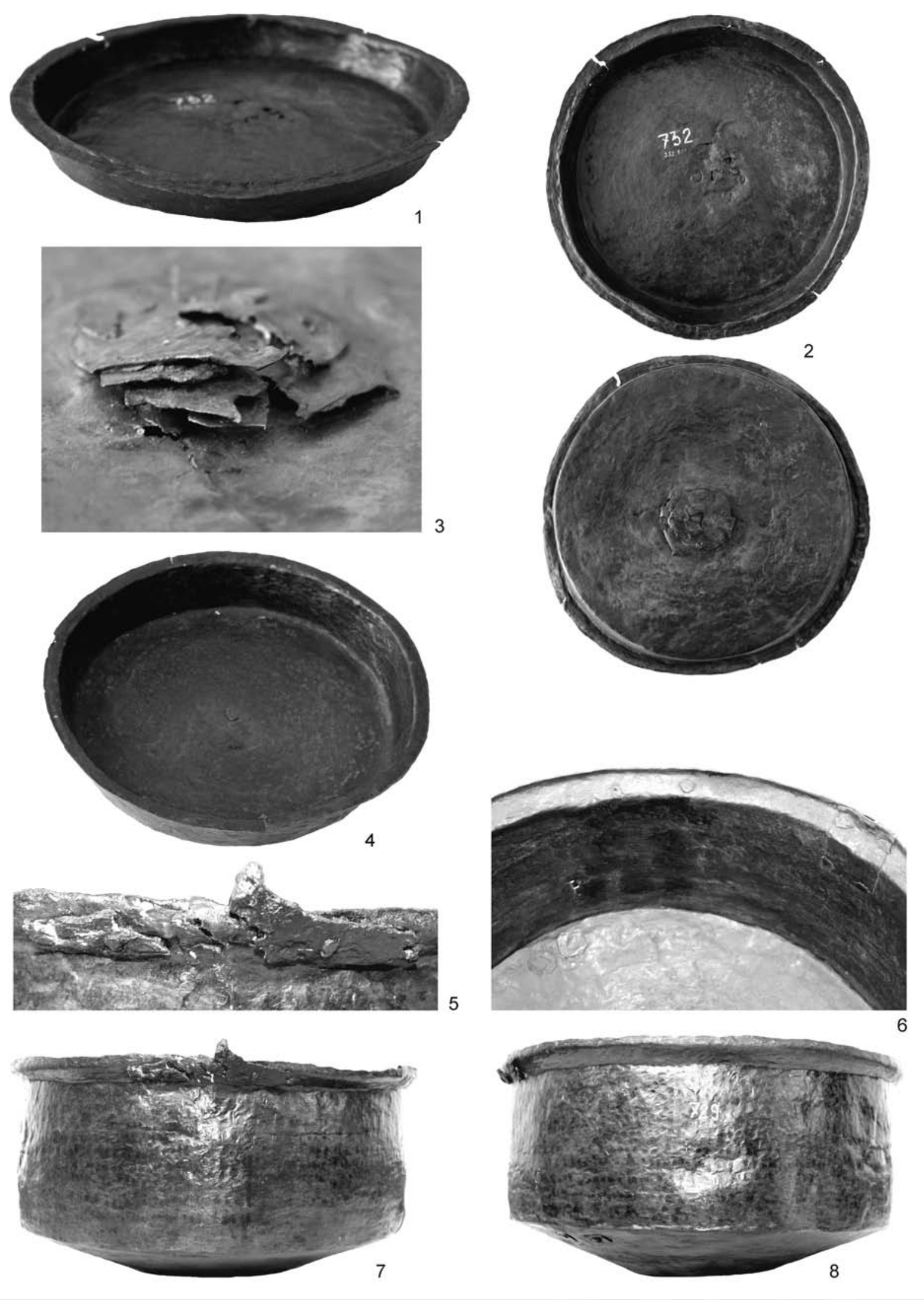

Abb. 18. Lety. Metallgefäße. 1-3 - Teller/Pfanne, Typ NE 24a; 4 - Pfanne, Typ Den Boesterd 91; 5-8 Schüsselförmiger Kessel. Foto R. Korený, bearbeitet von J. Jílek. 


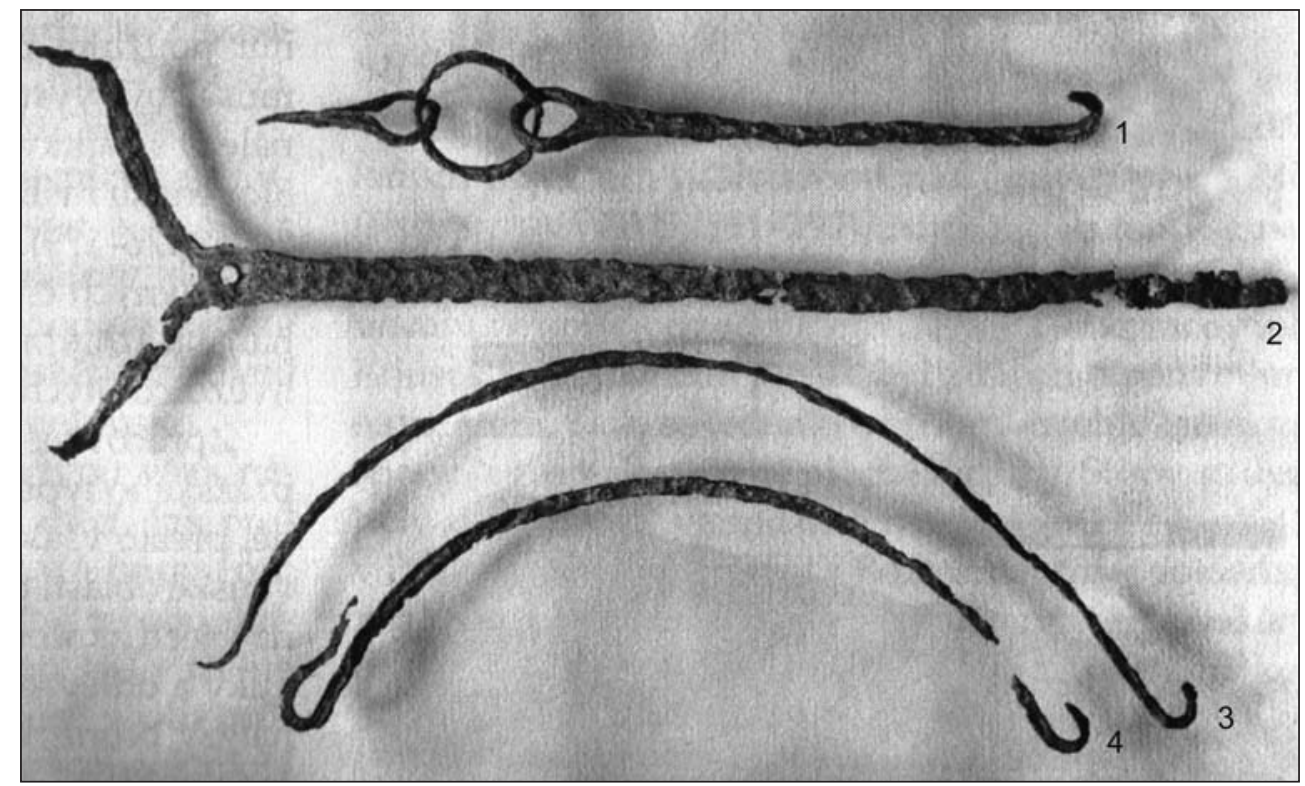

Abb. 19. Lety. 1 - Kesselgehänge; 2 - Eiserner Dreifuß; 3, 4 - Henkel (nach Beranová/Lutovský 2009).

würden auch ihre Reparaturen deuten, obwohl die nachgewiesenen Reparierungen der Kessel zur Zeit ihrer Deponierung in Provinzen gegen die einseitige Interpretation über deren längere Nutzung auf barbarischem Gebiet sprechen: z. B. sechs Flicken hatte ein zylindrischer Kessel aus dem Kastellvicus Rainau-Buch, aus dem Depot im Brunnen 13, der vor das Jahr 254 datiert ist (Greiner 2008, 79, Abb. 108; Taf. 111; Schmidts 2004, 65). Es lässt sich jedoch natürlich nicht ausschließen, dass diese Gebrauchsgefäße in Provinzen über eine längere Zeit benutzt worden sind und erst dann ins Barbarikum gelangten.

\section{Schüsselförmiger Kessel mit geknicktem Unterteil}

- Ausmaße: Höhe 17 cm, Mündungsdurchmesser am Rand 37-38 cm, Bauchweite 37 cm, Durchmesser des Bodens 13,5 cm. Zu dem Gefäß gehörte ein eiserner, fragmentarisch erhaltener Henkel (Abb. 17: 2; 18: 5-8; 19: 3; Bartošková 1986, Taf. III: 6; Beranová/Lutovský 2009, Abb. 25; Friedrich 1946, Abb. 1: 1). Aufbewahrungsort: Ursprünglich die Sammlung von F. Friedrich, Nr. 729, seit 1967 das Nationalmuseum in Prag, Inv.-Nr. 352564.

$\mathrm{Zu}$ dieser Form finden wir in den bisher verwendeten typologischen Systemen kein passendes Äquivalent. Mit seiner Tektonik nähert sich das Gefäß zwar den Formen der Eimer vom Typ E 43, ist jedoch deutlich breiter. Das von uns beschriebene Exemplar hat einen eingewölbten Boden, ähnlich wie der obenerwähnte Eimer. Die Schüssel ist auf eine ähnliche Weise getrieben wie der obenerwähnte Eimer vom Typ E 43. Direkte Parallelen zu dem beschriebenen Gefäß sind nicht sehr zahlreich. Ein repräsentatives Stück ist das Gefäß aus der römischen Villa in der Nähe von Stup in Bosnien. Die Villa ist rahmenhaft ins 3. bis 4. Jh. datiert (Abb. 20; Busuladžić 2011, 98, 99, 169). Das beschriebene Exemplar aus Lety nähert sich mit seinem Wandknick im unteren Teil des Gefäßbauchs teilweise den Formen, die in deutscher Literatur als "Knickwandschüsseln" oder "Knickwandtöpfe“ bezeichnet werden. Diese Formen sind aber sonst schon sehr entfernt. Sie unterscheiden sich sowohl durch die Verzierung als auch durch die Verzinnung der Innenoberfläche, aber vor allem durch das Vorkommen des Standrings - in der Klassifikation von E. Künzl (1993, 241, 242, Typtaf. 17: NE16) entsprechen sie dem Typ NE 16, zeitlich fallen sie vor allem ins 3. Jh., von wo wir sie oft aus Horten im römischen Rheinland und Gallien kennen (Bernhard u. a. 1990, 39, Abb. 22: 13; Kapeller 2003, 94, 95, 100, 101, 141, Taf. 28: 167; Künzl 1993, 241, 242; Petrovszky 2006, 190, 191, Abb. 247; Petrovszky/Bernhard 2016, 252, Tab. 1; Tomasevic-Buck 1980, 104, 109, Abb. 5: 6; 1984, 181, Abb. 6: 1). 


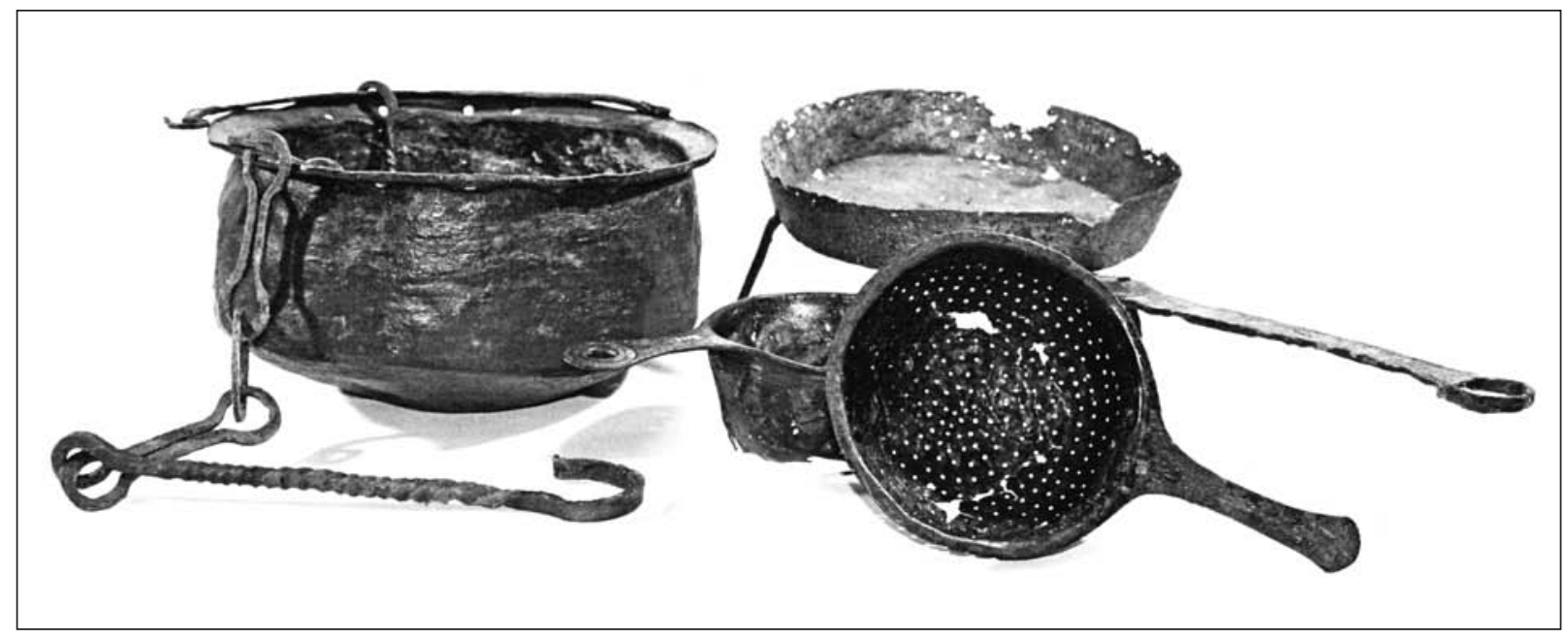

Abb. 20. Sarajevo-Stup. Ein Teil des Kochgeschirrs aus der römischen Villa, 3.-4. Jh. (nach Busuladžić 2011).

\section{Teller/Pfanne, Typ NE 24a}

- Beschreibung: getriebenes Gefäß mit gerader Wandung, flachem Boden und deformiertem Rand. Am Boden des Tellers befinden sich in der Mitte Reparaturspuren, auf der Außenseite sieht man eine Anhäufung von etwa 3-5 miteinander verbundenen Blechplättchen, vermutlich aus Kupfer. Dazwischen befindet sich ein Blechstück (Messing?), das die übrigen Bleche am Rande teilweise überdeckt. Ausmaße: Gefäßhöhe 2,8 cm, Mündungsdurchmesser 25,9 cm, Durchmesser des Bodens 22,2 cm (Abb. 17: 3; 18: 1-3; Bartošková 1986, Taf. III: 4; Friedrich 1946, Abb. 1: 6). Aufbewahrungsort: Ursprünglich die Sammlung von F. Friedrich, Nr. 732, seit 1967 das Nationalmuseum in Prag, Inv.-Nr. 352567.

\section{Pfanne, Typ Den Boesterd 91}

- Beschreibung: getriebenes Gefäß mit senkrechter Wandung und horizontalem Rand, mit leicht abgeschrägtem Unterteil des Gefäßbauchs. In der Mitte des Bodens ist ein Bronzeniet eingelassen, auf der Außenseite des Bodens sind deutliche eiserne Korrosionsspuren zu sehen. Ausmaße: Höhe 5,6 cm, Mündungsdurchmesser 27 cm, Durchmesser des Bodens 23,8 cm (Abb. 17: 4; 18: 4; Bartošková 1986, Taf. III: 5; Friedrich 1946, Abb. 1: 5). Aufbewahrungsort: Ursprünglich die Sammlung von F. Friedrich, Nr. 731, seit 1967 das Nationalmuseum in Prag, Inv.-Nr. 352500.

Auf die Funktion des zweiten Gefäßes deutet klar der eingelassene Bronzeniet und die eisernen Korrosionsspuren auf der Außenseite des Bodens (Abb. 17: 4). Gerade diese Relikte lassen sich eindeutig als Spuren eines eisernen Dreifußes interpretieren (Bienert 2007, 173). Das kleinere Gefäß können wir den Tellern/Pfannen vom Typ NE 24a in der Klassifikation von E. Künzl zuordnen (Künzl 1993, 253, 254, Typtaf. 18: NE 24a). Das größere Gefäß mit abgeschrägtem Boden nähert sich dann dem Typ Den Boesterd 91 (Den Boesterd 1956, 33, Taf. IV: 91). Es handelt sich um Gebrauchsformen, die im Römischen Reich seit dem 1. Jh. bis zur Spätantike benutzt wurden. Zahlreiche Exemplare sind aus Horten des 3. Jhs. belegt (Kapeller 2003, 54, Taf. 1: 2-5). Die beschriebenen Gefäßtypen waren sowohl in zivilen, als auch in militärischen provinzialen Kontexten vertreten (ausführlich Bienert 2007, 173, 174; Künzl 1993, 253, 254; Sedlmayer 1999, 69, 70). Aus einer überregionalen Perspektive ist es interessant, dass wir diese Kategorie der Bronzegefäße aus mitteleuropäischem Barbarikum nicht sehr gut kennen (Dušek/Becker 2017, 97, Taf. 38; XVII-09-8/1.1; Kramarkowa 1990, 100, 134, Abb. 32: d; Mylashevskyi/Pryszczepa/Wojtiuk 2018; Sedlmayer 2016, Abb. 1; Tab. 10-12; Wielowiejski 1985, 200, Taf. 13: 3). Aus böhmischem Milieu handelt es sich also mit Sicherheit um die allerersten Funde dieser Art.

\section{Eisernes Pfannengestell - Dreifuß}

- Beschreibung: Das Band war in drei Teile gebrochen, die erhaltene Länge betrug 44,5 cm, Länge der Arme $9 \mathrm{~cm}$ (Abb. 19: 2; Beranová/Lutovský 2009, Abb. 25; 28; Friedrich 1946, Abb. 2: 24). 


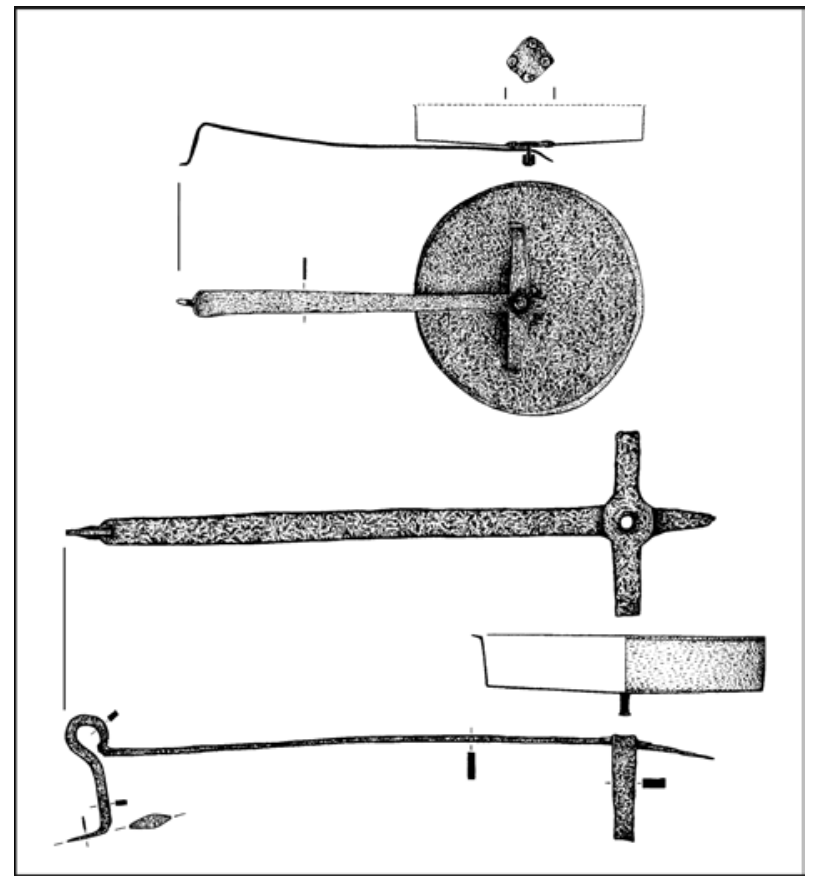

Abb. 21. Eiserne Dreifüße mit Pfannen (nach Greiner 2010).
Der eiserne Dreifuß ist als Zubehör der Pfannen im Provinzialmilieu häufig vorgekommen (Abb. 18; 19: 2; 21; Busuladžić 2011; 2014; Greiner 2002; 2008; 2010; Horisberger 2004; Junkelmann 2006). ${ }^{15}$

\section{Kesselgehänge}

- Beschreibung: Ein Haken aus tordiertem Draht mit einer Länge von 23,8 cm, mit einem Ring von 5,5 cm im Durchmesser, auf dem das Fragment eines weiteren Stäbchens mit erhaltener Länge von $8,2 \mathrm{~cm}$ aufgezogen ist (Abb. 19: 1; Bartošková 1986, Taf. I: 7; Friedrich 1946, Abb. 2: 25).

Von der ganzen Vorrichtung erhielt sich bloß ein kleines, nicht näher klassifizierbares Bruchstück, das sich nur dem Kontext zufolge allgemein in die römische Kaiserzeit datieren lässt (zur Klassifikation z. B. Hanemann 2014, 68-72). $\mathrm{Zu}$ dem obengenannten Bruchstück gehörten möglicherweise noch Stäbchen mit Öse (Abb. 29: 2, 3; Bartošková 1986, Taf. II: 2, 3; Friedrich 1946, Abb. 2: 7, 8) und ein Ring (Abb. 29: 6; Bartošková 1986, Taf. II: 9; Friedrich 1946, Abb. 2: 17).

\section{Werkzeuge und Geräte}

\section{Schere}

- Beschreibung: erhaltene Länge 19,5 cm, Breite der Klinge 1,6 cm, Breite des Bügels 1,5 cm (Abb. 22: 4; Bartošková 1986, Taf. I: 5; Friedrich 1946, Abb. 2: 14).

Die Bügelschere stellte ein gewöhnliches provinzialrömisches Erzeugnis dar (vgl. Gaitzsch 1980, 214, Abb. 39: 4). Anhand der Klassifikation von B. Hanemann handelt es sich um den Typ $1 B$ mit bügelförmigem Griff von mittlerer Größe, mit dem Vorkommen während der ganzen römischen Kaiserzeit (Hanemann 2014, 231, Abb. 195). In der Klassifikation von A. Knaack (1978, 18, 19, 21, Abb. 2a; 3c) handelt es sich um den Typ Ic, der vor allem in der frühen römischen Kaiserzeit und dann erst nach den Markomannenkriegen beliebt war.

\section{Sense}

- Beschreibung: erhaltene Länge 38,5 cm (F. C. Friedrich gibt 43,5 cm an), Breite des Blatts 3,9 cm. Erhalten ist die Rückenleiste, am Ende der gebrochenen Klinge befindet sich ein Teil eines nachträglich durchschlagenen Lochs, ein weiteres Loch mit einem Durchmesser von $3 \mathrm{~mm}$ ist von dem ersteren $23 \mathrm{~mm}$ entfernt. Die Klinge besitzt einen aufwärts gebogenen Rand. Auf einem Teil der Klinge ist ein Mittelgrat zu sehen. Die Hamme von dachförmigem Profil ist nur teilweise erhalten, der Dorn fehlt (Abb. 23: 1; Bartošková 1986, Taf. I: 1; Friedrich 1946, Abb. 2: 21). Aufbewahrungsort: Ursprünglich die Sammlung von F. Friedrich, seit 1967 das Nationalmuseum in Prag, verschollen, erhalten ist eine Acrylharzkopie K991.

Unter den Gegenständen des Hortes von Lety wurde eine große Aufmerksamkeit der teilweise erhaltenen Sense geschenkt. Am ausführlichsten befasste sich mit diesem Fund M. Beranová (1972, 639; 1980, 170; 2005, 27; Beranová/Kubačák 2010, 165; Beranová/Lutovský 2009). Sie klassifizierte sie als kurze Sense,

15 Weitere Fragmente von Dreifüßen mit Pfannen, bzw. von Pfannen mit Spuren des Dreifußes: Kastellvicus Tenedo-Zurzach, 3. Jh. (Hänggi/Doswald/Roth-Rubi 1994, Abb. 212f: E291), Kastell Rainau-Buch, Mitte des 3. Jhs. (Seitz 1999, 174, Taf. 4, B58), Vicus Baden, Kt. Aargau, 3. Jh. (Koller/Doswald 1996, Abb. 112 - Rekonstruktion; Taf. 88: 1909), Augst, Kt. Basel-Landschaft, 1.-2. Jh. (Lüdin/Sitterding/Steiger 1962, Abb. 21: 3), Weißenburg, "Westvicus“, Depotfund, Mitte des 3. Jhs. (Kellner/Zahlhaas 1993, Taf. 99, 100), Straubing-Kagers, 2. Jh. (Prammer 1993, 109, Abb. 66), Enns/Lauriacum, 2. Drittel des 3. Jhs. (Sedlmayer 1999, 70, Anm. 456; Taf. 28: 7). 

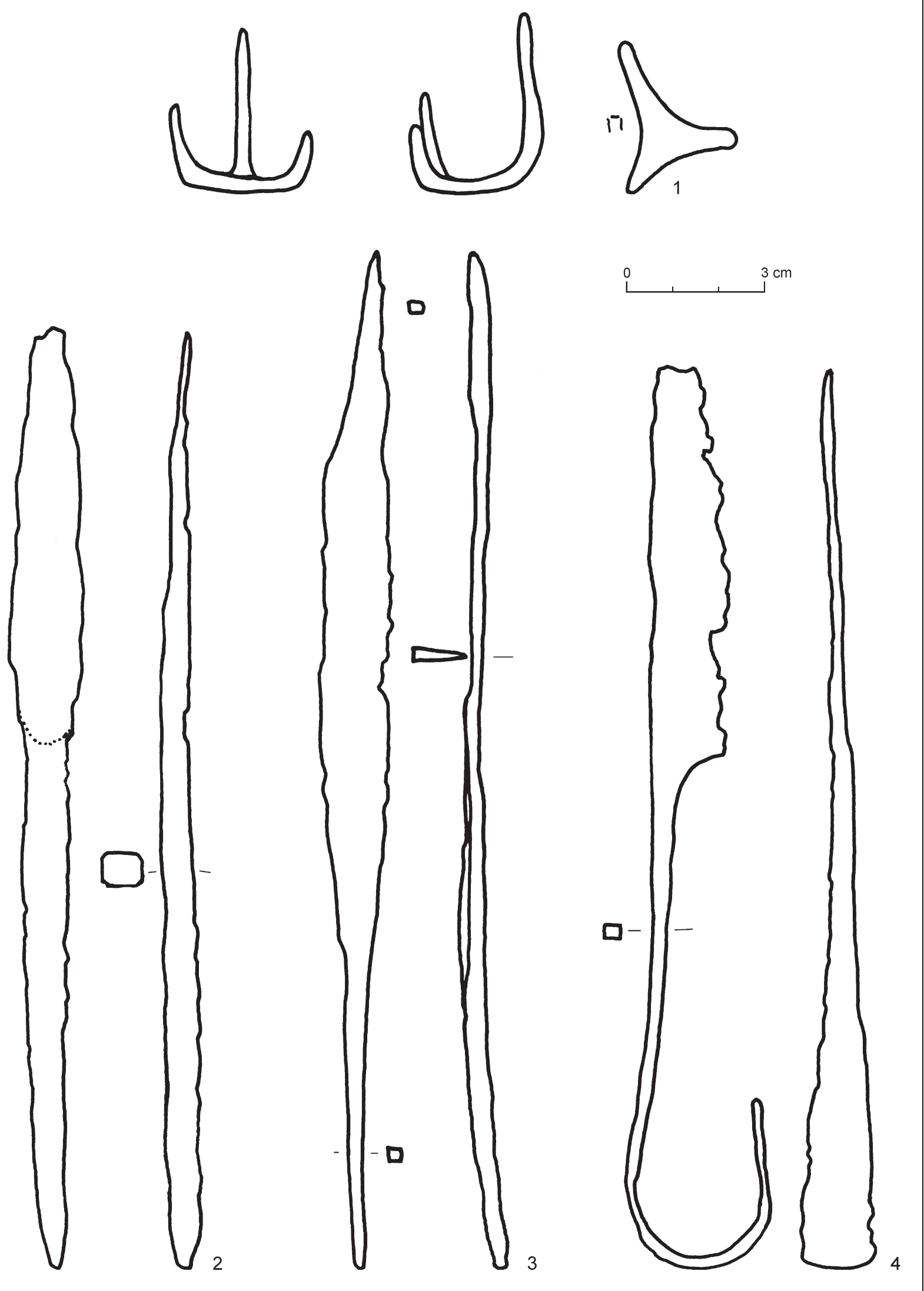

Abb. 22. Lety. 1 - Schöpfkelle/Schlüssel; 2 - Bohrer; 3 - Gerbereisen; 4 - Schere. Zeichnung R. Korený. 


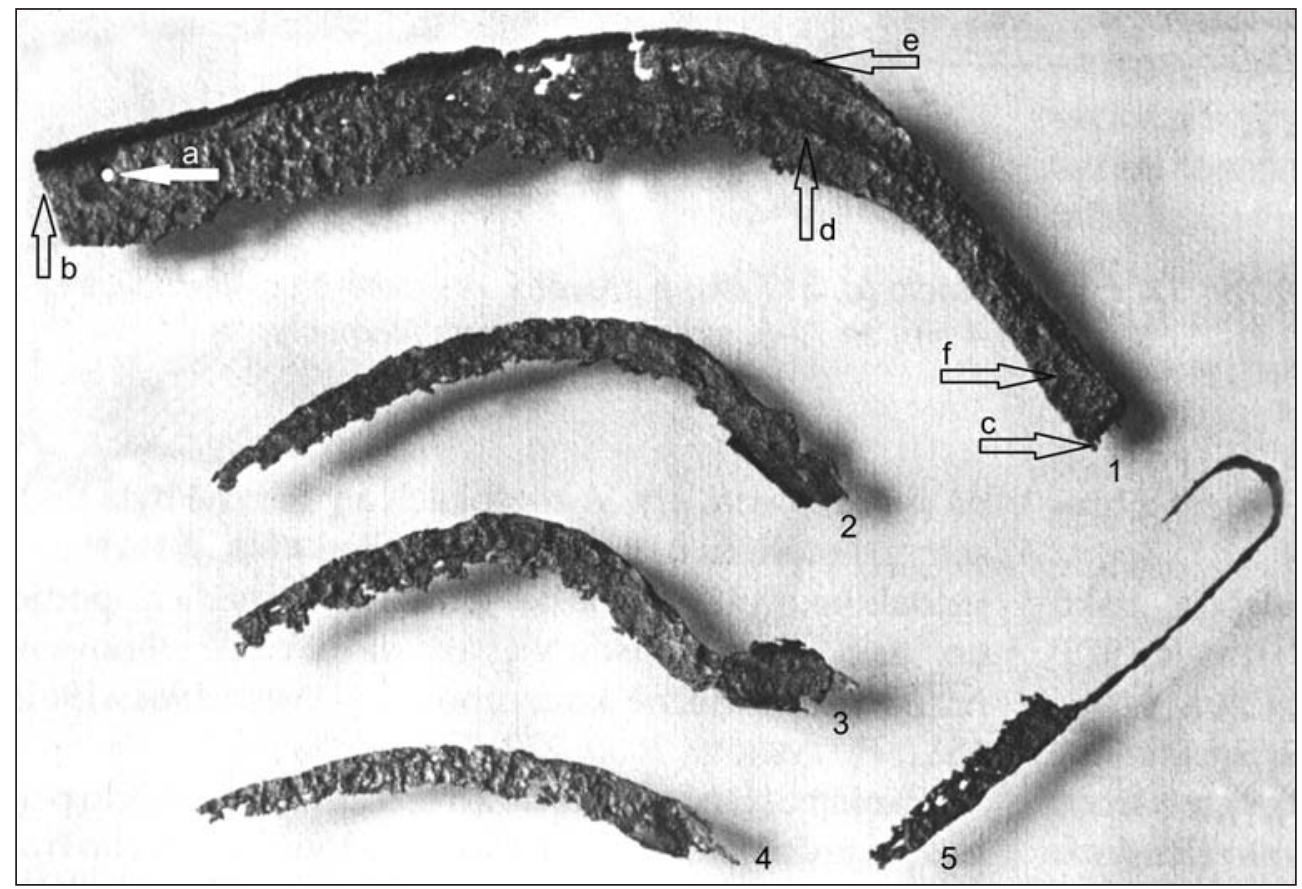

Abb. 23. Lety. 1 - Sense (a - Reparaturloch; b - Reparaturloch (Rest); c-Splitter nach dem Abbrechen der Hamme; d - Mittelgrat; e - Rückenleiste; f - schräger Bruch nach dem Abbrechen des Hammenendes); 2, 3 - Sicheln; 4 - Schere (Foto nach Beranová/Lutovský 2009, bearbeitet).

mit dem Hinweis, dass sie sich von den sämtlichen bekannten kurzen Sensen seit der Latènezeit bis zum Mittelalter unterscheide. Sie datierte sie ins 6.-7. Jh. Die typologisch-chronologische Klassifikation der Sense wurde jedoch bis heute noch nicht zufriedenstellend definiert. Wie es schon aus dem Kapitel über die Sensen aus Rosovice ersichtlich ist, nehme ich an, dass die Sense aus Lety keine kurze, sondern eine lange Sense war, genauer gesagt eine des 4 . Typs nach der Klassifikation von B. Hanemann. Jetzt ist es aber nötig, diese Behauptung mit Beweisen zu untermauern.

Das Hauptproblem der bisherigen Bewertung besteht darin, dass wir einen viel zu großen Wert auf den Winkel zwischen der Schneide und der Hamme legen. Dieser Winkel wird als das Hauptkriterium der Klassifikation betrachtet und die Elemente, die auf die ursprüngliche Form des Gegenstandes verweisen, bleiben gleichzeitig unbeachtet.

1. Der erste Moment ist eine Bemerkung von F. C. Friedrich in der sonst sehr kurzen Beschreibung der Sense: „... die ausgehämmerte Schneide hat eine Rückenleiste und darunter ein Loch“ (von R. K. markiert; Friedrich 1946, 43). Das Loch ist gut sichtbar in den Studien von J. Eisner (1948, Abb. 1: 1), M. Beranová (1980, Taf. XXVI: 1; 2005, 28, Abb. 25; Beranová/Lutovský 2009, Abb. 34) und in der Monografie von A. Bartošková (1986, Taf. I: 1), wo wir dank einem etwas schrägen Winkel seine regelmäßig runde Form sehen. Diese Beobachtung bestätigte auch die Untersuchung der Acrylharzkopie, auf der es klar zu sehen ist, dass das Loch von oben durchgeschlagen wurde (Abb. 23: 1a). Das Loch ist von dem Klingenbruch $23 \mathrm{~mm}$ entfernt und sein Durchmesser beträgt $3 \mathrm{~mm}$. Ein weiteres Loch, bzw. seinen kleineren Teil, finden wir am Klingenbruch. Es ist gut sichtbar auf der nächsten Abbildung (Abb. 23: 1b). Die Position der Löcher und ihre Größe bezeugen eine in der Vergangenheit durchgeführte Reparatur der gebrochenen Klinge (vgl. Turek 1982, 13, „Fragment einer Sense mit Verlängerungsspuren"). Ursprünglich war das Sensenblatt jedoch an einer anderen Stelle gebrochen. Damit die Sense nach der Reparatur funktionsfähig ist, müssen an beiden Seiten des Klingenbruchs wenigstens zwei Niete angebracht werden, welche die gebrochenen Teile mit dem Reparaturband fest fixieren. Wie eine solche Reparatur durchgeführt wurde, sehen wir auf einer Sense aus dem Hort von Osterburken (Henning 1985, Abb. 2: 1). Vermutlich auf dieselbe Weise wurde auch die Sense aus Loka pri Žusmu repariert (Ciglenečki 1983, Taf. II: 6; 2000, Tab. 3). ${ }^{16}$ Die Sense aus Lety ist jedoch nach der Reparatur noch

16 Beispiele für Reparaturen - Curle 1911, Taf. 62: 6; Drack 1990, Taf. 43: 165; Henning 1985, Abb. 2: 2; Koch 1991, Taf. 5; Pietsch 1983, 116, Taf. 24: 536; Pohanka 1986, 156, 360, Taf. 32: 122. 


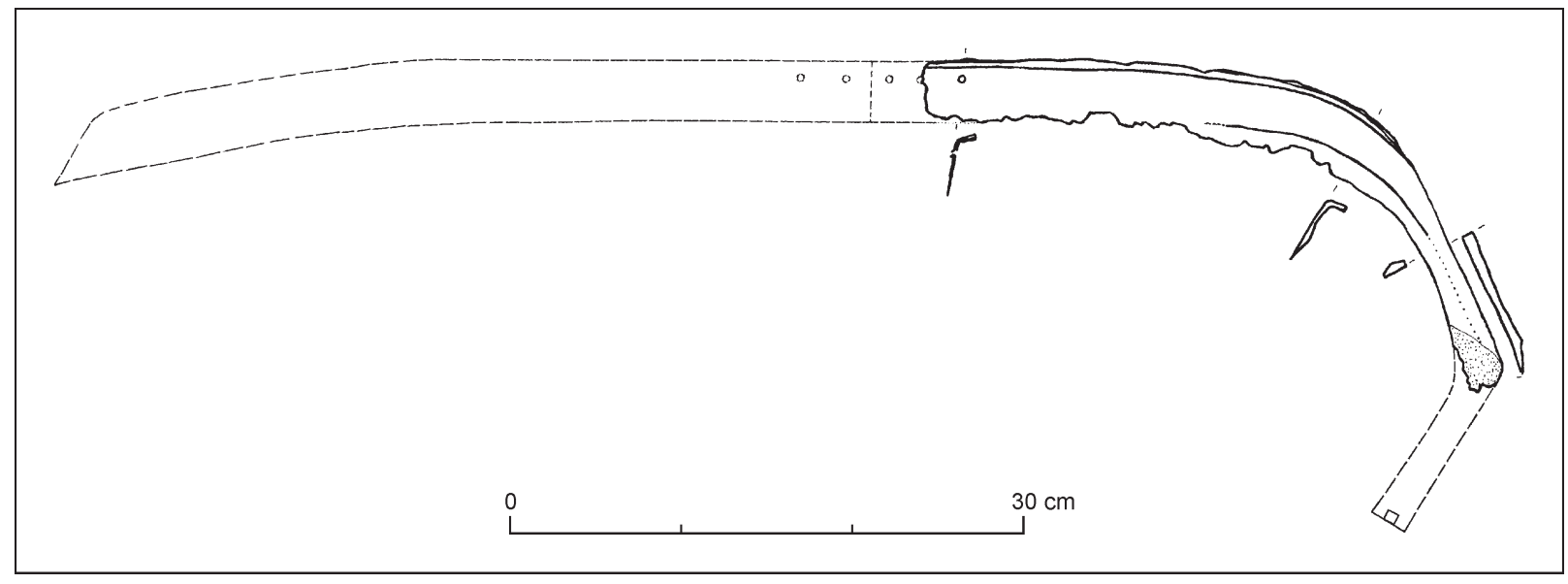

Abb. 24. Lety. Sense. Rekonstruktion. Zeichnung R. Korený.

einmal gebrochen (es ist gerade derjenige Bruch an der Stelle des zweiten Niets) und wurde in dieser Form bereits völlig unbrauchbar. Mit Rücksicht auf die Absenz eines Teiles der Hamme können wir in Betracht ziehen, dass sie weiter für einige Zeit als kurze Sense, oder eher als Sichel verwendet wurde.

2. Form der Hamme. Anhand der erhaltenen bildlichen Dokumentation ist es ersichtlich, dass an ihrem Ende der Dorn für die Befestigung des Stiels fehlt. Als erster bemerkte es J. Eisner $(1948,377)$. Der Dorn ist bei kurzen Sensen üblich (Beranová 1980; 2005). Heutzutage ermöglichen eine detaillierte Beobachtung nur einige Aufnahmen und die Acrylharzkopie. Auf der Kopie sieht man, dass der wahre Grund für die Absenz des Dorns das fehlende Ende der Hamme ist (Abb. 23: 1f). Aus dem schrägen Bruch ragen nämlich kleine eiserne Splitter heraus, die schließlich auch auf zeitgenössischen Fotos zu sehen sind (Abb. 23: 1c; Beranová 1980, Taf. XXVI: 1; 2005, 28, Abb. 25; Friedrich 1946, 41, Abb. 2: 21).

3. Rekonstruktion. Zur Rekonstruktion der Form führen weitere Elemente, wie die Stärke der Klinge, die Rückenleiste (Abb. 23: 1e), die Beugungskurve der Hamme und der Mittelgrat, der ungefähr durch die Mitte der Klinge und der sich leicht erweiternden massiven Hamme führt (Abb. 23: 1d). Nachdem wir die Funktion der Löcher in der Klinge erläutert haben, ist es völlig klar, dass wir jetzt schon von einer Langsense sprechen (Abb. 24). Alle obengenannten Elemente deuten wieder, genauso wie im Fall der Sensen aus Rosovice, auf die behandelte Gruppe von Langsensen des 4. Typs nach der Klassifikation von B. Hanemann (2014, 193, Abb. 171). Die Hamme der Sense aus Lety entsprach den Sensen aus Bengen, Dellach-Gurina, Loka pri Žusmu und aus dem Runden Berg (entsprechende Literatur im Kapitel über den Hort von Rosovice). Aus den obenerwähnten Tatsachen ergibt sich also auch ihre Datierung ins 2.-3. Jh.

\section{Sicheln}

- Beschreibung: Die Korrosion änderte auf eine deutliche Weise die Form der Sicheln (es fehlen offensichtlich wesentliche Teile der Klingen), ihre gegenwärtigen Ausmaße sind wie folgt: Sichel mit "Griffangel“ (vermutlich Überrest eines Schaftlappens), Länge $18 \mathrm{~cm}$, Breite 1,7 cm (Abb. 23: 4), Sichel mit Schaftlappen und zwei Befestigungslöchern, Länge 21,8 cm, Breite 1,9 cm (Abb. 23: 3; 25: 3), Sichel mit Schaftlappen, Länge $24 \mathrm{~cm}$, Breite 2,2 cm (Abb. 23: 2; 25: 4; Bartošková 1986, Taf. I: 2-4; Friedrich 1946, Abb. 2: 20, 22, 23). Aufbewahrungsort: Ursprünglich die Sammlung von F. Friedrich, seit 1967 das Nationalmuseum in Prag, verschollen, erhalten sind zwei Acrylharzkopien K993, K994.

Zwei Sicheln besitzen Griffe mit Überresten der Schaftlappen, in einem Fall mit zwei Befestigungslöchern, bei der dritten Sichel sind die Schaftlappen nicht erhalten. Nach der Klassifikation von J.-J. Penack (1993, 22, 23, Taf. II: 12) handelt es sich um Typ 12, der aus dem ganzen Verlauf der römischen Kaiserzeit und aus dem Anfang der Völkerwanderungszeit bekannt ist. B. Hanemann (2014, 199, Abb. 175) ordnet die Sicheln mit Schaftlappen ihrem Typ 3C zu und charakterisiert sie als den Übergang zwischen Sicheln und Sensen mit dem Vorkommen während der römischen Kaiserzeit und am Anfang der Völkerwanderungszeit (z. B. Schleßlitz-Burgellern - Reisberg; Haberstroh/Faßbinder 2003, Abb. 10: 8, 9; Mannersdorf, zweiter Hort; Pollak 2006, Taf. 62: 61, 62). 


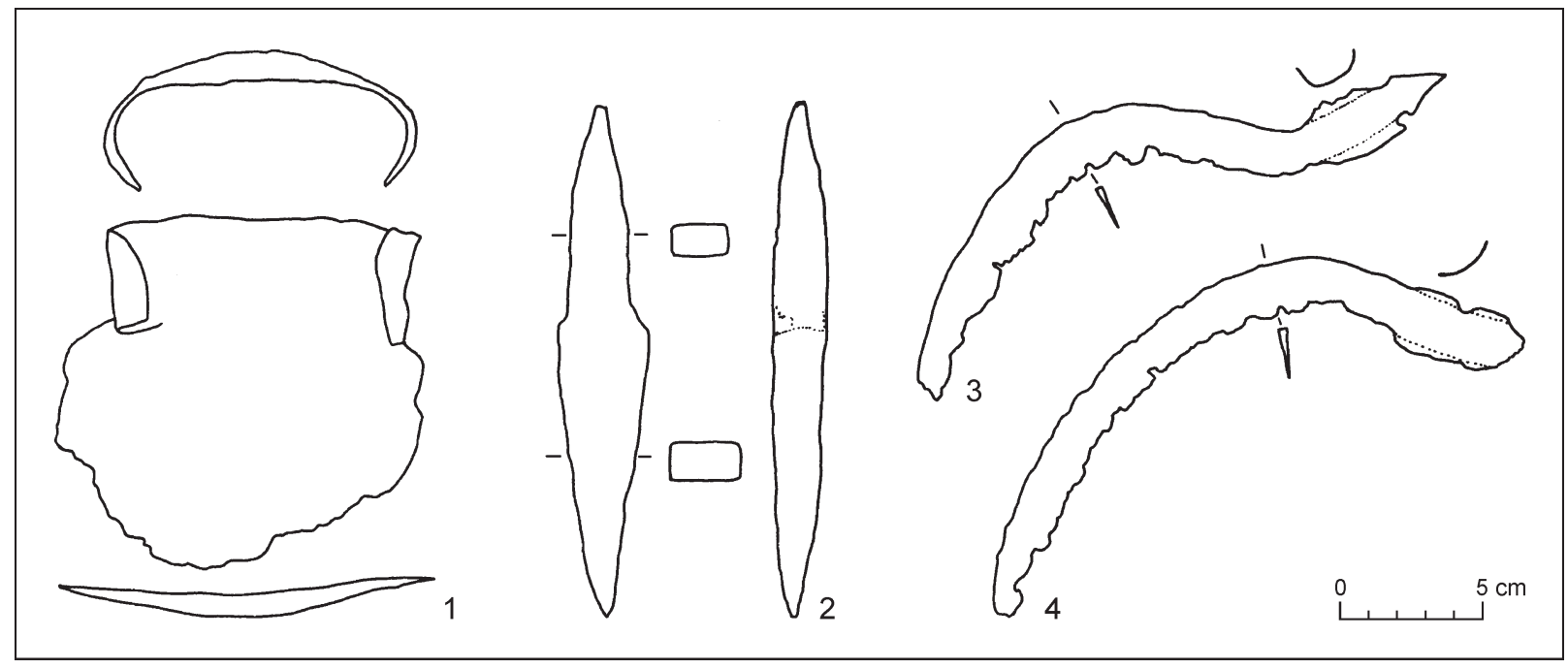

Abb. 25. Lety. 1 - Pflugschar; 2 - Doppelspitze; 3, 4 - Sicheln. Zeichnung R. Korený.

\section{Pflugschar}

- Beschreibung: Die Pflugschar ist durch die Einwirkung von Korrosion höchstwahrscheinlich deutlich kleiner geworden, ihre gegenwärtige Länge nach der Konservierung beträgt 12,2 cm, Breite $13 \mathrm{~cm}$, Spannweite der Schaftlappen 11 cm, Blechstärke 12 mm (Abb. 25: 1; Bartošková 1986, Taf. II: 15; Beranová/Lutovský 2009, Abb. 85: 6; Friedrich 1946, Abb. 2: 28; Šach 1961, Abb. 41; Taf. II). Aufbewahrungsort: Ursprünglich die Sammlung von F. Friedrich, seit 1967 das Nationalmuseum in Prag, verschollen, erhalten ist eine Acrylharzkopie K988.

Wir können der Ansicht von M. Beranová zustimmen, dass die Pflugschar ursprünglich um 5 bis $6 \mathrm{~cm}$ länger war und daher vermutlich zu blatt- bis dolchförmigen Pflugscharen mit zahlreichen römerzeitlichen Parallelen gehörte (Beranová 1980, 168; vgl. Übersicht Fries 1995, Typ 6). Wegen der vermutlich deutlichen Änderung der Form, die nach der Konservierung entstand, verzichten wir auf eine genauere typologische Klassifikation der Pflugschar aus Lety (ähnlich Šach 1961, 66).

\section{Axt}

- Beschreibung: Die erste Axt (Bartaxt) ist deutlich beschädigt, die Schneide ist abgebrochen. Erhaltene Länge $10 \mathrm{~cm}$, erhaltene Breite 6,5 cm, Höhe des Auges 3,5 cm, Breite des Auges 2,3 cm. Die Axt hatte ursprünglich eine verlängerte Schneide (Abb. 26: 1; Bartošková 1986, Taf. II: 13; Friedrich 1946, Abb. 2: 27). Aufbewahrungsort: Ursprünglich die Sammlung von F. Friedrich, seit 1967 das Nationalmuseum in Prag, verschollen, erhalten ist eine Acrylharzkopie K990.

Die Form der Schneide ist deutlich geändert; bei der gleichzeitigen Hervorhebung der Dorne am verlängerten Nacken betrachtete man die Axt als eine den burgwallzeitlichen Äxten sehr nahe Form (z. B. Eisner 1948). Die Axt aus Lety entspricht dem Typ 15 B (Bartaxt) nach B. Hanemann (2014, 339, Abb. 294). Der von ihr gewählte Vertreter des Typs ist nicht nur wesentlich jünger (2. Hälfte des 6. Jhs.), sondern unterscheidet sich vor allem durch die Absenz der unterseitigen Nackenkehlung. Diese Kehlung erhielt sich auf Äxten aus der römischen Villa in Stup bei Sarajevo (Abb. 27), die ins 3.-4. Jhs. datiert ist; deren Form korrespondiert in vollem Maße mit der Axt aus Lety (Abb. 26; Busuladžić 2014, Tab. 8; Čremošnik 1930, Taf. XII). Weitere Funde der jüngeren/späten römischen Kaiserzeit und des Anfangs der Völkerwanderungszeit sind wieder aus dem Balkan bekannt: Taraneš (1. Hälfte des 4. Jhs., Ivanovski 1987, 84, 89, Abb. 6: 7), Relja, sog. Grab des Zimmermanns (Ende des 4.-Anfang des 5. Jhs., Gluščevič 2014). Dieser Typ wurde auch in der Völkerwanderungszeit hergestellt. ${ }^{17}$

17 Die zusammenfassende Auflistung von W. Hübener (1980, 84, Form L) führt zehn Exemplare an, nur vier von ihnen stammen jedoch aus geschlossenen Befunden (Gräbern) des 5.-6. Jhs. Die übrigen sind Streufunde ohne bekannte Fundumstände oder Fundstelle. Bei einigen Äxten ist die Datierung in diese Zeitperiode deswegen umstritten. 


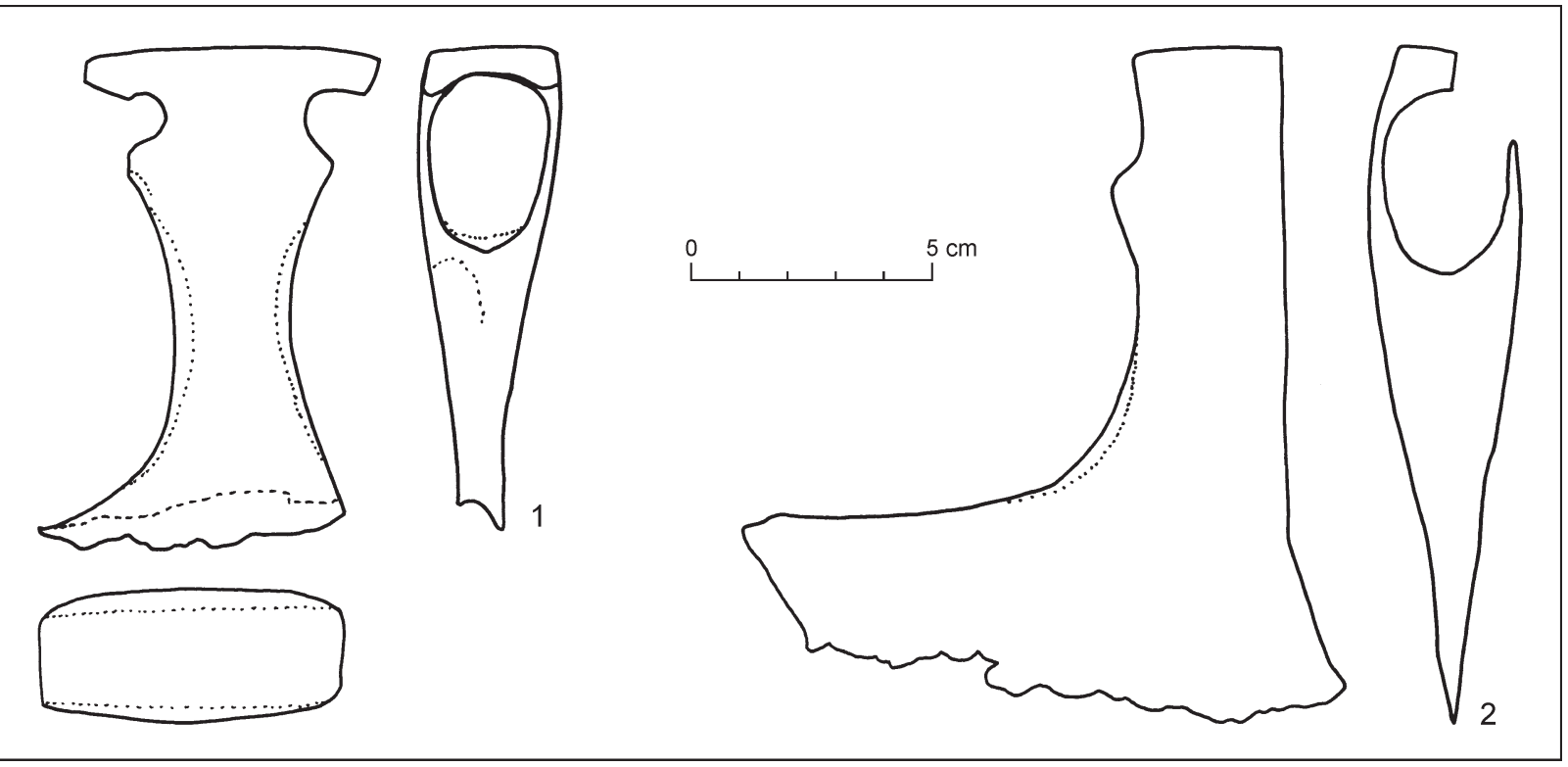

Abb. 26. Lety. Äxte. Zeichnung R. Korený.

\section{Axt}

- Beschreibung: Die zweite Axt hat eine verlängerte, für die als Bartäxte bezeichneten Werkzeuge charakteristische Schneide. Die Höhe beträgt 13,5 cm, erhaltene Länge der Schneide $13 \mathrm{~cm}$, Höhe des Auges 3,7 cm, Breite des Auges 2,5 cm. Das Auge ist gebrochen, ein Teil fehlt (Abb. 26: 2; Bartošková 1986, Taf. II: 14; Friedrich 1946, Abb. 2: 26). Aufbewahrungsort: Ursprünglich die Sammlung von F. Friedrich, seit 1967 das Nationalmuseum in Prag, verschollen, erhalten ist eine Acrylharzkopie K989.

M. Beranová hat in einer ihrer späten Studien (unter dem Einfluss von J. Eisner) über die Einordnung der Bartaxt in die Völkerwanderungszeit nachgedacht (Beranová 2005, 27, 28; vgl. Svoboda 1965, Taf. XCII: 4 Záluží u Čelákovic). In der unlängst erschienenen Monographie hat sie jedoch solche Datierung der Äxte aus Lety in die römische Kaiserzeit oder Völkerwanderungszeit strikt abgelehnt (Beranová/Lutovský 2009, 123).

J. Henning $(1985,588)$ und B. Hanemann datieren die Axt aus Lety in die Völkerwanderungszeit $(\mathrm{Ha}-$ nemann 2014, 348, Abb. 294: 26, Typ 14). Äxte von dieser Form sind im Umfeld des römischen Limes schon im 3. Jhs. (Pietsch 1983, 15, Abb. 5: 3; Stockstadt: Schulze-Dörrlamm 1985, 516-518, Abb. 7: 6) sowie im 4. Jhs. (Karth: 2./3.-4. Jh., Cech u. a. 2013, Abb. 27: 2; vgl. auch Abusina: Gschwind 2004, Taf. 69: C831-832; Hanemann 2014, 339, 345; Lang u. a. 2010, 57, Taf. I: 1; Vodice: 4. Jh., Pflaum 2007, Taf. 2: 18) anzutreffen.

\section{Löffelbohrer}

- Beschreibung: Erhalten blieb nur der Schaft mit flachem Teil, der Bohrlöffel fehlt, erhaltene Länge 20,5 cm, Stärke des Schafts 0,9 9 0,6 cm, mit abgeschrägten Kanten, Länge des Schafts 11,5 cm, Spitzenlänge $9 \mathrm{~cm}$ (Abb. 22: 2; Bartošková 1986, Taf. II: 6; Friedrich 1946, Abb. 2: 16). Aufbewahrungsort: Ursprünglich die Sammlung von F. Friedrich, seit 1967 das Nationalmuseum in Prag, verschollen, erhalten ist eine Acrylharzkopie K996.

Zahlreiche Funde sind im ganzen Imperium belegt, sowohl in zivilen als auch in militärischen Anlagen (Hanemann 2014; Künzl 1993, 350; allgemein Pietsch 1983). Vergleichbare Exemplare können jedoch auch in Kontexten aus der Zeit um die Mitte des 5. Jhs. vorkommen (vgl. Szameit 1997, 235, 251, Taf. 2: 6; zur Datierung Tejral 2015, 350, 351).

\section{Gerbereisen}

- Beschreibung: Die Schneide besaß Handgriffe an beiden Enden, von einer Hälfte fehlt jedoch der Großteil. Erhaltene Länge des Werkzeugs beträgt $22 \mathrm{~cm}$, Profil der Handgriffe ist ungefähr quadratisch, ihre Länge ist 6,2 und 4 cm, Länge der Schneide 11,5 cm, Breite der Schneide 1,4 cm (Abb. 22: 3; Bartošková 1986, Taf. II: 7; Friedrich 1946, 


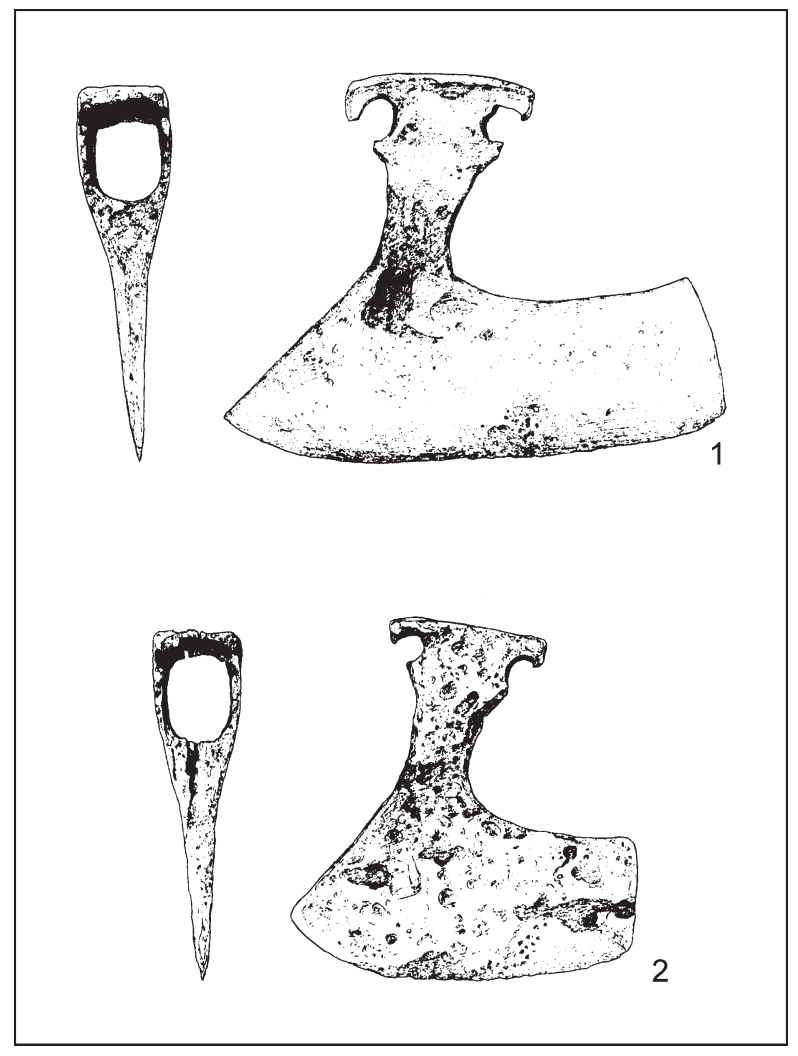

Abb. 27. Sarajevo-Stup. Römische Villa. Äxte (nach Busuladžić 2014).

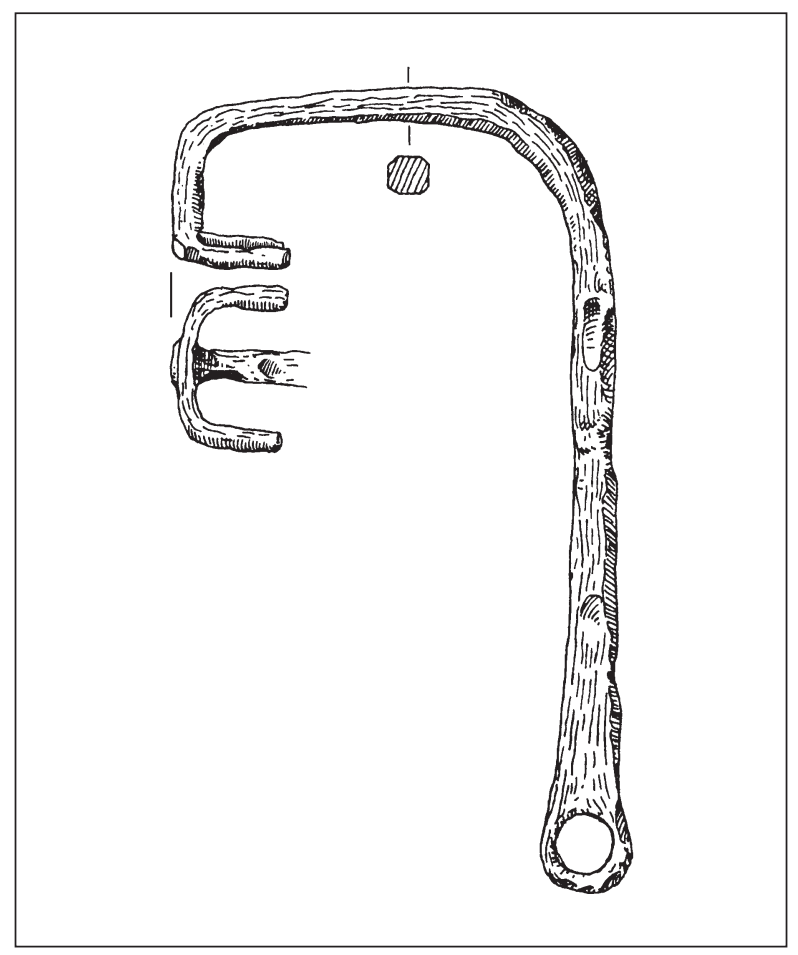

Abb. 28. Manching. Schlüssel (nach Jacobi 1974).
Abb. 2: 15). Aufbewahrungsort: Ursprünglich die Sammlung von F. Friedrich, seit 1967 das Nationalmuseum in Prag, verschollen, erhalten ist eine Acrylharzkopie K997.

Die Funktion des Werkzeugs wurde bisher nicht bestimmt, anhand der Kopie lässt es sich zuverlässig als Gerbereisen (scalprum, Haareisen) identifizieren. Das Exemplar aus Lety gehört zur Gruppe C nach der Klassifikation von W. Gaitzsch, wo ihm hinsichtlich der Größe die Funde aus Pompeji und Valcum nahestehen (Gaitzsch 1980, 63-71, Taf. 25: 128, 130). Aus Mogorjelo in Bosnien kennen wir vier Gerbereisen von ähnlicher Form und Größe (Busuladžić 2014, Tab. 10; 11). Aus der Höhensiedlung Bločice-Žernovnišček stammt ein in die Latènezeit bis römische Kaiserzeit datiertes Gerbereisen (Laharnar 2009, 131, Taf. 4: 7). Aus dem Siedlungsbefund 15/03 in Bratislava-Rusovce ist das Bruchstück eines Zugmessers (vermutlich Schrott) bekannt, der Befund ist in die 1. Hälfte des 5. Jhs. datiert (Bazovský 2008, 135, Abb. 4: 4). Ein Gerbereisen befand sich vermutlich auch in einem Männergrab aus dem 6. Jh. in Roztoky bei Prag. Das Werkzeug wurde bis unlängst als Webschwert interpretiert (Urbanová/Kostka/Korený 2010, 382, 383, Abb. 14: 4 - Zugmesser).

\section{Gegenstände mit einer nicht eindeutig bestimmbaren Funktion}

\section{Radnabe (?)}

- Beschreibung: Erhalten ist die Hälfte eines massiven Rings mit polierter Oberfläche und einem Durchmesser von 4,6 cm. Auf den Fotos lässt sich an einem Ende ein Vorsprung oder Dorn beobachten, an dem anderen Ende die Zerspaltung des Bands (Abb. 29: 5; Bartošková 1986, Taf. II: 8; Friedrich 1946, Abb. 2: 18).

Gewisse Ähnlichkeit findet man in einem als Radnabe klassifizierten Gegenstand aus dem Depotfund von Königsforst, der ins 4. Jhs. datiert ist (Gaitzsch u. a. 1984, Abb. 18: 65, 66).

\section{Schöpfkelle/Schlüssel/Unterteil einer Fleischgabel (?)}

- Beschreibung: Von dem ursprünglichen Gegenstand blieb vermutlich nur das Ende des Schafts mit zwei Haken erhalten. Gesamtlänge $36 \mathrm{~mm}$, Breite 31 mm, Stärke des Stabs 4 mm (Abb. 22: 1; Bartošková 1986, Taf. II: 12; Friedrich 1946, Abb. 2: 10). Aufbewahrungsort: Ursprünglich die Sammlung von F. Friedrich, seit 1967 das Nationalmuseum in Prag, verschollen, erhalten ist eine Acrylharzkopie K998. 


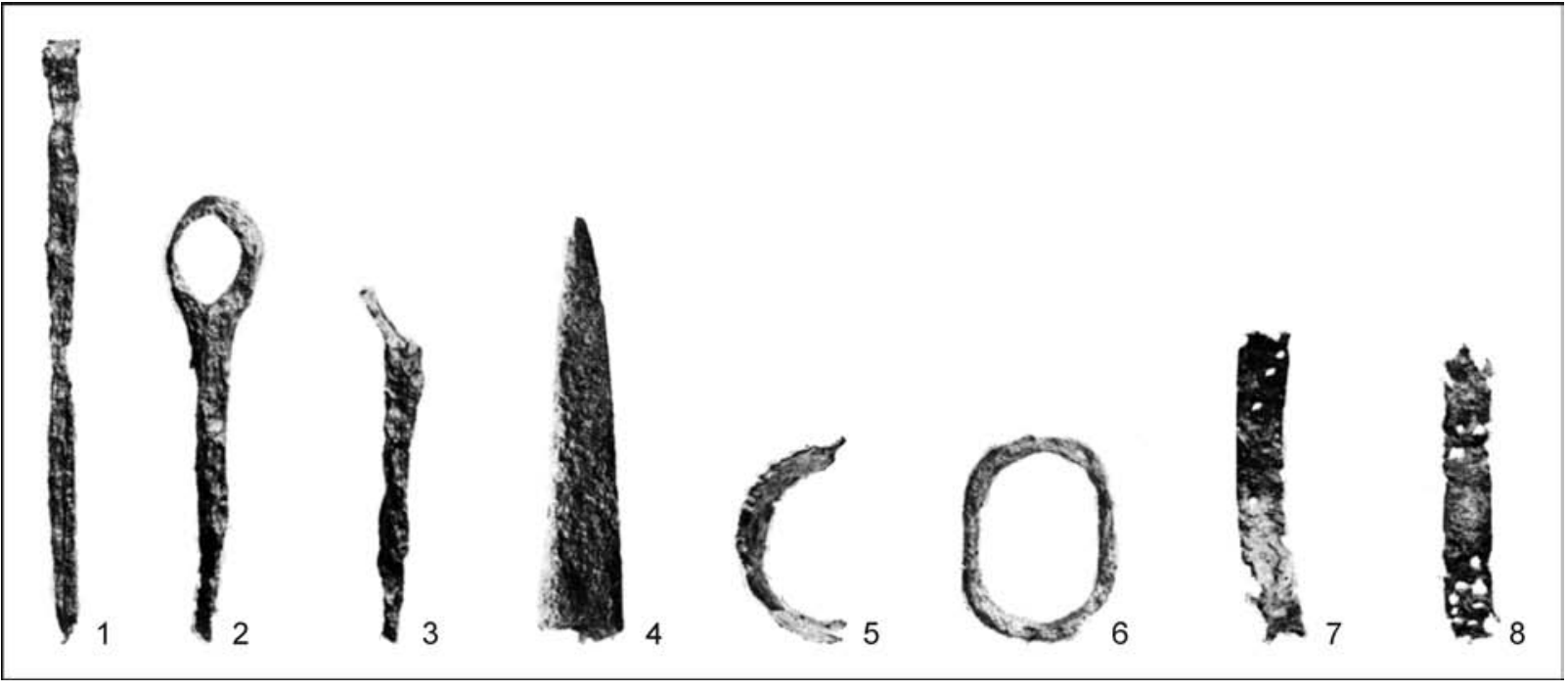

Abb. 29. Lety. 1 - Schlüssel/Pfriem (?); 2, 3 - flache Ösenbeschläge; 4 - Gabelzinke (?); 5 - Radnabe (?); 6 - Ring; 7, 8 Blechstücke (nach Bartošková 1986).

Die eindeutige Identifikation des Fundes ist durch den fragmentarischen Erhaltungszustand erschwert. Die hakenförmigen Beendigungen des Artefakts erinnern jedoch entfernt an die Endpartien der Fleischgabeln (Leconte 2013, Abb. 243: 10; Manning 1985, Taf. 51: P38; Miglbauer 1994, 290, Abb. 19). Die Datierung ist im Fall des Typs Manning 2 problematisch und nur rahmenhaft, von der römischen Kaiserzeit bis zum Mittelalter. Den Gegenstand können wir mit gewisser Vorsicht auch als den Abschluss des Griffs einer Schöpfkelle interpretieren. Nach der Klassifikation von B. Hanemann würde es sich in diesem Fall um den Typ 1 S handeln (Feugère 1986; Hanemann 2014, 82, Abb. 62). Es könnte sich auch um einen Hakenschlüssel handeln, wie er aus Manching bekannt ist, dort allerdings mit latènezeitlicher Datierung (Abb. 28; Jacobi 1974, Taf. 47: 757).

\section{Doppelspitze/Barren (?)}

- Beschreibung: Die Länge von diesem Gegenstand beträgt $18 \mathrm{~cm}$, Breite 2 und $3 \mathrm{~cm}$, Höhe 1,8 cm, die Spitzen sind vermutlich abgerundet (Abb. 25: 2; Bartošková 1986, Taf. II: 5; Friedrich 1946, Abb. 2: 12). Aufbewahrungsort: Ursprünglich die Sammlung von F. Friedrich, seit 1967 das Nationalmuseum in Prag, verschollen, erhalten ist eine Acrylharzkopie K995.

Der Gegenstand diente möglicherweise zur Lederbearbeitung (Harnecker 1997, 11, Taf. 21: 224), als Durchschlageisen (Busuladžić 2014, 39, 157, Taf. 22: 69; Pietsch 1983, 41). Es ist jedoch gut möglich, dass es sich um einen Doppelspitzbarren handelt (Drack/Fellmann 1988, 187, Abb. 153 - Augusta Raurica).

\section{Gabelzinke (?)}

- Beschreibung: Querschnitt 1,7 cm (Friedrich führt $20 \mathrm{~mm}$ an), Länge 11,1 cm, der Gegenstand ist am breiteren Ende offensichtlich gebrochen, Profil ist vermutlich trapezförmig (Abb. 29: 4; Bartošková 1986, Taf. II: 4; Friedrich 1946, Abb. 2: 11).

Aufgrund der Profilierung und Länge könnte es sich um die gebrochene Zinke einer höchstwahrscheinlich dreizinkigen Gabel handeln. Nach den Parametern unseres Bruchstücks zu urteilen ging es vielleicht um den Typ 3 nach der Klassifikation von B. Hanemann $(2014,184)$. Gabeln erschienen in den Depotfunden aus Kreimbach und im ersten Hort von Waldfischbach, die ins 4. Jhs. datiert sind (Hanemann 2014, 550, 570, Taf. 11: 34; 33: 12).

\section{Schlüssel/Pfriem (?)}

- Beschreibung: Länge 155 mm, Öhr $7 \times 10$ mm, Stäbchen mit rundem Profil und verdicktem Ende (Abb. 29: 1; Bartošková 1986, Taf. II: 1; Friedrich 1946, Abb. 2: 9). 
F. Friedrich nahm an, dass das Stäbchen zu einem Holzgriff gehört haben könnte. Ähnliche Gegenstände erschienen auch unter den Funden aus Tinje oberhalb von Loka pri Žusmu (Schlüssel?, Ciglenečki 1994, Taf. 5: 10), Gradec pri Prapretnem (Schlüssel, Länge 22,8 cm, Durchmesser des Öhrs 1,4 cm, Bausovac 2003, Taf. 2: 10) und Vodice, (4. Jh., Länge 16 cm, Pflaum 2007, Taf. 4: 40).

\section{Tüllenschar (?)}

- Beschreibung: F. Friedrich führte bei diesem Gegenstand nur die Tüllenlänge an - $7 \mathrm{~cm}$. Anhand der Fotografien lässt sich die Gesamtlänge des Gegenstandes auf 19-22 cm und die Breite auf $5 \mathrm{~cm}$ schätzen (Abb. 15: 1; Bartošková 1986, Taf. II: 11 - abgebildet ist nur ein Drittel des Gegenstandes mit Tülle; BeranoválLutovský 2009, 44, Abb. 25; Friedrich 1946, Abb. 2: 13).

Wie der Gegenstand vor der Konservierung aussah, wissen wir nicht; auf den alten Aufnahmen kann man sehen, dass der Arbeitsteil in drei Fragmente zerbrochen und die Tülle etwas schräg und unter einem sehr stumpfen Winkel mit dem oberen Teil der Klinge verbunden ist. Die Fotografien und die Beschreibung von Friedrich lassen auf eine Tüllenschar schließen (Fries 1995, Taf. 23 - Typ 14?; Hanemann 2014, 163 - Typ 3?; Pohanka 1986; zur Klassifikation von Pflugscharen Šach 1961).

\section{Blechstücke}

- Beschreibung: Länge der erhaltenen Fragmente 8,4 und 7,4 cm, Breite 1,2 cm, Löcher auf dem kleineren Bruchstück (?) Das längere Band ist leicht gebogen (Abb. 29: 7, 8; Bartošková 1986, Taf. II: 10; Friedrich 1946, Abb. 2: 19).

Die Klassifikation ist sehr problematisch, mit einem gewissen Maß an Vorsicht käme auch Schuppenpanzer in Erwägung (Ivanišević/Špehar 2005, 148, Abb. 9: 4, 5 mit Literature; Komoróczy 2000).

\section{HYPOTHESE EINES GEMEINSAMEN URSPRUNGS DER HORTE VON ROSOVICE UND LETY U DOBŘICHOVIC (R. Korený)}

Nun kehren wir zu dem Hort von Rosovice zurück und untersuchen seine mögliche Verbindung mit dem Hort von Lety u Dobřichovic. Ansprechen werden wir folgende Problembereiche:

1. Anzahl der Sensen an ausgewählten Fundstellen in den Rhein- und Donauprovinzen.

2. Die Wege durch das Brdy-Bergland.

3. Frage des gemeinsamen Ursprungs der Horte von Rosovice und Lety u Dobřichovic.

\section{Anzahl der Sensen an ausgewählten Fundstellen}

In Horten, welche die Sensen des 4. Typs enthalten und im sog. lebendigen Kontext im Verlauf des 3. Jhs. deponiert wurden, treten diese Sensen gewöhnlich in Sätzen von drei Stück auf. Einige von ihnen wurden im Moment des Untergangs des gegebenen Ortes (Villa, Kastell) oder unmittelbar danach deponiert. Es lässt sich also hypothetisch annehmen, dass die Sensen in Kastellen oder ländlichen Villen am meisten in Serien von drei Stück verwendet wurden, ähnlich wie z. B. auch die Sätze von Meißeln, Hämmern, Äxten usw. in gewissen logischen Einheiten benutzt wurden. Die Anwendung dieses Modells im ländlichen Milieu wäre gar nicht merkwürdig, denn auf dem Lande haben sich sehr oft die Veteranen niedergelassen (z. B. auch der bekannte Veteran L. Iunius Moderatus Columella, obwohl der Genannte Güter in Italien besaß), wodurch es zur Übertragung gewisser Bräuche und Normen kam (Ployer 2006). Die „drei Stück“-Hypothese wurde deswegen anschließend auf einer breiteren Auswahl der Depotfunde von dem Rheingebiet bis zum pannonischen Limes getestet. Unberücksichtigt blieben die Horte, die außerhalb des Gebietes des Römischen Reichs deponiert wurden (z. B. Neupotz, Osterburken, je 6 Sensen), oder diejenigen, deren Vollständigkeit nicht garantiert ist (z. B. Nagyvenyim, 1 Stück). Die Tabelle geht mit nur kleinen Ergänzungen von den Auflistungen von B. Hanemann $(2014,196)$ und J. Henning $(1987,114$, Nr. 16, 124, 159) aus.

Aus der Übersicht ergibt sich folgendes: unter den Befunden mit mehr als einer Sense überwiegt die Variante von 3 Stück, was im Rahmen des gegebenen Gebietes auf eine gewisse Norm in der Ausstattung der römischen Gutshöfe, Villen oder sogar Kastelle im Verlauf des 2.-4. Jhs. schließen lässt. 


\section{Trassen der Wege durch die nördliche Hälfte des Brdy-Berglandes in der Vor- und Frühgeschichte}

Die vorangehende Auslegung bringt uns zur Problematik der Fernwege im Gebiet des Brdy-Berglandes, genauer gesagt, in dessen nördlicher Hälfte Namens Hřebeny. Bis unlängst galt allgemein die Vorstellung, dass die Fernroute aus Südböhmen in die Region um Beroun und ins Prager Becken durch das Flusstal der Litavka führte. In den letzten Jahren ist es dank einer eingehenden Geländeprospektion (bes. auf der Trasse zwischen Lety u Dobřichovic und Mníšek pod Brdy, Bolina/Klimek/Cílek 2018, 454-464) und dank neuen Detektorfunden möglich, diese These auf eine bedeutende Weise anzuzweifeln. Nach dem Verlauf des Fernweges sucht man anhand der indirekten Indizien in folgender Achse: alte Furt durch den Fluss Berounka in Lety (Siedlung der älteren römischen Kaiserzeit, Fibel mit dem Vorkommensoptimum von der 2. Hälfte des 3. bis zum Anfang des 4. Jhs.; Halama 2006, 338, Abb. 1; 11: 3; Varsik 2017) mit einer Fortsetzung über Řevnice, wobei eine der Trassen dann an dem polykulturellen Burgwall Pišták vorbei (John/Stolz 2012) über Hřebeny nach Kytín und weiter südwärts nach Voznice und Dobř́šs führte. Auf die Nutzung gerade des letztgenannten Abschnittes dieser Trasse schon in der Vorgeschichte verweisen die neuen Detektorfunde. Sie ergänzen die schon vorher bekannten Siedlungs- oder Grabkomponenten und Einzelfunde aus der Bronze-, Eisen-, Römerzeit und dem Früh- und Hochmittelalter (Bravermanová 1991; Korený 1998, 41; Korený u. a., in Vorbereitung; Korený, im Druck; Korený/Frána/Fikrle 2011, 261-263; Smejtek 2005, 193-195).

\section{Das Vorkommen von Sensen des 4. Typs in Provinzen und im Barbarikum}

Jetzt können wir bereits die folgende Hypothese des gemeinsamen Ursprungs der Sensen aus Rosovice und Lety formulieren. Es führen uns dazu diese Gründe:

1. Die Sensen des 4. Typs benutzte man im Verlauf des 2.-3. Jhs. auf dem Gebiet der Provinzen Rätien und Noricum gewöhnlich in Serien von drei Stück (belegt sind vier Beispiele, im Allgemeinen dann sieben Fälle: Tab. 3).

2. Außerhalb der obengenannten Provinzen ist deren Vorkommen völlig vereinzelt und beschränkt sich in der Regel auf ein einziges, gewöhnlich schon beschädigtes, bzw. nicht funktionsfähiges Exemplar. Dies geschah vermutlich erst zu einer Zeit, wo wir in Rätien und Noricum das Vorkommensoptimum der Sensen des 4. Typs nicht mehr in Betracht ziehen. Es könnten jedoch immer noch ältere Exemplare in Gebrauch gewesen sein.

Aus den obengenannten Tatsachen können wir Folgendes ableiten:

Die Sonderfunde von provinzialen Langsensen im Barbarikum, alle von demselben Typ und auf dem vermutlichen Weg durch die Hřebeny-Berge nur $18 \mathrm{~km}$ voneinander entfernt, sind aus dieser Sicht sehr auffällig. Die Deutung, sie seien Spuren verschiedener voneinander völlig unabhängiger Ereignisse, ist zwar möglich, aber wenig wahrscheinlich. Besonders darum, weil es sich um die Wiederholung eines ohnehin äußerst seltenen Phänomens auf einem sehr kleinen Gebiet, in einer relativ kleinen Entfernung voneinander und auf einem vermutlichen Verbindungsweg von großer Bedeutung handeln würde.

Wahrscheinlicher ist die Interpretation, nach der alle drei Sensen aus dem Inventar einer nicht näher identifizierbaren Villa oder eines Kastellvicus auf dem Gebiet der Provinzen Rätien und Noricum stammten. Irgendwann nach der Mitte des 3. und im Verlauf des 4. Jhs., vermutlich nach einer Plünderung, gelangten sie zusammen mit anderen Gegenständen ins Barbarikum (der Hort von Lety muss in seiner Endgestalt jedoch nicht unbedingt mit dem Konvolut der aus Provinzen weggebrachten Gegenstände übereinstimmen). Dort wurden spätestens im 4. Jhs. zuerst zwei Sensen in der Nähe eines vorgeschichtlichen Weges durch die Hřebeny-Berge begraben und die dritte Sense deponierte man vermutlich erst nach einiger Zeit an der Furt durch den Fluss Berounka bei einer vermutlichen Siedlung der jüngeren römischen Kaiserzeit.

Die Deponierung von Gegenständen in der Nähe oder entlang der Wege während der römischen Kaiserzeit wurde neulich durch die Funde an der Grenze zwischen Ostböhmen und Nordwestmähren belegt (Vích/Jílek 2016; Vích u. a. 2018; 2020). 
Tab. 3. Vertretung der Sensen in ausgewählten Depotfunden.

\begin{tabular}{|c|c|c|c|}
\hline Fundstelle & Kontext & Anzahl & Datierung \\
\hline Herzberg & Depotfund & 1 & 3.-4. Jh. \\
\hline Knittelsheim & Depotfund & 1 & Mitte des 4. Jh. \\
\hline Mutterstadt & Depotfund & 1 & 3./4. Jh. \\
\hline Szalacska & Depotfund & 1 & 3.-4. Jh. \\
\hline Gyulafirátót & Villa/Depotfund & 1 & 3.-4. Jh. \\
\hline Parndorf & Villa & 2 & 2.-4. Jh. \\
\hline Kreimbach & Depotfund & 3 & 352 \\
\hline Mainz-Philipsch. & Kastell/Depotfund & 3 & 2.-3. Jh. \\
\hline Dellach-Gurina & Villa/Depotfund? & 3 & Römmerzeit \\
\hline Rainau-Buch & Kastell/Depotfund $(2+1)$ & 3 & 254 \\
\hline Regensburg-Harting & Villa/Depotfund & 3 & vor der Mitte des 3. Jh. \\
\hline Sarajevo-Stup & Villa/Depotfund & 3 & 3.-4. Jh. \\
\hline Dormagen & Kastell/Depotfund & 4 & 2./3. Jh. \\
\hline
\end{tabular}

BENÁTKY NAD JIZEROU, BEZ. MLADÁ BOLESLAV

(R. Korený, J. Jílek)

\section{Fundumstände und Fundstelle}

Der Hort wurde etwa Ende Mai oder im Juni des Jahres 1936 beim Bau einer neuen Straße rund um den damaligen Viehmarktplatz (sog. Pucovka) freigelegt. Die Fundstelle befindet sich inmitten der heutigen Straße Na Kosince (795/10) zwischen der Čeňka Prause-Straße und der Kirche St. Maria Magdalena (Abb. 30) am nördlichen Stadtrand, in einer Höhe von $225 \mathrm{~m}$ ü. d. M., etwa $150 \mathrm{~m}$ von dem Wasserlauf. Den Angaben im Inventarbuch des Museums von Benátky nad Jizerou zufolge wurden die Gegenstände vom Herrn Špitálský gefunden, der sie (direkt?) bei Josef Šturm, Mitglied des Stadtrats in Nové Benátky abgegeben hat. Der Letztgenannte hat dann den gegebenen Hortfund noch in demselben Jahr in die Sammlungen des örtlichen Museums übergeben.

\section{Beschreibung und Analyse}

\section{Kesselgehänge, Typ Neupotz NE 10}

- Beschreibung: Gesamtlänge 1270 mm, Gewicht 3150 g (Abb. 31: 1; Waldhauser 1990; 1996; Waldhauser/Košnar 1997) Aufbewahrungsort: Museum der Region Mladoboleslavsko - Museum Benátky nad Jizerou, Inv.-Nr. 4896.

Im Fall des Kesselgehänges handelt es sich um den Typ mit einem Arm zum Aufhängen des Kessels Typ Neupotz NE 10 (Abb. 32; Künzl 1993, 238, Typtaf. 14), obwohl es möglich ist, dass der zweite Arm nicht erhalten blieb. Der Teil des Gehänges zum Aufhängen auf eine feste Konstruktion oder (nach Verkürzung der Kette) auf einen Dreifuß ist ungewöhnlicherweise einteilig. Die ungewöhnliche Konstruktion des Exemplars aus Benátky reagierte jedoch offensichtlich auf eine Beschädigung/Zerbrechung des oberen Teiles. Dies belegen die Spuren von Umschmiedung der Tordierung, die auf dem Haken immer noch sichtbar sind. Mit der Bearbeitungsweise, aber nicht mit der Anzahl der Haken, ähneln diesem Exemplar die Funde aus Rainau-Buch (deutliche Tordierung, eckiger Anker, Datierung in die Mitte des 3. Jhs., Greiner 2010, Taf. 138: 83) und Laufenburg (2.-4. Jhs., Rothkegel 1994, Taf. 103: 1126). Die Datierung der Kesselgehänge aus römischen westlichen Provinzen ist rahmenhaft, denn sie gehen von den spätlatènezeitlichen Vorlagen aus. Wir können sie also in die Zeit von der Mitte des 1. Jhs. bis zum Verfall der Limes-Strukturen in der späten römischen Kaiserzeit datieren (Jacobi 1974, 113, Abb. 28; Manning 1983, 134). 


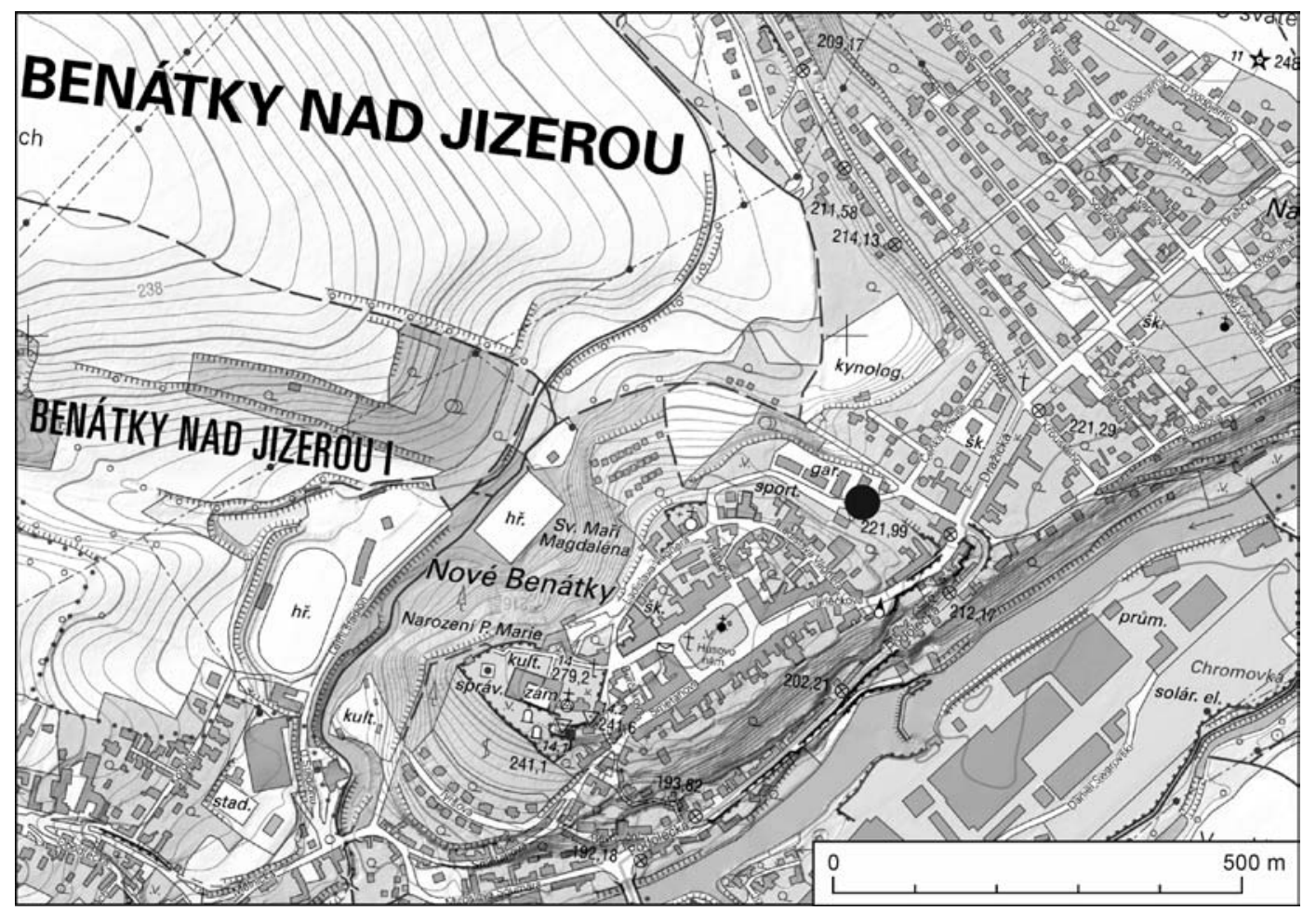

Abb. 30. Benátky nad Jizerou. Fundstelle des Hortes. Hergestellt von P. Čechák und R. Korený.

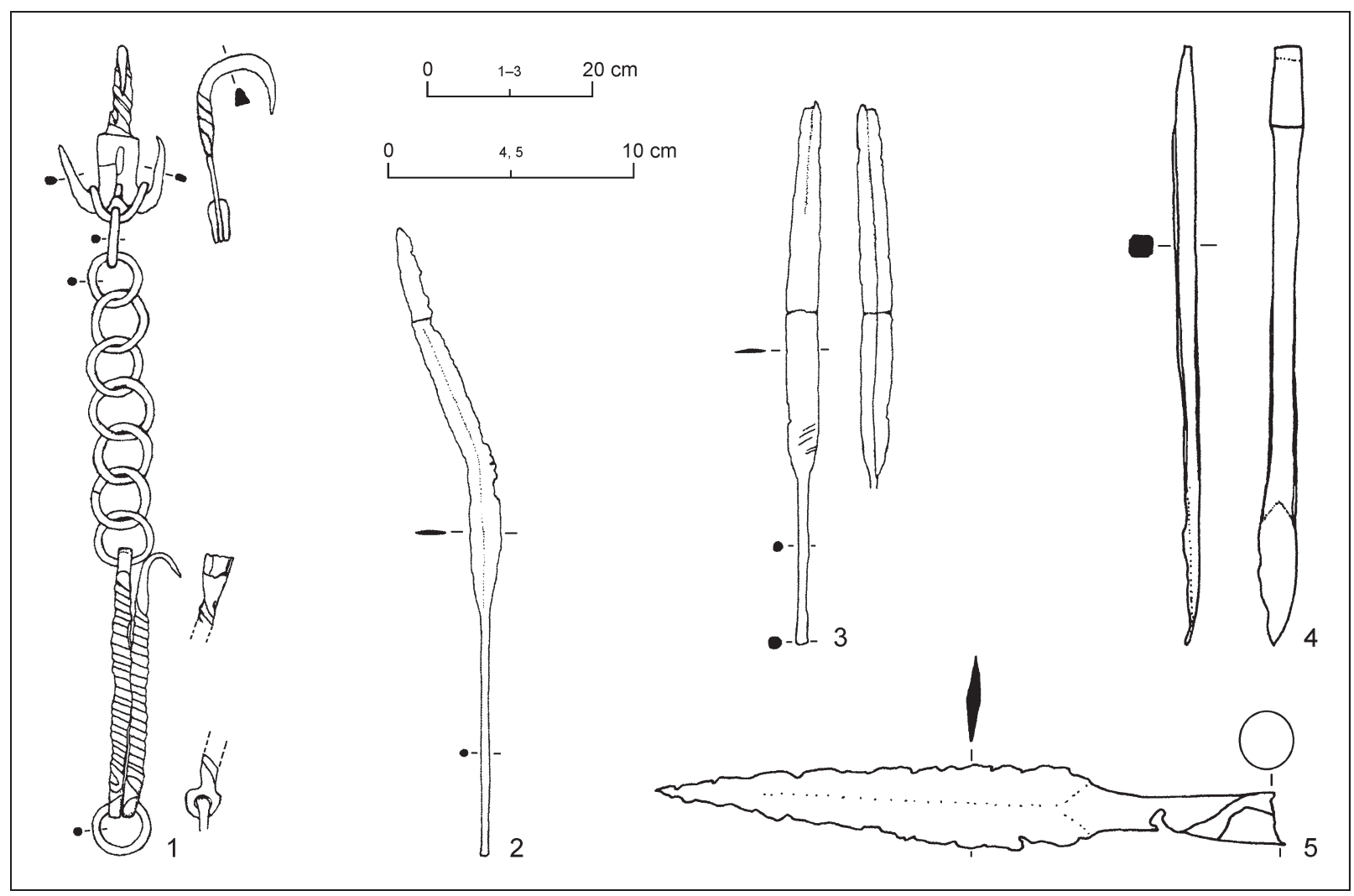

Abb. 31. Benátky nad Jizerou. 1 - Kesselgehänge; 2, 3 - Webschwerter; 4 - Löffelbohrer; 5 - Lanze. Zeichnung R. Korený. 


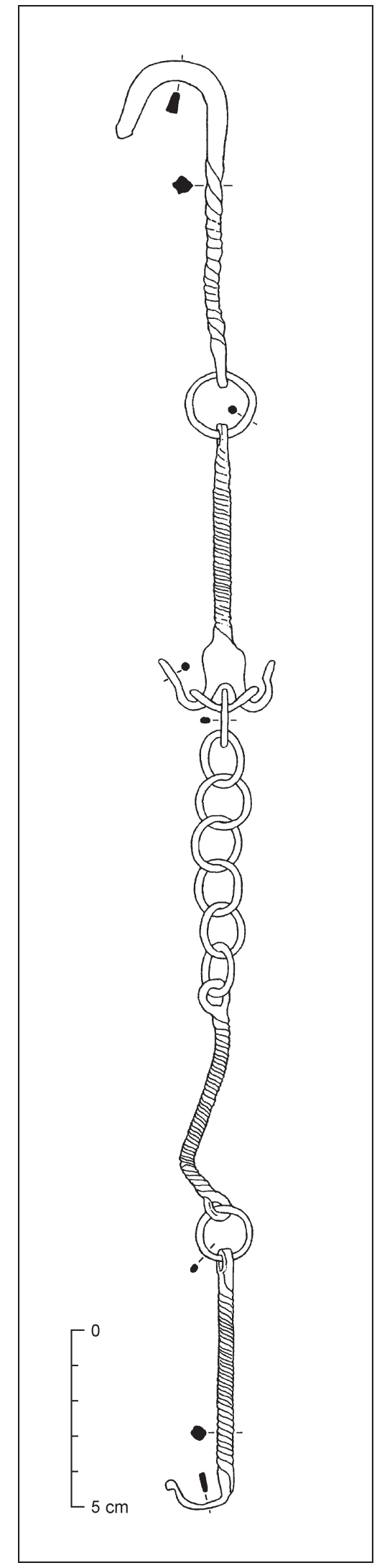

Abb. 32. Neupotz. Einarmiges Kesselgehänge, Typ N 10 (nach Künzl 1993).

\section{Webschwerter, Typ Benátky}

- Beschreibung: eisernes Webschwert mit einer Klinge von dachförmigem und einem Schaft von rundem Querschnitt, teilweise beschädigt durch doppelte Biegung. Die Gesamtlänge beträgt 750 (in der Literatur findet man die Angabe 770) mm, Länge des Schafts 275 (in der Literatur findet man die Angabe 300) mm, Breite der Klinge 36 (in der Literatur findet man die Angabe 40) mm, Gewicht $410 \mathrm{~g}$, Abb. 31: 2. Aufbewahrungsort: Museum der Region Mladoboleslavsko Museum Benátky nad Jizerou, Inv.-Nr. 4894.

- Eisernes Webschwert mit einseitig (?) dachförmigem Profil der Klinge und mit Schaft von rundem Querschnitt; die Klinge war gebogen und die Spitze fehlt. Die Gesamtlänge beträgt 630 (in der Literatur findet man die Angabe 660) mm, Länge des Schafts 190 (in der Literatur findet man die Angabe 200) mm, Breite der Klinge 36-37 (in der Literatur findet man die Angabe 40) mm, Gewicht 410 g, Abb. 31: 3. Aufbewahrungsort: Museum der Region Mladoboleslavsko - Museum Benátky nad Jizerou, Inv.-Nr. 4893. Die fraglichen Gegenstände galten bisher als Schwerter (Kotýnek 2018, 27, 116, 117, 120, 123, Tab. 11, Abb. 22; 36; Machara 2016, 33, 48; Waldhauser/Košnar 1997, 111, 112).

Funktionell versuchte diesen Gegenstand zum ersten Mal J. Henning $(1985,588)$ einzuordnen und seiner Klassifikation stimmen wir zu, obwohl es wahrscheinlich ist, dass die Frage der funktionellen Einordnung dieser Gegenstände noch eine Diskussion erfordern wird.

Aus Böhmen kennen wir außer den Gegenständen aus Benátky noch zwei genaue Parallelen aus Karlovice - Čertova ruka, Bez. Liberec. Das erste Exemplar mit abgerundeter Spitze wurde im Abri 19 (Turm Opomenutá), Schnitt 1, bzw. im oberen Teil der Schicht 20 mit latènezeitlichen Funden (Keramik, Fibel) sowie mit spätkaiserzeitlicher Keramik gefunden. Der Fundverband aus der Schicht 20 umfasste auch einen fragmentarisch erhaltenen bronzenen Drahtarmring mit umgeschlagenen Enden mit einer Datierung von der Mittellatènezeit zum Verlauf der römischen Kaiserzeit (Beckmann 1981, 12, Abb. 1: 5; Endert 1991, 11, 12, Taf. 3: 50, 51; Píč 1903, 53, Tab. 28: 5). Aus der Fundstelle stammen auch völkerwanderungszeitliche Funde (Jiřík 2008). Das zweite Webschwert wurde bei der Detektorprospektion im Bereich des Oberen Plateaus in der Nähe des „Kreuzgangs"/Kř́žzová chodba (Kotýnek 2018, 41, 120-123, Kat. Nr. 58, 110; Prostředník 2015, NS56).

Ein weiterer analoger Fund ist aus dem Hort von Osterburken bekannt, der im Graben eines römischen Kastells freigelegt wurde; der Hort selbst wurde vermutlich schon im 4 . Jhs. deponiert (zur Datierung siehe Kap. II. 3; Henning 1985, 576, Abb. 1: 8). Die Spitze des Webschwerts ist oval. Im ursprünglichen Fundbericht sind auch Fragmente von einem weiteren Webschwert erwähnt (Wagner 1897, 325).

Aus dem angeblichen Depot von Hoym, Ldkr. Salzlandkreis, der auch ein Keramikgefäß und eine kurze Sense enthält, stammt ein weiteres Webschwert. Der "Fundverband“ ist ins 5./6. Jhs. datiert (Schmidt 1976, 60, 230, Taf. 42: 3b - bei dem angeführten Verhältnis beträgt die minimale Länge $46,5 \mathrm{~cm}$ ). Mit großer Wahrscheinlichkeit handelt es sich jedoch um ein chronologisch älteres Erzeugnis und dasselbe gilt vielleicht auch für die kurze Sense, die in Fragmenten erhalten blieb. 
Tab. 4. Webschwerter und ihre Parameter (Gesamtlänge, Länge, Breite und Profil der Klinge, Länge und Profil des Dorns, Längenverhältnis zwischen der Klinge und dem Dorn).

\begin{tabular}{|c|c|c|c|c|c|c|c|}
\hline Fundstelle & Länge (cm) & Klingenlänge & Klingenbreite & Klingenprofil & Dornlänge & Dornprofil & $\begin{array}{l}\text { Verhältnis } \\
\text { Klinge/Dorn }\end{array}$ \\
\hline Benátky 1 & 75 & 47,5 & 3,6 & mit Rippe & 27,5 & rund & $1,7: 1$ \\
\hline Benátky 2 & Min 63 & Min 44 & 3,6 & mit Rippe & 19 & rund & $2,3: 1$ \\
\hline Karlovice 1 & 73,7 & 45,7 & 4 & mit Rippe & 28 & rund & $1,6: 1$ \\
\hline Karlovice 2 & $56(58)$ & $30,2(32,2)$ & 4 & flach & 25,8 & quadratisch & $1,2: 1$ \\
\hline Osterburken 1 & 64,8 & 38,1 & 4,3 & mit Rippe & 26,5 & rund & $1,4: 1$ \\
\hline Osterburken 2 (?) & Burchstücke & - & - & - & - & - & - \\
\hline Hoym & $\operatorname{Min} 46,5$ & 25,5 & 3,1 & mit Rippe & 20 & rund & - \\
\hline Vodice? & $\operatorname{Min} 59,2$ & 56,6 & 4 & mit Rippe & $\operatorname{Min} 2,6$ & rechteckig & - \\
\hline
\end{tabular}

Als angebliches Schwert interpretiert man einen Gegenstand aus dem problematischen Befund von Vodice (4. Jh., Pflaum 2007, Abb. 3: 1), dessen erhaltene Länge 56,6 cm und die Breite der Klinge $4 \mathrm{~cm}$ beträgt. Wenn wir die Parameter des zweiten Webschwerts aus Benátky mit einem Klinge/Schaft-Verhältnis von 2,3:1 anwenden würden, dann würde die Gesamtlänge des Webschwerts aus Vodice etwa $80 \mathrm{~cm}$ und die Schaftlänge $24 \mathrm{~cm}$ betragen. Diese Werte sind vergleichbar mit den längeren Webschwertern aus Benátky und Karlovice (bei einem Verhältnis von 2,7:1 würde die Schaftlänge 20,9 cm und die Gesamtlänge des Webschwerts 77,5 cm betragen; vgl. Kotýnek 2018, Tab. 11 - das Verhältnis bei dem Webschwert Benátky 2).

Es lässt sich zusammenfassen, dass sich die Funde von Webschwertern des Typs Benátky (Tab. 4; wenn wir den etwas unsicheren Fund aus Vodice außer Acht lassen) im Rahmen des Barbarikums auf einem relativ kleinen Gebiet zwischen den Flüssen Rhein, Elbe und Jizera konzentrieren (Abb. 33). Vermutlich irgendwo in diesem Raum sind diese Webschwerter in der jüngeren bis späten römischen Kaiserzeit hergestellt und distribuiert worden. Bemerkenswert ist, dass sie in Horten paarweise vorgekommen sind (wenn wir auch das literarisch belegte Exemplar aus Osterburken hinzuzählen, Wagner 1897, 325) und mit Rücksicht auf ihre Ausführung und Parameter kann man auch deren symbolische Funktion nicht ausschließen.

\section{Löffelbohrer, Typ A}

- Beschreibung: eiserner Löffelbohrer mit einem Schaft von vierkantigem Querschnitt, mit leicht abgesetzter Angel und Bohrlöffel. Gesamtlänge $245 \mathrm{~mm}$, Schaftlänge $34 \mathrm{~mm}$, Schaftbreite 9-11 mm, Länge des Löffels 60 mm, Breite des Löffels 16 mm, Länge der Angel 35 mm, Breite der Angel 14 mm, Gewicht 180 g, Abb. 31: 4. Aufbewahrungsort: Museum der Region Mladoboleslavsko - Museum Benátky nad Jizerou, Inv.-Nr. 4895.

Der Klassifikation von M. Pietsch zufolge handelt es sich um einen Löffelbohrer vom Typ A, der in der römischen Kaiserzeit, insbesondere in der jüngeren Stufe, sehr häufig war (Pietsch 1983, 43). Die erhaltene Breite der Bohrlöffel (16 mm) entspricht einem römischen Fingerbreit (digitus; Gaitzsch 1980, 32). In böhmischen Depotfunden erschien der Löffelbohrer noch in Lety u Dobřichovic und in Opolany (4. Jhs., Lička 1969, Abb. 2). Die Angel bei diesen Exemplaren ist interessanterweise stumpf, im Unterschied zu den zahlreichen Funden aus dem Rhein- oder dem oberen Donaulimes. Genaue Analogien zu dieser Form finden wir jedoch z. B. in einer Serie von fünf Löffelbohrern aus den Villen in Stup und Mogorjelo (3.-4. Jhs., Busuladžić 2014, Tab. 16-18; Čremošnik 1930, Taf. XII), oder in Dellach-Gurina (Jablonka 2001, Taf. 99: 4).

\section{Lanze}

- Beschreibung: eiserne Lanze mit abgesetzter blattförmiger Spitze, einem Mittelgrat und Tülle, gegenwärtig durch die Einwirkung von Korrosion deutlich geändert. Gesamtlänge 260 mm, Länge der Spitze 180 (in der Literatur findet man die Angabe 165) mm, erhaltene Breite der Spitze 35 (in der Literatur findet man die Angabe 45) mm, Länge der Tülle 80 mm, Durchmesser der Tülle 20 mm, Gewicht 105 g, Abb. 31: 5. Aufbewahrungsort: Museum der Region Mladoboleslavsko - Museum Benátky nad Jizerou, Inv.-Nr. 4892. 


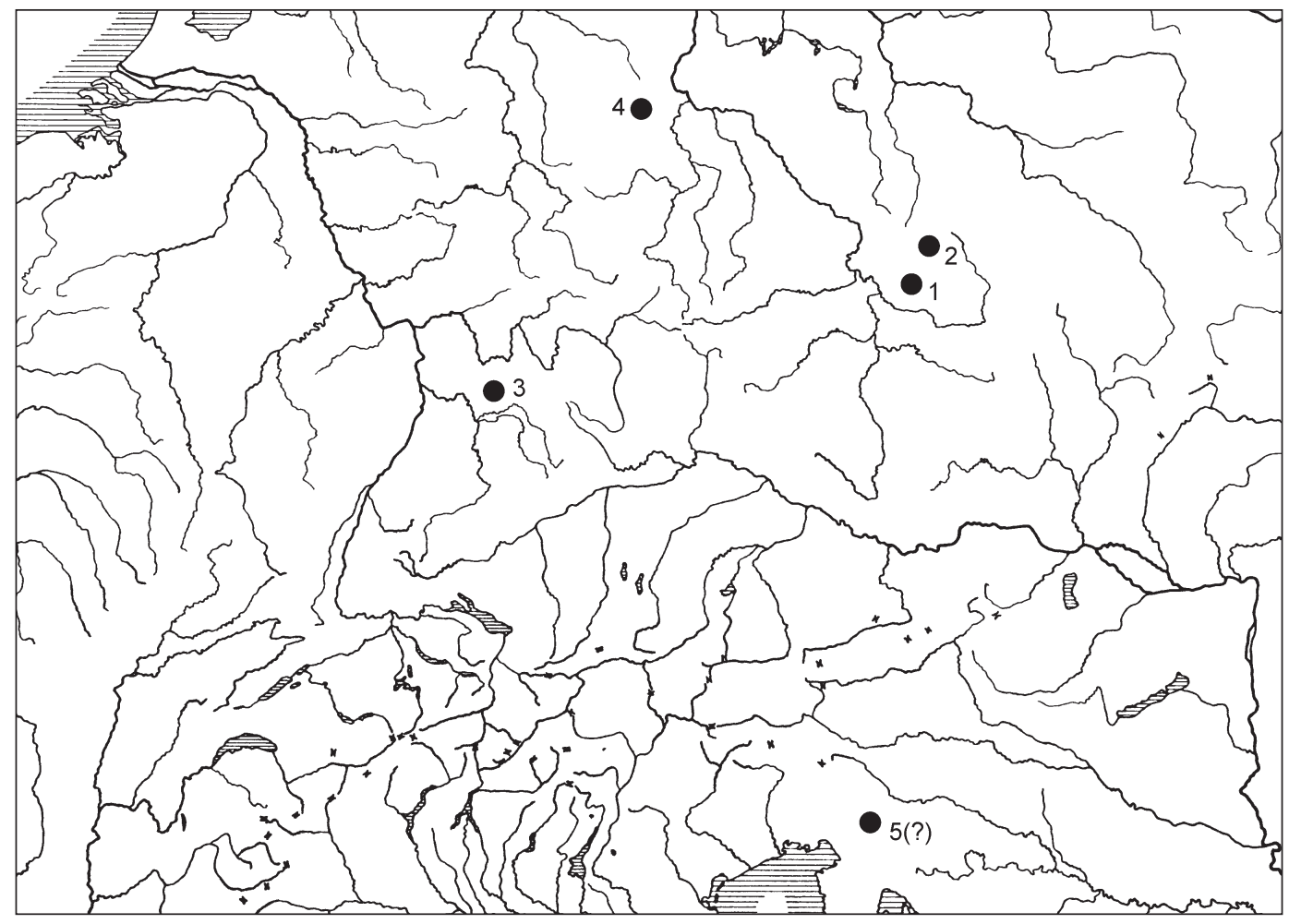

Abb. 33. Webschwertfunde vom Typ Benátky.

Die typologisch-chronologische Klassifikation der Lanzenspitze ist wegen ihres Erhaltungszustandes kompliziert. Das untersuchte Exemplar nähert sich in seiner Form dem Typ XX nach der Klassifikation von P. Kaczanowski (1995, 25, Taf. XIV: 5). Die Chronologie des Vorkommens von Spitzen des Typs XX auf dem Gebiet der Przeworsk-Kultur entspricht den Stufen C2 bis D1, mit einem Optimum des Vorkommens in der Stufe C2 (Kaczanowski 1995, 25). Von den Inventaren der Mooropferstätten in Illerup Ådal und Vimose nähern sich unserem Exemplar am meisten die Typen 4 und 4/6, die jedoch gleichzeitig eine kürzere Tülle haben und deren Gesamtlänge in nur einigen wenigen Fällen über $26 \mathrm{~cm}$ hinausreicht. Die Datierung fällt dann in eine breite Zeitspanne von der Stufe B1 bis zu den Phasen C1/C2 (Ilkjaer 1990, 48-50, Taf. 9: BEC-AB; Pauli Jensen 2008, 10-12). Aufgrund eines Rahmenvergleichs erscheint der Fund eher als ein Erzeugnis barbarischer Herkunft, das nur allgemein in die ältere bis späte römische Kaiserzeit datierbar ist.

\section{DISKUSSION UND INTERPRETATION (J. Jílek)}

Die Hortfunde von Rosovice, Lety u Dobřichovic und Benátky nad Jizerou müssen aus mehreren Aspekten betrachtet werden. Die Schlüsselpunkte der Interpretation betreffen die a) Chronologie einzelner Komponenten der Befunde, b) Chorologie der Komponenten und kulturgeschichtlichen Zusammenhänge und c) Deponierung und Lokalisation in der Landschaft.

\section{Chronologie}

\section{Rosovice}

Zwei Langsensen des 4. Typs wurden den Analogien zufolge vermutlich in der zweiten Hälfte des 3. oder im Verlauf des 4. Jhs. deponiert. 


\section{Lety u Dobřichovic}

Die Auswertung der Metallgefäße und des eisernen Dreifußes bringt aus chronologischer Sicht einige Probleme. Das erste von ihnen ist die Bestimmung der Verwendungsdauer der vertretenen Formen im römischen Milieu und im Barbarikum. Alle vier Gefäße stellen herkömmliches Kochgeschirr dar, das im Unterschied z. B. zum Tafelgeschirr leider nicht zu sehr den „Modetrends“ nachging. Wir nehmen deswegen an, dass es wichtig ist, das Vorkommensoptimum der vertretenen Formen zu verfolgen. Im Fall des Eimers vom Typ E 43 registrieren wir die meisten Vertreter innerhalb der Zeitspanne von der Mitte des 2. Jhs. bis zum Ende des 3. s. Ähnlich kann man auch das Vorkommen und die Datierung des eisernen Dreifußes abgrenzen. Aus dem 3. Jhs. kennen wir auch eine relativ hohe Anzahl von Tellern/ Pfannen des Typs NE 24a/Den Boesterd 91. Die Verfolgung des Vorkommensoptimums bringt jedoch natürlich methodische Probleme, denn wir können das Vorkommen dieser Gefäße in früheren Phasen der römischen Kaiserzeit sowie in späteren Zeitperioden kritisch nicht ausschließen. Einen wichtigen Faktor stellen die zahlreichen Reparaturen dar, die bei dem Eimer, dem schüsselförmigen Kessel mit geknicktem Unterteil und bei einem der Teller belegt wurden. Diese könnten auf einen längeren Gebrauch der Gefäße schon im provinzialen Milieu verweisen.

Ein bedeutendes Datierungselement repräsentiert die Langsense des 4. Typs, deren Parallelen im 2.-3. Jhs. hergestellt worden sind. Aus dem 4. Jhs. kennen wir diese Sensen ausschließlich in einem beschädigten, nicht funktionsfähigen oder reutilisierten Zustand. Die beiden Äxte (Bartäxte) sind aus dem 3.-4. Jhs. belegt. Deren Produktion setzte jedoch auch in der Völkerwanderungszeit fort. Aus den obenerwähnten Tatsachen ergibt sich, dass der Hort innerhalb einer breiten Zeitspanne von der Mitte des 3. Jhs. über das ganze 4. Jhs. deponiert werden konnte, d. h. irgendwo zwischen der Phase C1b und der Stufe C3, oder D1.

\section{Benátky nad Jizerou}

Die genauen Fundumstände des Hortfundes sind nicht bekannt, der Fundsatz muss daher nicht unbedingt komplett sein. Ein bemerkenswertes Element ist das Kesselgehänge, bei dem wir jedoch nicht mit Sicherheit wissen, ob es ursprünglich zweiarmig war, oder ob es von Anfang an nur einen Arm besaß. Datieren können wir es in eine relativ breite Zeitspanne von dem Ende des 1. Jhs. bis zum Verfall der Limes-Strukturen in der eintretenden Völkerwanderungszeit. Die chronologische Position des Löffelbohrers ist etwas günstiger, denn diese Form kommt eher in der jüngeren römischen Kaiserzeit vor, einschließlich der Endphase (z. B. Gaitzsch u. a. 1984). Fraglich bleiben die Webschwerter - ihre Analogien sind zwar ins 4.-5. Jhs. datiert, aber die sog. späten Exemplare haben sehr ungewisse Fundumstände. Der letzte Gegenstand dieses Fundverbands ist die Lanzenspitze. Die Datierung des Hortes kann somit nur rahmenhaft sein, mit Nachdruck auf den Abschnitt von der Stufe B1 bis zur Stufe C3.

\section{Chorologie, römische Küchenausstattung im Barbarikum und die kulturgeschichtlichen Zusammenhänge}

Bei der Auswertung von Hortfunden der jüngeren/späten römischen Kaiserzeit kann zum einen der Ausgangspunkte für deren Interpretation auch das Spektrum der enthaltenen Artefakte werden. Bei dem Fundverband aus Rosovice, der aus zwei Langsensen zusammengesetzt ist, bietet sich die Idee des Torsos von einem provinzialen Satz von landwirtschaftlichem Werkzeug, der jedoch im Barbarikum keinen Sinn ergeben haben könnte und deswegen zerteilt wurde. Mit Rücksicht auf das Vorkommen einer weiteren identischen Sense in der Region, nämlich in dem Hort von Lety u Dobřichovic, können wir spekulativ einen gemeinsamen Ursprung aller drei Exemplare in Betracht ziehen. Sie könnten jedoch in verschiedenen Zeitabschnitten im Boden gelandet sein. Mehr Raum für die Interpretation bietet der Hort von Lety u Dobřichovic. Landwirtschaftliches Werkzeug ist hier durch eine Pflugschar, eine Sense und mehrere Sicheln vertreten. Weitere handwerkliche Tätigkeiten sind durch eine Schere, das Fragment eines Löffelbohrers und ein Gerbereisen repräsentiert. Die Äxte lassen sich nicht eindeutig einordnen, denn sie können auch als mögliche Waffen angesehen werden. Zu handwerklichen Geräten in dem Hort von Benátky nad Jizerou zählen wir auch einen Löffelbohrer und zwei Webschwerter (?). Waffen sind durch eine Lanzenspitze vertreten. Werkzeuge, Geräte und Waf- 
fen sind in Depotfunden aus dem Barbarikum belegt (Půlpánová-Reszcyńska/Půlpán/Ondráčková 2018; Schindlerová 2016; Vích u. a. 2018). Sie treten auch als eine häufige Komponente der provinzialen Horte auf (Gaitzsch u. a. 1984, Tab. 1).

Von den Werkzeugen verdienen eine spezielle Aufmerksamkeit gerade die Webschwerter, denn diese Gegenstände kennen wir neben den Hortfunden (Benátky nad Jizerou, Osterburken) auch aus der Fundstelle Karlovice-Čertova Ruka, wo menschliche Aktivitäten seit der Jungsteinzeit bis zum Mittelalter belegt sind (Jiř́k 2008, 164; Kotýnek 2018). Deren Interpretation ist jedoch immer noch nicht zufriedenstellend gelöst. Anhand des gegenwärtigen Kenntnisstandes denkt man im Zusammenhang mit der späten römischen Kaiserzeit und Völkerwanderungszeit über ein Refugium nach, genauso wie auch über einen Platz für die Durchführung von Ritualen (zuletzt Jiř́k 2008, 172, 173). Es ist nicht uninteressant, dass gerade die Webschwerter eine wichtige Status-Rolle in der Ausstattung der Frauengräber, vor allem während der jüngeren Stufe der Völkerwanderungszeit, gespielt haben (Urbanová/Kostka/Korený 2010, 381-383, Tab. 2).

Das Spektrum der Metallgefäße in dem Hort von Lety u Dobřichovic verweist auf Komponenten der provinzialrömischen Küchenausstattung (Leconte 2013). In dem Fundsatz fehlt das Tafel- und Trinkgeschirr. Aus den vertretenen Gefäßtypen ragen vor allem die beiden Teller und der Dreifuß heraus. Diese Typen sind anhand des publizierten Materials aus dem mitteleuropäischen Barbarikum nicht sehr bekannt. Gerade die letztgenannten Funde lassen die Frage aufkommen, welche Funktion sie auf dem barbarischen Gebiet wohl haben konnten. Komponenten der römischen Küchenausstattung, abgesehen von den einfachen tonnenförmigen Eimern, Kesseln und Schöpfkellen mit Sieben des Typs E 161, sind in der jüngeren römischen Kaiserzeit und am Anfang der Völkerwanderungszeit im barbarischen Teil Mitteleuropas nicht sehr zahlreich.

Ein interessantes Phänomen ist jedoch die Vertretung der ausgewählten Gefäße und Küchenausstattungsteile in anderen Horten des mitteleuropäischen Barbarikums während der ganzen römischen Kaiserzeit. Zu erwähnen sind hier die chronologisch älteren Funde aus der Siedlung in Blučina, Befund 1 (Droberjar 1997, 129, 130), wo der dort deponierte Fundsatz eine Schöpfkelle enthielt. Aus demselben Horizont stammt auch das Depot aus dem niederösterreichischen Hanfthal, in dem sich ein Teil der Kette von einem Kesselgehänge befand (Sauer 1994, Abb. 4: 4). Einen eisernen Rost entdeckte man in dem Hort von Čataj (Bazovský 2007, 252, Abb. 5: 1). Aus der Wende von der späten römischen Kaiserzeit zum Anfang der Völkerwanderungszeit stammt dann der Hortfund aus der Siedlung in Mušov „U svatého Jana“ (Befund 10), der eine eiserne Bratpfanne enthielt (Trňáčková 1985). Eine nahe Analogie finden wir in dem Hort aus der Fundstelle Lotzdorf - Radeberg in Sachsen. Dieser Befund enthielt auch zwei eiserne Schöpfkellen (Krause/Limpach/Spehr 1966, Abb. 5, 6; Meyer 1971, 146-150; 1976, 53, 54, 159, 160). Aus slowakischem Gebiet können wir einen Neufund aus der Höhenlage Dolná Súča-Krasín nennen - den Hort 7 (Pieta 2020, 60, Abb. 11: 1), der ebenfalls an die Wende von der späten römischen Kaiserzeit zur ersten Hälfte des 5. Jhs. datiert ist. Zu der behandelten Kategorie der Gegenstände gehören vielleicht auch die Fragmente eiserner Bleche und eines eisernen Bandhenkels (?) aus dem Hortfund der späten römischen Kaiserzeit in Opolany (Lička 1969, Abb. 2: 1-3). Weitere Beispiele für die Küchenausstattung in Hortfunden wurden von J. Henning zusammengefasst (Henning 1985, 575, 589). Aus den von uns bewerteten Fundverbänden müssen wir zu der Küchenausstattung ebenfalls den Torso einer Hängekette aus Benátky nad Jizerou und vielleicht auch das Fragment einer eisernen Fleischgabel aus dem Hort von Lety hinzuzählen.

Es scheint also, dass die in provinzialrömischen Küchen vorkommenden Gegenstände im mitteleuropäischen Raum nicht ganz unbekannt waren. Zu einem gewissen Maß zeugen davon auch die Funde (z. B. Roste, bronzene Kochgefäße - Kessel, Pfanne Typ NE 24a, Kesselgehänge ${ }^{18}$ ) aus reich ausgestatteten Gräbern der Barbarenelite aus Čáčov (Ondrouch 1957; Pieta 2002, 348, Abb. 2: 9) und Mušov (Peška/Tejral 2002; Schönfelder 2009, hier auch die Überlegungen über die Datierung). In Grabkontexten interpretiert man diese Gegenstände als bedeutende Statusobjekte (Steuer 2006, 14, 19, 22; Tejral 2016, 285), die schon seit der Spätlatènezeit/frühen römischen Kaiserzeit einen untrennbaren Teil der ritualisierten Ausstattung einiger reicher Gräber bildeten, und zwar sowohl auf dem Gebiet unter römischer Verwaltung und römischem Einfluss (Lindenthal/Rupp 2000, 171-175; Metzler u. a. 1991, 44, 101, 143-145, Abb. 22, 36, 101; Nenova/Angelov 1999, 55, Abb. 9; Oesterwind 1989, 116, 198, 199, Taf. 44: 6; Tejral 2016, 285, Abb. 14; 15; Voss 2006, 25, Abb. 4: 16), als auch im Barbarikum (Jílek/Lamprecht 2020, 35, 36; zu Kesseln siehe Voss 2006, 25).

18 Das eiserne Kesselgehänge aus Přerov nad Labem (Šnajdr 1906) ist den Funden mit ungewissem Kontext (gestörte Gräber/ Hort?) zuzuordnen. 
Das Küchenzeug, einschließlich der Kessel, ist auch in wikingerzeitlichen Gräbern belegt (Lund 2008, 62). Gegenwärtig interpretiert man die Elemente der Grabausstattung als Gegenstände, die bei Leichenschmäusen verwendet wurden. Diese Schmäuse spielten dann eine wichtige Rolle in damaliger Gesellschaft und konnten wichtige Ereignisse im Leben der damaligen Elite darstellen (dazu ausführlich Steuer 2006, 14, 19, 20).

Die Frage der Beziehung zwischen den Funden aus Horten und Gräbern wird ständig diskutiert. In den beiden Typen der Kontexte können archaische Gegenstände vorkommen, die eine spezifische Bedeutung haben konnten, und zwar sowohl für die Hinterbliebenen, als auch für diejenigen, die sie für die Deponierung ausgewählt haben. N. Myrberg $(2009,135,136)$ nahm an, dass in der späten Völkerwanderungszeit und Wikingerzeit besonders die aus Gräbern und Horten bekannten Luxusartefakte sorgfältig mit Rücksicht auf die Funktion und Symbolik ausgewählt wurden. Die beiden Typen der Kontexte waren dann eng miteinander verbunden. Es ist also gut möglich, dass es sich um Denkmäler mit eigener Geschichte handeln kann und einige von ihnen, vor allem die prachtvollen oder anders ungewöhnlichen Gegenstände, können dann als die sog. Gedächtnisobjekte betrachtet werden (Bradley 2017, 53, 54, hier auch weitere Literatur; dazu ausführlich Lund 2008, 63; Myrberg 2009, 135-138; Quast 2011, 263-265).

Aus den obenerwähnten Tatsachen kann man folgern, dass die römische Küchenausstattung im Barbarikum keine unbedeutende Rolle spielte. Um diese Behauptung zu untermauern, können wir nach den sog. „praktischen Argumenten“ suchen. Eines von ihnen ist das Verstecken der ausgewählten Horte mit dieser Ausstattung in Krisensituationen. Als passende Beispiele können die Horte von Blučina (Droberjar 1997, 129, Taf. 20; 21), Hanfthal (Sauer 1994), Dunajská Lužná und Čataj (Bazovský 2007, 253, 254; 2010, 24, 25) dienen, die mit der unruhigen Periode der Markomannenkriege verbunden werden. Auf eine ähnliche Weise können wir dann den Hort von Mušov „U svatého Jana“ mit der turbulenten Anfangsphase der Völkerwanderungszeit in Zusammenhang bringen (Jílek 2012, 17, 18).

Einen anderen Blickwinkel bietet die Lösung, die oft an die rituellen Gründe gebunden ist. Im Fall der Siedlungsdepots unter dem Fußboden der Grubenhäuser, beziehungsweise in Siedlungskontexten, ist diese Interpretation jedoch nur schwer ergreifbar (dazu Roymans/Scheers 2012, 20), trotz unserer Überlegungen über die möglichen Opfer in Verbindung mit hypothetischer Nutzung der gegebenen Siedlungsobjekte, d. h. mit deren Erbauung, Benutzung und der anschließenden Auflassung (dazu ausführlich Kolon 2015). Eine interessante Erklärung für die Deponierung der Horte in gefährlichen Zeiten wurde von N. Roymans und S. Scheers $(2012,19,20)$ vorgelegt. Diese Autoren haben am Beispiel der Deponierung keltischer Goldmünzen und Kostbarkeiten aus der Zeit Caesars geschickt und sinnvoll demonstriert, dass das Verstecken der Gegenstände vor den Feinden mit einem Ritual verbunden sein konnte, welches auf die Rettung der Gemeinschaft sowie der Artefakte selbst abgezielt war.

\section{Deponierung und Lokalisation in der Landschaft}

Der Hort von Rosovice befand sich in einer Grube mit den Ausmaßen von 80x30 cm und einer Tiefe von $25 \mathrm{~cm}$, mit der Längsseite in Richtung NO - SW orientiert. Anhand der Deponierungsweise, wie sie von dem Finder beschrieben und teilweise fotografisch dokumentiert wurde, können wir in Betracht ziehen, dass die Sensen vor der Deponierung im Boden möglicherweise in einem Beutel aus organischem Material eingepackt waren, dessen Anwesenheit jedoch nicht eindeutig nachgewiesen wurde. Die Orientierung nach den Himmelsrichtungen muss ebenfalls nicht unbedingt zufällig gewesen sein (Hrádečná: Půlpánová-Reszcyńska/Půlpán/Ondráčková 2018, 577; Jevíčko-Předměstí: Vích/Jílek 2016, 364). Der Hort wurde im heutigen Waldbestand gefunden und es ist hoch wahrscheinlich, dass die Fundstelle auch in der jüngeren römischen Kaiserzeit bewaldet war, denn die zeitgleiche Besiedlung ist selbst in breiterer Umgebung nicht nachgewiesen (die nächsten bekannten Siedlungen: z. B. Lážovice $8 \mathrm{~km}$, Lety u Dobřichovic 18 km). Der Ort befindet sich in einer Höhe von $440 \mathrm{~m}$ ü. d. M., jenseits der Wasserläufe. Aus dem Fundkontext der anderen vorgeschichtlichen Perioden und aus der Geländekonfiguration ergibt sich, dass die Gegenstände vermutlich entweder direkt auf der Trasse eines Weges, oder in seiner Umgebung deponiert wurden (siehe Anm. 32).

Die Details über die Form von Deponierung des Hortes von Benátky nad Jizerou sind unbekannt, zu diesem Befund gibt es keine erforderlichen Informationen. Nur die Zusammenlegung des Kesselgehänges und die (ursprünglich komplett?) verbogenen Webschwerter lassen auf mögliche (organi- 
sche?) Verpackung schließen, in welcher der Hort ursprünglich deponiert war. Das Depot befand sich am Übergang vom Tal zum Hang auf der nördlichen Seite des Berges, in einer Höhe von $225 \mathrm{~m}$ ü. d. M. Der Ort wurde im Mittelalter und in der Neuzeit durch den Aufbau der Stadt und des Schlosses geändert. Trotzdem blieb die Lage gewissermaßen exponiert - sie bietet einen relativ weiten Ausblick über die Landschaft, besonders in nördlicher Richtung. Obwohl sie von dem gegenwärtigen zeitweiligen Wasserlauf etwa $150 \mathrm{~m}$ entfernt ist, ist es im Hinblick auf die heutige Geländekonfiguration gut möglich, dass in der Vergangenheit in ihrer Nähe eine Quelle, oder direkt ein Quellbecken situiert sein konnte.

Aus den bewerteten Fundsätzen ragt mit Rücksicht auf die Deponierung und Lokalisation vor allem der Hort von Lety u Dobřichovic heraus. Die Gegenstände wurden in zwei Metallgefäße eingeräumt und in eine Grube gelegt. Die Anwesenheit eines Stoffs oder einer anderen Umhüllung aus organischem Material lässt sich nicht mehr nachweisen, denn die Gegenstände wurden unprofessionell konserviert. Die Steinverpackung des besprochenen Objektes deutet an, dass es sich z. B. um eine Herstellungsanlage, vielleicht einen Ofen, gehandelt haben könnte (vgl. Lotzdorf - Radeberg: Krausel Limpach/Spehr 1966). Für diese Spekulation können wir heutzutage aber nicht mehr argumentieren. Den verfügbaren Informationen zufolge befand sich der Hort vermutlich auf der Fläche einer Terrasse, die von den Pražská- und Řevnická-Straßen und einer namenslosen Quergasse umgrenzt war. Was es die Berounka angeht, entstand ihr heutiges Flussbett an der inkriminierten Stelle erst nach einer Überschwemmung im 17. Jhs. Ursprünglich befand es sich etwas südlicher, vermutlich in der Flur Namens „V Tůních“. Die Fundstelle selbst lässt viele Fragen aufkommen. Überdauerte die Siedlung der frühen römischen Kaiserzeit (Halama 2006, 338, Abb. 1) auch noch im 3.-4. Jhs., oder wurde der Hort erst nach dem Verlassen der Siedlung im Boden deponiert (?) Einen indirekten Verweis auf die Besiedlung der behandelten Stelle könnte der Fund einer einteiligen Bronzefibel mit spitzem Fuß darstellen. Die genaue Fundstelle dieser Fibel ist jedoch unbekannt (Halama 2006, 337-340, Abb. 11: 3); anhand der neuesten Auswertung dieser Fibeln von V. Varsik (2017, 334, Tab. 1) können wir sie in einen Zeitabschnitt datieren, der schon vor der Mitte des 3. Jhs. beginnt (Phase C1a). Das Optimum ihres Vorkommens fällt dann in die 2. Hälfte des 3. und an den Anfang des 4. Jhs.

Eine wichtige Information ergibt sich aus der Lage des Befundes in der Nähe des Flusses Berounka, ungefähr an seinem Zusammenlauf mit dem Bach Kejná. Gerade die Bindung zu Wasserläufen und Zusammenflüssen bildet oft einen wichtigen Argument für die rituelle Interpretation der Depotfunde (Bradley 2017, siehe z. B. 19, 169-172), wie es unter anderem schon früher auch M. Lutovský angedeutet hat (Lutovský 2001, 156). Diese Beziehung illustrieren gut die entfernten jüngeren wikingerzeitlichen Analogien aus Skandinavien, wo die Horte oft in der Nähe von Seen, Mooren und Flüssen deponiert wurden (Lund 2008, 56, 63). Aufgrund der oben umgerissenen Indizien können wir den Befund aus Lety als sog. rituellen Hort betrachten. Neben der Lokalisation sprechen für eine solche Interpretation auch die Komponenten der provinzialrömischen Küchenausstattung (Kessel, Dreifuß, Schüssel und Teller, Teil einer Fleischgabel?), die man als bedeutende Statusobjekte bezeichnen kann und die eine wichtige Rolle bei Totenschmäusen der damaligen Elite gespielt haben könnten.

\section{SCHLUSSFOLGERUNGEN}

(R. Korený, J. Jílek)

In dem Beitrag wurden die Funde der jüngeren/späten römischen Kaiserzeit aus Mittelböhmen veröffentlicht - der neuentdeckte Hort von Rosovice und die komplex ausgewerteten alten Depotfunde von Benátky nad Jizerou und Lety u Dobřichovic, die bisher in die Latènezeit und ins Frühmittelalter datiert wurden. Die Depotfunde lassen sich in die jüngere oder späte römische Kaiserzeit datieren. Sie erweitern damit auf eine bedeutende Weise die bisherige Basis, die noch bis unlängst in Böhmen nur durch einen einzigen Befund vertreten wurde, nämlich durch den Hort von Opolany (Abb. 34). Die Analyse der Sensen hat angedeutet, dass die Depotfunde aus Rosovice und Lety u Dobřichovic ursprünglich eine einzige Einheit gebildet haben könnten. Im Fall aller drei obengenannten Depotfunde kann man als den Grund für ihre Deponierung die sog. rituelle Interpretation vorlegen. Die Hauptbegründung ist vor allem die Nähe der Wasserläufe und im Fall des Hortes von Rosovice die Lokalisation in einer bergigen Landschaft ohne Spuren der naheliegenden römerzeitlichen Besiedlung (die nächsten bekannten Siedlungen: z. B. Zalužany $30 \mathrm{~km}$, Lážovice $8 \mathrm{~km}$, Tihava $16 \mathrm{~km}$, Lety u Dobřichovic $18 \mathrm{~km}$ ). 


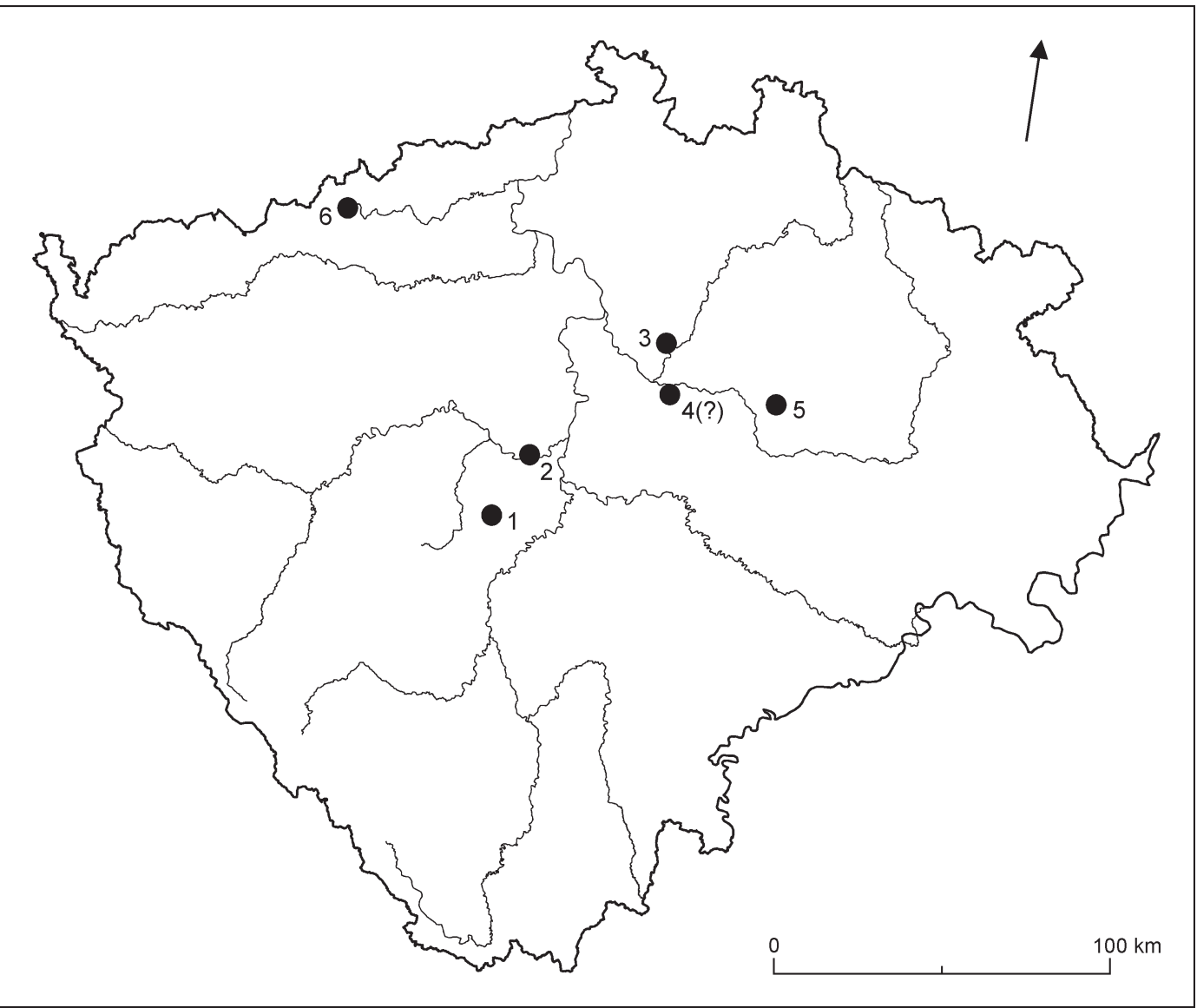

Abb. 34. Römerzeitliche Eisendepotfunde aus Böhmen. 1-Rosovice (Bez. Př́íbram); 2 - Lety u Dobřichovic (Bez. Beroun); 3 - Benátky nad Jizerou (Bez. Mladá Boleslav); 4 - Přerov nad Labem (?, Bez. Nymburk); 5 - Opolany (Bez. Nymburk); 6 - Hrádečná (Bez. Chomutov). Hergestellt von P. Čechák und R. Korený.

Im Interesse der Erhaltung der Originalgegenstände für die Zukunft wurde es entschieden, die Kopien der Sensen aus Rosovice herzustellen. Dieser Prozess umfasste auch eine experimentelle Überprüfung des zur Herstellung einer Sense nötigen Arbeits- und Zeitaufwands und funktionelle Überprüfung und Bewertung der Arbeit mit dem genannten Typ der Sensen. Die Herstellung einer Sense dauerte ungefähr 30 Stunden; in der römischen Kaiserzeit, mit Rücksicht auf die Erfahrung des Schmiedes, erforderte die Erzeugung einer Sense etwa 20 Stunden.

Die beiden Sensen aus Rosovice wurden einer metallographischen Untersuchung unterzogen, um die Art ihrer Herstellung und Pflege zu verdeutlichen. Es wurde nachgewiesen, dass die Klingen der beiden Sensen aus qualitätsvollem Stahl mit einem ungefähr eutektoiden Kohlenstoffgehalt hergestellt wurden. Sie wurden nicht gehärtet, obwohl die Abkühlung von den Schmiedetemperaturen relativ schnell gewesen sein könnte. Da die Schneide einer der Sensen die Spuren einer intensiven Kaltumformung trägt, ist es offensichtlich, dass die hohe Schärfe dieser Sensen durch zeitweiliges Dengeln mit einem Dengelhammer und häufiges Nachschärfen mit einem Wetzstein erreicht wurde. Die Klingen wurden an die Hammen angeschweißt, deren Material offensichtlich einer nicht so strengen Selektion unterlag. Es lässt sich konstatieren, dass die Sensen aus Rosovice dieselbe Pflege erforderten wie die heutigen Sensen.

Im Text wurde ebenfalls die Frage der Webschwerter aus dem Hort von Benátky nad Jizerou aufgeworfen, die das Hauptargument für die Datierung dieses Depots in die jüngere oder späte römische Kaiserzeit darstellen. Die funktionelle Bestimmung dieser Gegenstände ist jedoch vermutlich nicht definitiv gelöst und es wird sicherlich noch in der Zukunft diskutiert werden. 


\section{LITERATUR}

Bartoli 2017

Bartošková 1986

Bausovac 2003

Bazovský 2007

Bazovský 2008

Bazovský 2010

Beckmann 1981

Beljak 2009

Beran 2012

Beranová 1963

Beranová 1972

Beranová 1980

Beranová 2005

Beranová/Kubačák 2010

Beranová/Lutovský 2009

Berke 1990

Bernhard u. a. 1990

Biborski/Ilkjaer 2006

Bienert 2007

Bitenc/Knific 2015

Bolina/Klimek/Cílek 2018

Božič 2005

Božič/Ciglenečki 1995

Böhme 1974

Bradley 2017

Bravermanová 1991

Bubeník/Pleinerová/Profantová 1998

Busuladžić 2011

Busuladžić 2014

Cech u. a. 2013
P. Bartoli: Were some Late Roman forms of scythes really created by the Celts in the Eastern Alpine region and in Western Hungary? In: J. Kysela/A. Danielisová (eds.): Stories that made the Iron Age. Studies in honour of Natalie Venclová. Praha 2017, 317-337.

A. Bartošková: Slovanské depoty železných předmětů v Československu. Studie archeologického ústavu ČSAV v Brně 13/2. Praha 1986.

M. Bausovac: Poznoantični kovinski predmeti z Gradca pri Prapretnem. Arheološki vestnik 54, 2003, 315-324.

I. Bazovský: Depot železných predmetov z germánskeho sídliska v Čataji (okr. Senec, juhozápadné Slovensko). In: O. Chvojka (ed.): Archeologie barbarů 2006. Př́spěvky z II. protohistorické konference České Budějovice, 21.-24. 11. 2006. Archeologické výzkumy v jižních Čechách. Supplementum 3. České Budějovice 2007, 249-260.

I. Bazovský: Ďalšie sídliskové objekty z obdobia stahovania národov z Bratislavy-Rusoviec. Zborník SNM 102. Archeológia 18, 2008, 131-138.

I. Bazovský: Depot z doby rímskej z Dunajskej Lužnej. In: J. Beljak/G. Březinová/V. Varsik (eds.): Archeológia barbarov 2009. Archaeologica Slovaca Monographiae. Communicationes 10. Nitra 2010, 13-32.

Ch. Beckmann: Arm- und Halsringe aus den Kastellen Feldberg, Saalburg und Zugmantel. Saalburg Jahrbuch 37, 1981, 10-22.

J. Beljak: Osada zo začiatku obdobia st’ahovania národov v Štúrove v kontexte osídlenia na Dolnom Pohroní. Zborník SNM 103. Archeológia 19, 2009, 227-246.

V. Beran: Analýza železných předmětů ze starší a mladší doby římské z nálezových celků z Hradiska (Burgstall) u Mušova a jeho okolí. Diplomarbeit. Masaryk-Universität. Brno 2012. Unpubliziert.

M. Beranová: Zemědělství v Čechách na počátku feudalismu. Archeologické rozhledy 15, 1963, 471-483.

M. Beranová: Slovanský hromadný nález ze Semic. Archeologické rozhledy 24, 1972, 629-643.

M. Beranová: Zemědělství starých Slovanů. Praha 1980.

M. Beranová: Historie senoseče v Čechách podle archeologie. Archeologie ve středních Čechách 9, 2005, 9-65.

M. Beranová/A. Kubačák: Dějiny zemědělství v Čechách a na Moravě. Praha 2010.

M. Beranová/M. Lutovský: Slované v Čechách. Archeologie 6.-12. století. Praha 2009.

S. Berke: Römische Bronzegefässe und Terra Sigillata in der Germania Libera. Münstersche Beiträge zur Archäologie 7. Münster 1990.

H. Bernhard u. a.: Der römische Schatzfund von Hagenbach. Mainz 1990.

M. Biborski/J. Ilkjaer: Illerup Ådal 11. Die Schwerter. Textband. Århus 2006.

B. Bienert: Die römischen Bronzegefässe im Rheinischen Landesmuseum Trier. Trierer Zeitschrift Beiheft 31. Trier 2007.

P. Bitenc/T. Knific: Zgodnjesrednjeveški zakladi železnih predmetov z Gorjancev, Starega gradu nad Uncem in Ljubične nad Zbelovsko Goro. Arheološki vestnik 66, 2015, 103-146.

P. Bolina/T. Klimek/V. Cílek: Staré cesty v krajině středních Čech. Praha 2018.

D. Božič: Die spätrömischen Hortfunde von der Gora oberhalb von Polhov Gradec. Arheološki vestnik 56, 2005, 293-368.

D. Božič/S. Ciglenečki: Zenonov tremis in poznoantična utrdba Gradec při Veliki Strmici. Arheološki vestnik 46, 1995, 247-277.

H. W. Böhme: Germanische Grabfunde des 4. bis 5. Jahrhunderts zwischen unterer Elbe und Loire. Münchner Beiträge zur Vor- und Frühgeschichte 19. München 1974.

R. Bradley: A Geography of Offerings: Deposits of Valuables in the Landscapes of Ancient Europe. Oxbow Insights in Archaeology. Oxford - Philadelphia 2017.

M. Bravermanová: Dvorce u Dobříše - dvorec či tvrziště? Sborník společnosti prátel starožitností 2, 1991, 79-85.

J. Bubeník/I. Pleinerová/N. Profantová: Od počátků hradišt k počátkům přemyslovského státu. Památky archeologické 89, 1998, 104-145.

A. Busuladžić: Rimske vile u Bosni i Hercegovini - Roman Villas in Bosnia and Herzegovina. Sarajevo 2011.

A. Busuladžić: Antički željezni alat i oprema sa prostora Bosne i Hercegovine. Iron tools and implements of the Roman period in Bosnia and Herzegovina. Sarajevo 2014.

B. Cech u. a.: Ein römisches Goldbergbau revier im „Karth“, einer Landschaft südöstlich von Neunkirchen, Niederösterreich. Römisches Österreich 36, 2013, 1-94. 
Ciglenečki 1983

Ciglenečki 1994

Ciglenečki 2000

Curle 1911

Čremošnik 1930

D’Andria 1974

Den Boesterd 1956

Drack 1990

Drack/Fellmann 1988

Droberjar 1997

Dušek/Becker 2017

Eggers 1951

Eggers 1955

Eisner 1948

Endert 1991

Faber 1994

Fabricius 1914

Feugère 1986

Friedrich 1946

Fries 1995

Gaitzsch 1980

Gaitzsch u. a. 1984

Garbsch 2003

Gluščevič 2014

Gralfs 1992

Greiner 2002

Greiner 2008

Greiner 2010

Grönke 1997
S. Ciglenečki: Die Eisenwerkzeuge aus den befestigten Höhensiedlungen Sloweniens aus der Völkerwanderungszeit. Balcanoslavica 10, 1983, 45-54.

S. Ciglenečki: Höhenbefestigungen als Siedlungsgrundeinheit der Spätantike in Slowenien. Arheološki vestnik 45, 1994, 239-266.

S. Ciglenečki: Tinje na Loko pri Žusmu. Poznoantična in zoodnjesrednjeveška naselbina (Tinje oberhalb von Loka pri Žusmu. Spätantike und frühmittelalterliche Siedlung). Opera instituti archaeologici Sloveniae 4. Ljubljana 2000.

J. Curle: A Roman frontier post and its people. The fort Newstead in the Parish Melrose. Glasgow 1911.

G. Čremošnik: Nalazi iz rimskog doba na Stupu kod Sarajeva. Glasnik Zemaljskog muzeja u Bosni i Hercegovini 42, 1930, 211-225, taf. XII-XVI.

F. D'Andria: Vasi di bronzo Romani del Museo nazionale „Ridola“ di Matera. Bulletin des Musees Royaux D'Art ed D'Histoire Parc du cinquantenaire Bruxelles 6, 46, 1974, 53-68.

M. H. P. Den Boesterd: The Bronze Vessels. Description of the Collections in the Rijksmuseum G. M. Kam at Nijmegen V. Nijmegen 1956.

W. Drack: Der römische Gutshof bei Seeb, Gem. Winkel. Berichte der Zürcher Denkmalpflege Archäologische Monographien 8. Zürich 1990.

W. Drack/R. Fellmann: Die Römer in der Schweiz. Stuttgart - Jona 1988.

E. Droberjar: Studien zu den germanischen Siedlungen der älteren römischen Kaiserzeit in Mähren. Fontes Archaeologici Pragenses 21. Praha 1997.

S. Dušek/M. Becker (Bearb.): Corpus der römischen Funde im europäischen Barbaricum. Freistaat Thüringen Teil 1: Südharzvorland, Saale-Elster-Region, Thüringer Wald. Band 8/1. Wiesbaden 2017.

H. J. Eggers: Der römische Import im freien Germanien. Hamburg 1951.

H. J. Eggers: Die römischen Bronzegefässe von der Saalburg. Saalburg Jahrbuch 14, 1955, 45-49.

J. Eisner: Základy kovářství v době hradištní v Československu. Slavia antiqua 1, 1948, 367-396.

D. Endert: Die Bronzefunde aus dem Oppidum von Manching. Die Ausgrabungen in Manching 13. Stuttgart 1991.

A. Faber: Das römische Auxiliarkastell und der Vicus von Regensburg-Kumpfmühl. Münchner Beiträge zur Vor- und Frühgeschichte 49. München 1994.

E. Fabricius: Das Kastell Weissenburg. In: E. Fabricius/F. Hettner/O. V. Sarwey (Hrsg.): Der Obergermanisch-raetische Limes des Roemerreiches. Abteilung B. Die Kastelle Nr. 71-75. Band VII. Heidelberg 1914.

M. Feugère: Note sur un type particulier dinstrument culinaire composite à l'époque romaine. Germania 64, 1986, 173-179.

F. C. Friedrich: Staroslovanský hromadný nález v Letech u Dobřichovic. Obzor Prehistorický 13, 1946, 39-44.

J. C. Fries: Vor- und frühgeschichtliche Agrartechnik auf den Britischen Inseln und dem Kontinent. Eine vergleichende Studie. Internationale archäologie 26. Espelkamp 1995. W. Gaitzsch: Eiserne römische Werkzeuge. BAR International Series 78. Oxford 1980. W. Gaitzsch/A. Geissen/W. M. Arendt/B. Päffgen/G. Quarg/G. Schauerte/A. Steiner: Ein Verwahrfund des 4. Jahrhunderts aus dem Königsforst bei Köln. Bonner Jahrbücher 184, 1984, 335-478.

J. Garbsch: Der römische Bronzeglockenfund von Monatshausen in Oberbayern. Arheološki vestnik 54, 2003, 299-314.

S. Gluščevič: Grob tesara s nekropole na Relji u Zadru. Diadora 28, 2014, 53-82.

B. Gralfs: Ackergerät der Alamannen. Der Hortfund von Osterburken, NeckarOderwald-Kreis. In: H.-P. Kuhnen (Hrsg.): Gestürmt-Geräumt-Vergessen? Der Limesfall und das Ende der Römerherrschaft in Südwestdeutschland. Stuttgart 1992, 109-112.

B. A. Greiner: Der Kastellvicus von Rainau-Buch: Siedlungsgeschichte und Korrektur dendrochronologischer Daten. In: L. Wamser/B. Steidl (Hrsg.): Neue Forschungen zur römischen Besiedlung zwischen Oberrhein und Enns. München 2002, 83-89.

B. A. Greiner: Rainau-Buch II. Der römische Kastellvicus von Rainau-Buch (Ostalbkreis). Die archäologischen Ausgrabungen von 1976 bis 1979. Band I. Forschungen und Berichte zur Vor- und Frühgeschichte in Baden-Württemberg 106. Stuttgart 2008.

B. A. Greiner: Rainau-Buch II. Der römische Kastellvicus von Rainau-Buch (Ostalbkreis). Die archäologischen Ausgrabungen von 1976 bis 1979. Band II. Forschungen und Berichte zur Vor- und Frühgeschichte in Baden-Württemberg 106. Stuttgart 2010. E. Grönke: Das römische Alenkastell Biriciane in Weißenburg i. Bay: die Grabungen von 1890 bis 1990. Limesforschungen 25. Mainz 1997. 
Gschwind 2004

Haberstroh 2000

Haberstroh/Faßbinder 2003

Halama 2006

Hanemann 2014

Hansen 1987

Harnecker 1997

Hänggi/Doswald/Roth-Rubi 1994

Henning 1985

Henning 1986

Henning 1987

Henning 1991a

Henning $1991 b$

Henning 2004

Henning 2005

Henning 2007

Horisberger 2004

Hübener 1980

Cholakov/Atanasov 2007

Ilkjaer 1990

Ivanišević/Špehar 2005

Ivanovski 1987

Jablonka 2001

Jacobi 1974
M. Gschwind: Abusina: das römische Auxiliarkastell Eining an der Donau vom 1. bis 5. Jahrhundert nach Christus. Münchner Beiträge zur Vor- und Frühgeschichte 53. München 2004.

J. Haberstroh: Germanische Funde der Kaiser- und Völkerwanderungszeit aus Oberfranken. Materialhefte zur bayerischen Vorgeschichte 82. Kallmünz 2000.

J. Haberstroh/J. Faßbinder: Der Reisberg bei Schleßlitz-Burgellern in der Völkerwanderungszeit. Überlegungen zum 5. Jahrhundert n. Chr. in Nordbayern. Germania 81, 2003, 201-262.

J. Halama: Polozapomenuté nálezy doby římské z Letů u Dobřichovic, okr. Praha-západ. In: E. Droberjar/M. Lutovský (eds.): Archeologie barbarů 2005. Praha 2006, 337-359.

B. Hanemann: Die Eisenhortfunde der Pfalz aus dem 4. Jahrhundert nach Christus. Forschungen zur Pfälzischen archäologie 5. Speyer 2014.

U. L. Hansen: Römischer Import im Norden. Warenaustausch zwischen dem Römischen Reich und dem freien Germanien. Nordiske Fortidsminder, serie B, 10. København 1987.

J. Harnecker: Katalog der römischen Eisenfunde von Haltern. Bodenaltertümer Westfalens 35. Mainz am Rhein 1997.

R. Hänggi/C. Doswald/K. Roth-Rubi: Die frühen römischen Kastelle und der Kastell-Vicus von Tenedo-Zurzach. Veröffentlichungen der Gesellschaft Pro Vindonissa XI. Brugg 1994.

J. Henning: Zur Datierung von Werkzeug- und agrargerätefunden im germanischen Landnahmegebiet zwischen Rhein und oberer Donau. Der Hortfund von Osterburken. Jahrbuch des Römisch-Germanischen Zentralmuseums Mainz 32, 1985, 570-594.

J. Henning: Zum Problem der Entwicklung materieller Produktivkräfte bei den germanischen Staatsbildungen. Klio 68, 1986, 128-138.

J. Henning: Südosteuropa zwischen Antike und Mittelalter. Archäologische Beiträge zur Landwirtschaft des 1. Jahrtausends unserer Zeitrechnung. Schriften Ur- und Frühgeschichte 42. Berlin 1987.

J. Henning: Een Zeis uit de Merovingische nederzetting te Kerkhove, deelgemeente Avelgem (W. VI.). Westvlaamse Archaeologica 7, 1991, 90-96.

J. Henning: Fortleben und Weiterenetwicklung spätrömischer Agrargerätetraditionen in Nordgallien. Acta Archaeologica Lovaniensia 30, 1991, 49-59.

J. Henning: Germanisch-romanische Agrarkontinuität und -diskontinuität im nordalpinen Kontinentaleuropa - Teile eines Systemwandels? Beobachtungen aus archäologischer Schicht. In: D. Hägermann/W. Haubrichs/J. Jarnut (eds.): Akkulturation - Probleme einer germanisch-romanischen Kultursynthese in Spätantike und frühem Mittelalter. Egänzungsbände zum Reallexikon der Germanischen Altertumskunde 41. Berlin - New York 2004, 396-435.

J. Henning: Ways of Life In Eastern and Western Europe during the Early Middle Ages: Which Way was „normal“? In: F. Curta (ed.): East Central \& Eastern Europe in the Early Middle Ages. Ann Arbor 2005, 41-59.

J. Henning: Early European Towns. The development of the economy in the Frankisch realm between dynamism and deceleration AD 500-1100. In: J. Henning (ed.): Post-Roman Towns, Trade and Settlement in Europe and Byzantium. Berlin - New York 2007, 3-40.

B. Horisberger: Der Gutshof in Buchs und die römische Besiedlung im Furttal. Monographien der Kantonsarchäologie Zürich 37. Zürich 2004.

W. Hübener: Eine Studie zu den Beilwaffen der Merowingerzeit. Zeitschrift für Archäologie des Mittelalters 8, 1980, 65-127.

I. D. Cholakov/G. Atanasov: A hoard of late Roman metalwork from Belokopitovo, Shumen district. In: L. Vagalinski (ed.): The Lower Danube in Antiquity (VI C BC - VI C AD). Acta of International Archaeological Conference, Bulgaria-Tutrakan 06-07.10.2005. Sofia 2007, 257-264.

J. Ilkjær: Illerup Ådal 2. Die Lanzen und Speere. Textband. Århus 1990.

V. Ivanišević/P. Špehar: Early Byzantine finds from Čečan and Gornji Streoc (Kosovo). Starinar 55, 2005, 133-159.

M. Ivanovski: The Grave of a Warrior from the Period of Licinius I found at Taraneš. Archaeologia Iugoslavica 24, 1987, 81-90.

P. Jablonka: Die Gurina bei Dellach im Gailtal. Aus Forschung und Kunst 33. Klagenfurt 2001.

G. Jacobi: Werkzeug und Gerät aus dem Oppidum von Manching. Die Ausgrabungen in Manching. Band 5. Frankfurt am Main 1974. 
Jílek 2012

Jílek/Lamprecht 2020

John/Stolz 2012

Jiř́k 2008

Junkelmann 2006

Kaczanowski 1995

Kapeller 2003

Keller 1846-1847

Kellner/Zahlhaas 1993

Klčo/Krupa 2008

Knaack 1978

Koch 1988

Koch 1991

Kolčin 1953

Koller/Doswald 1996

Kolon 2015

Komoróczy 2000

Korený 1998

Korený, im Druck

Korený u. a., in Vorbereitung

Korený/Frána/Fikrle 2011

Koster 1997

Kotýnek 2018

Krause/Limpach/Spehr 1966

Krupa/Klčo 2015

Kramarkowa 1990

Kunow 1983
J. Jílek: Bronzové nádoby z doby římské na Moravě a naddunajské části Dolního Rakouska. Pardubice 2012.

J. Jílek/A. Lamprecht: Žárový bojovnický hrob ze sklonku starší doby římské z Vlkova nad Lesy, okr. Nymburk. Archeologie východních Čech 18, 2020, 30-49.

J. John/D. Stolz: Výsledky průzkumu hradiště Pišták u Řevnic (okr. Praha-západ). Archeologie západních Čech 3, 2012, 50-53.

J. Jiřík: Ein Beitrag zur Erforschung der Besiedlung Ost- und Nordostböhmens während der späten Kaiserzeit- und der frühen Völkerwanderungszeit. In: B. Niezabitowska-Wiśniewska u. a. (eds.): The Turbulent Epoch. New Materials from the Late Roman Period and the Migration Period. Monumenta Studia Gothica V. Lublin 2008, 157-177.

M. Junkelmann: Panis militaris. Die Ernährung des römischen Soldaten oder der Grundstoff der Macht. Mainz 2006.

P. Kaczanowski: Klasyfikacja grotów broni drzewcowej kultury przeworskiej. Kraków 1995.

A. Kapeller: La vaiselle en bronze d'Avenses/Aventicum. Bulletin de l'Association Pro Aventico 45, 2003, 83-146.

F. Keller: Beschreibung der helvetischen Heidengräber und Totenhügel welche seit dem Jahre 1836 eröffnet worden. Mitteilungen des Antiquarischen Gesellschaft in Zürich 3, 1846-1847, 11-37.

H. J. Kellner/G. Zahlhaas: Der Römische Tempelschatz von Weißenburg i. Bay. Mainz am Rhein 1993.

M. Klčo/V. Krupa: Hroby z doby st’ahovania národov z Krakovan-Stráží. Pieštany 2008.

A. Knaack: Beobachtungen an Scherenbeigaben in Gräbern des elbgermanischen Siedlungsgebietes während der römischen Kaiserzeit. Ethnographisch-Archäologische Zeitschrift 19, 1978, 15-50.

U. Koch: Ein Depotfund vom Runden Berg: Gerätschaften eines alamannischen Wirtschaftsbetriebes der Terrassensiedlung. Archäologisches Korrespondenzblatt 18, 1988, 205-208.

U. Koch: Der Runde Berg bei Urach VII. Frühgeschichtliche Funde von den Hängen und Terrasen und Nachträge zu Urach V und VI. Heidelberg 1991.

B. A. Kolčin: Černaja metallurgija i metalloobrabotka v Drevnej Rusi. Materialy i issledovanija po archeologii SSSR (MIA) 32. Moskva 1953.

H. Koller/C. Doswald: Aquae Helveticae - Baden. Veröffentlichungen der Gesellschaft Pro Vindonissa XIII. Brugg 1996.

T. Kolon: Príspevok k možnostiam identifikácie rituálnych činností na germánskych sídliskách. Vybrané problémy. In: L. Tyszler/E. Droberjar (eds.): Archeologia barbarzyńców 2014. Barbari superiores et inferiores. Łódź - Wieluń 2015, 497-508.

B. Komoróczy: Panzerschuppentypen aus der römischen Befestigungsanlage am Burgstall bei Mušov. In: J. Bouzek/H. Friesinger/K. Pieta/B. Komoróczy (Hrsg.): Gentes, Reges und Rom. Auseinandersetzung - Anerkennung - Anpassung. Spisy AÚ AV ČR Brno 16, 2000, 79-86.

R. Korený: Dobříšs, okr. Př́ibram. Výzkumy v Čechách 7, 1998, 41.

R. Korený: Středověké nákončí pochvy meče z Voznice, okr. Př́ibram a několik kritických poznámek k nálezům středoevropské skupiny. In: Sborník věnovaný M. Slivkovi, im Druck.

R. Korený u. a.: Nové jednotlivé nálezy z eneolitu až doby halštatské na Př́bramsku. Př́spěvek k environmentálnímu výzkumu vybraných kovových předmětů, in Vorbereitung.

R. Korený/J. Frána/M. Fikrle: Nové poznatky o střední až pozdní době bronzové na Příbramsku. Archeologie ve středních Čechách 15, 259-265.

A. Koster: The Bronze Vessels 2. Description of the Collections in the Provinciaal Museum G. M. Kam at Nijmegen XIII. Acquisitions 1954-1996 (including vessels of pewter and iron). Nijmegen 1997.

M. Kotýnek: Laténské nálezy z hradiště Karlovice - Čertova ruka. Diplomarbeit. Hradec Králové Universität. Hradec Králové 2018. Unpubliziert.

G. Krause/R. Limpach/R. Spehr: Ein spätkaiserzeitlich-völkerwanderungszeitlicher Hortfund mit Eisengeräten von Radeberg-Lotzdorf, Kreis Dresden. Arbeitsund forschungsberichte zur sächsischen Bodendenkmalpflege 14/15, 1966, 159-219.

V. Krupa/M. Klčo: Bohaté hroby z doby rímskej z Krakovian-Stráží. Pieštany 2015.

I. Kramarkowa: Groby książęce z III/IV w. n. e. we Wrocławiu-Zakrzowie. w stulecie odkryć. Silesia antiqua 32, 1990, 61-174.

J. Kunow: Die römische Import in der Germania Libera bis zu den Markomannenkriege. Studien zu Bronze- und Glassgefässe. Neumünster 1983. 
Künzl 1993

Laharnar 2009

Lang u. a. 2010

Leconte 2013

Lička 1969

Lindeberg 1973

Lindenthal/Rupp 2000

Lund 2008

Lund Hansen 1987

Lutovský 2001

Lutovský 2005

Lutovský/Slabina 2004

Lüdin/Sitterding/Steiger 1962 Maddin/Hauptmann/Baatz 1991

Machara 2016

Manning 1983

Manning 1985

Metzler u. a. 1991

Meyer 1971

Meyer 1976

Miglbauer 1994

Miks 2007

Mylashevskyi/Pryszczepa/Wojtiuk 2018

Myrberg 2009

Nenova/Angelov 1999

Neustupný 1936

Nothdurfter 1979
E. Künzl: Die Alamannenbeute aus dem Rhein bei Neupotz. Plünderungsgut aus dem Römischen Gallien. Monographien-Römisch-Germanisches Zentralmuseum Mainz 34. Mainz 1993.

B. Laharnar: The Žerovnišček Iron Age hillfort near Bločice in the Notranjska region. Arheološki vestnik 60, 2009, 97-157.

R. Lang/A. Drack/G. Fitz/R. Ployer/A. Steiner: Depot- und Siedlungsfunde den späten römischen Kaiserzeit aus dem Karth im südlichen Niederösterreich. Römische Österreich 33, 2010, 43-111.

L. Leconte: L'instrumentum métallique lié à la cuisine en Gaule romaine. Gallia 70, 2013, 233-251.

M. Lička: Sklad železných předmětů pozdní doby římské z Opolan (o. Nymburk). Archeologické rozhledy 21, 1969, 681-684.

I. Lindeberg: Die Einfuhr römischen Bronzegefässe nach Gotland. Saalburg-Jahrbuch 30, 1973, 5-70.

J. Lindenthal/V. Rupp: Reiche Villengräber in der Wetterau. In: L. Wamser (ed.): Die Römer zwischen Alpen und Nordmeer. Zivilisatorisches Erbe einer europäischen Militärmacht. Katalog-Handbuch zur Landesausstellung des Freistaates Bayern, Rosenheim. Mainz 2000, 171-175.

J. Lund: Banks, Borders and Bodies of Water in a Viking Age Mentality. Journal of Wetland Archaeology 8, 2008, 53-72.

U. Lund Hansen: Römischer Import im Norden. Nordiske Fortidsminder. Serie B 10. København 1987.

M. Lutovský: Encyklopedie slovanské archeologie v Čechách, na Moravě a ve Slezsku. Praha 2001.

M. Lutovský: Raně středověké nálezy ze sbírky F. C. Friedricha. In: M. Metlička (ed.): Archeologie doby hradištní v Čechách. Plzeň 2005, 126-133.

M. Lutovský/M. Slabina: Archeologické dílo Františka C. Friedricha. Archeologie ve středních Čechách 8, 2004, 9-64.

O. Lüdin/M. SitterdingR. Steiger: Ausgrabungen in Augst II. Insula 24. Basel 1962. R. Maddin/A. Hauptmann/A. Baatz: A metallographic examination of some iron tools from the Saalburgmuseum. Saalburg-Jahrbuch 46, 1991, 5-23.

F. Machara: Depoty z doby laténské na území bývalého Československa. Bachelorarbeit. Universität Pardubice, Fakultät Philosophisch. Pardubice 2016. Unpubliziert.

W. H. Manning: The Cauldron Chains of Iron Age and Roman Britain. In: B. Hartley/J. Wacher (eds.): Rome and her northen Provinces. London 1983, 132-154. W. H. Manning: Catalogue of the Romano-British Iron Tools, Fittings and Weapons in the British Museum. London 1985.

J. Metzler u. a.: Clemency et les tombes de l'aristocratie en Gaule Belgique. Luxembourg 1991.

E. Meyer: Die germanischen Bodenfunde der spätrömischen Kaiserzeit und der frühen Völkerwanderungszeit in Sachsen. I. Katalog. Arbeits- und Forschungsbericht zur sächsischen Bodendenkmalpflege Beiheft 9. Berlin 1971.

E. Meyer: Die germanischen Bodenfunde der spätrömischen Kaiserzeit und der frühen Völkerwanderungszeit in Sachsen. II. Text. Arbeits- und Forschungsbericht zur sächsischen Bodendenkmalpflege Beiheft 11. Berlin 1976.

R. Miglbauer: Ein römerzeitlicher Verwahrfund aus Wels. Oberösterreich. Akten der 10. Internationalen Tagung über antike Bronzen. Forschungen und Berichte zur vorund frühgeschichte in Baden-Württemberg 45. Stuttgart 1994, 285-291.

Ch. Miks: Studien zur römischen Schwertbewaffnung in der Kaiserzeit. Kölner Studien zur Archäologie der römischen Provinzen 8. Text, Katalog und Tafeln. Rahden 2007.

O. Mylashevskyi/B. Pryszczepa/O. Wojtiuk: Eine Einzelbestattung der WielbarkKultur beim Dorf Samostríli, Rívne obl. In: B. Niezabitowska-Wiśniewska u. a. (eds.): Studia barbarica I. Profesorowi Andrzejowi Kokowskiemu w 65. rocznicę urodzin. Lublin 2018, 202-211.

N. Myrberg: The Hoarded Death. Late Iron Age hoards as grave. In: I. M. Danielsson u. a. (eds.): On The Treshold: Burial Archaeology in the twenty-first century. Stockholm 2009, 131-145.

R. Nenova/A. Angelov: A rich Thracian's grave from Marcianopolis. Archaeologia Bulgarica 3/2, 1999, 49-59.

J. Neustupný: Příspěvky k době stěhování národů v Karpatské kotlině. Obzor Praehistorický 9, 1936, 11-32.

J. Nothdurfter: Die Eisenfunde von Sanzeno im Nonsberg. Römisch-germanische Forchschungen 38. Mainz 1979. 
Oesterwind 1989

Ondrouch 1957

Osterhaus 1985

Pauli Jensen 2008

Penack 1993

Peška/Tejral 2002

Petrovszky 2006

Petrovszky/Bernhard 2016

Pflaum 2007

Piaskowski 1958

Piaskowski 1959

Pič 1903

Pieta 2002

Pieta 2020

Pietsch 1983

Planck 1983

Pleiner 1962

Pleiner 1982

Ployer 2006

Pohanka 1986

Pollak 2006

Prammer 1993

Pribyl/Schmidt 1944

Prostředník 2015
B. C. Oesterwind: Die Spätlatènezeit und die frühe Römische Kaiserzeit im Neuwieder Becken. Bonner Hefte zur Vorgeschichte 24. Bonn 1989.

V. Ondrouch: Bohaté hroby z doby rímskej na Slovensku. Bratislava 1957.

U. Osterhaus: Zwei römische Brunnen aus einer Villa rustica in Regensburg-Harting. Das archäologische Jahr in Bayern 1984, 1985, 115-118.

X. Pauli Jensen: Våben fra Vimose - bearbejdning og tolkning af et gammelkendt fund. Doktorarbeit. Det Humanistiske Fakultet Københavns Universitet. København 2008. Unpubliziert.

J.-J. Penack: Die eisernen eisenzeitlichen Erntegeräte im freien Germanien. BAR International Series 583. Oxford 1993.

J. Peška/J. Tejral: Das Königsgrab aus der älteren römischen Kaiserzeit von Mušov, Mähren (Tschechische Republik). Monographien des Römisch-Germanischen Zentralmuseums Mainz 55. Mainz 2002.

R. Petrovszky: Der Hortfund von Hagenbach. In: J. Stadler (red.): Geraubt und im Rhein versunken. Der Barbarenschatz. Speyer - Stuttgart 2006.

R. Petrovszky/H. Bernhard: Versunken im Rhein - Typenspektren der „Beutehorte“ im Vergleich. In: H. U. Voss/N. M. Scheessel (eds.): Archäologie zwischen Römern und Barbaren. Zur Datierung und Verbreitung römischer Metallarbeiten des 2. und 3. Jahrhunderts n. Ch. im Reich und im Barbaricum-ausgewählte Beispiele (Gefässe, Fibeln, Bestandteile militärischer Ausrüstung, Kleingerät, Münzen). Teil I. Kolloquien zur Vor- und Frühgeschichte. Band 22. Frankfurt am Main - Bonn 2016, 245-260.

V. Pflaum: The supposed the Late Roman hoard of tools and a steelyard from Vodice near Kalce. Arheološki vestnik 58, 2007, 285-332.

J. Piaskowski: Metaloznawcze badania zabytków archeologicznych z Wyciąża, Igołomni, Jadownik Mokrych i Piekar. Studia z Dziejów Górnictwa i Hutnictwa 2, 1958, 7-98.

J. Piaskowski: Metaloznawcze badania wczesnośredniowiecznych wyrobów żelaznych na przykładzie zabytków archeologicznych z Łęczycy, Czerchowa i Buczka. Studia z Dziejów Górnictwa i Hutnictwa 3, 1959, 7-102.

J. L. Píč: Starožitnosti země České II. Čechy na úsvitě dějin II. Hradiště u Stradonic jako historické Marobudum. Praha 1903.

K. Pieta: Anmerkungen zum Grab aus Čáčov. In: K. Kuzmová/K. Pieta/J. Rajtár (Hrsg.): Zwischen Rom und dem Barbaricum. Festschrift für Titus Kolník zum 70. Geburtstag. Nitra 2002, 343-354.

K. Pieta: Die frühvölkerwanderungszeitliche Höhensiedlung in Dolná Súča, Westslowakei. Slovenská archeológia 68, 2020, 37-68.

M. Pietsch: Die römischen Eisenwerkzeuge von Saalburg, Feldberg und Zugmantel. Saalburg-Jahrbuch 39, 1983, 5-132.

D. Planck: Das Freilichtmuseum am rätischen Limes im Ostalbkreis. Führer zu archäologischen Denkmälern in Baden-Württemberg 9. Stuttgart 1983.

R. Pleiner: Staré evropské kovářství. Praha 1962.

R. Pleiner: Untersuchungen zur Schmiedetechnik auf den keltischen Oppida. Památky archeologické 73, 1982, 86-173.

R. Ployer: Die ländliche Besiedlung zwischen Leitha und Leithagebirge in römischer Zeit. In: M. Pollak (ed.): Stellmacherei und Landwirtschaft: Zwei römische Materialhorte aus Mannersdorf am Leithagebirge, Niederösterreich. Fundberichte aus Österreich, Materialhefte Reihe A. Band 16. Wien 2006, 43-53.

R. Pohanka: Die eisernen Agrargeräte der Römischen Kaiserzeit in Österreich. Studien zur römischen Agrartechnologie in Rätien, Noricum und Pannonien. BAR International Series 298. Oxford 1986.

M. Pollak: Stellmacherei und Landwirtschaft: Zwei römische Materialhorte aus Mannersdorf am Leithagebirge, Niederösterreich. Fundberichte aus Österreich, Materialhefte Reihe A. Band 16. Wien 2006.

J. Prammer: Römische Siedlungspuren in der Donauniederung bei Kagers, Stadt Straubing, Niederbayern. Das Archäologische Jahr in Bayern 1992, 1993, 109-111.

R. Pribyl/H. Schmidt: Untersuchungen an zwei Sensenfunden aus Wels und Pichling. In: J. Zeitlinger (ed.): Sensen, Sensenschmiede und ihre Technik. Jahrbuch des Vereines für Landeskunde und Heimatpflege im Gau Oberdonau 91. Linz 1944, 174-178, Taf. 35; 36.

J. Prostředník: „Záchranný detektorový prĩzkum a konzervace kovových artefaktů z pravěkého hradiště a středověkoho hradu Čertova ruka na Hruboskalsku“. Výzkumná zpráva OLP/2378/2015. Dokumentace Archeologického odd. Muzea Českého ráje v Turnově. Turnov 2015. Unpubliziert. 
Půlpánová-Reszcyńska/Půlpán/Ondráčková 2018

A. Půlpánová-Reszcyńska/M. Půlpán/L. Ondráčková: Depot zbraní z doby římské v krušnohorské Hrádečné, okr. Chomutov. Archeologické rozhledy 70, 2018, 554-595.

Quast 2011

Rieckhoff 1997

Rothkegel 1994

Roymans/Scheers 2012

Sauer 1994

Sedlmayer 1999

Sedlmayer 2016

Seitz 1999

Semykin 2015

Schindlerová 2016

Schönfelder 2009

Schmidt 1976

Schmidts 2004

Schönberger 1967

Schulze-Dörrlamm 1985

Schwab 2002

Schwarz 1967

Smejtek 2005

Soukal 1936

Spors-Gröger 2005

Steuer 2006
D. Quast: Symbolic Treasures in Barbarian Burials ( $3^{\text {rd }}-7^{\text {th }}$ century AD). In: I. Baldini Lippolis/A. Lina Morelli (eds.): Oggetti-simbolo: produzione, uso e significato nel mondo antico. Ornamenta 3. Bologna 2011, 253-268.

S. Rieckhoff: „Römische Schatzfunde“ - ein historisches Phänomen aus prähistorischer Schicht. In: Internationale archeologie. Studia Honoraria 3. Tradition und innovation. Festschrift für Christian Strahm. Rahden 1997, 479-542.

R. Rothkegel: Der römische Gusthof von Laufenburg/Baden. Forschungen und Berichte zur Vor- und Frühgeschichte in Baden-Württemberg 43. Stuttgart 1994.

N. Roymans/S. Scheers: Eight gold hoards from Low Countries. A synthesis. In: N. Roymans/G. Creemers/S. Scheers (eds.): Late Iron Age Gold Hoards from Low Countries and the Caesarian Conquest of Northern Gaul. Amsterdam 2012, 1-46.

F. Sauer: Eine germanische Siedlung mit Depotfund in der KG Hanfthal, Niederösterreich. In: H. Friesinger/J. Tejral/A. Stuppner (Hrsg.): Markomannenkriege. Ursachen und Wirkungen. Spisy Archeologického ústavu AV ČR Brno 1, 1994, 263-283.

H. Sedlmayer: Die römischen Bronzegefäße in Noricum. Monographies Instrumentum 10. Montagnac 1999.

H. Sedlmayer: Die Spektren römischer Bronzegefässe in Noricum und dem angrenzenden Barbaricum im Vergleich - Typen 2./3. Jahrhunderts n. Chr. In: H. U. Voss/N. M. Scheessel (eds.): Archäologie zwischen Römern und Barbaren. Zur Datierung und Verbreitung römischer Metallarbeiten des 2. und 3. Jahrhunderts $n$. Ch. im Reich und im Barbaricum - ausgewählte Beispiele (Gefässe, Fibeln, Bestandteile militärischer Ausrüstung, Kleingerät, Münzen). Teil I. Kolloquien zur Vor- und Frühgeschichte. Band 22/1. Frankfurt am Main - Bonn 2016, 379-397.

G. Seitz: Rainau-Buch I. Steinbauten im römischen Kastellvicus von Rainau-Buch (Ostalbkreis). Forschungen und Berichte zur Vor- und Frühgeschichte in Baden-Württemberg 57. Stuttgart 1999.

Ju. A. Semykin: Cernaja metallurgija i kuznečnoe proizvodstvo Volžskoj Bulgarii v VIII načale XIII vv. Serija "Archeologija evrazijskich stepej“. Vypusk 21. Kazan' 2015.

P. Schindlerová: Depoty doby rímskej z oblasti stredoeurópskeho barbarika. Brno. Diplomarbeit. Masaryk-Universität. Brno 2016. Unpubliziert.

M. Schönfelder: Zu den Herdgeräten aus dem kaiserzeitlichen Prunkgrab von Mušov. In: S. Grunwald u. a. (eds.): ARTeFACT. Festschrift für Sabine Rieckhoff zum 65. Geburtstag. Universitätsforschungen zur prähistorischen Archäologie 172/2. Bonn 2009, 773-787.

B. Schmidt: Die späte Völkerwanderungszeit in Mitteldeutschland. Katalog (Nord- und Ostteil). Veröffentlichungen des Landesmuseums für Vorgeschichte in Halle 29. Berlin 1976.

T. Schmidts: LOPODUNUM IV. Die Kleinfunde aus den römischen Häusern an der Kellerei in Ladenburg. Forschungen und Berichte zur Vor- und Frühgeschichte in Baden-Württemberg 91. Stuttgart 2004.

H. Schönberger: Ein Eisendepot, römische Floßfesseln und andere Funde im Bereich des Kastells Heilbronn-Böckingen. Fundberichte aus Schwaben. Neue Folge 18, 1967, 131-151.

M. Schulze-Dörrlamm: Germanische Kriegergräber mit Schwertbeigabe in Mitteleuropa aus dem späten 3. Jahrhundert und der ersten Hälfte des 4. Jahrhunderts n. Chr. Jahrbuch des Römisch-Germanischen Zentralmuseums Mainz 32, 1985, 509-569. R. Schwab: Evidence for carburized steel and quench-hardening in the 'Celtic' oppidum of Manching. Historical Metallurgy 36, 2002, 6-16.

K. Schwarz: Die Bodendenkmalpflege in Bayern in den Jahren 1964 und 1965. Jahresbericht der Bayerischen Bodendenkmalpflege 6/7, 1967, 145-168.

L. Smejtek: Hradiště a archeologické nálezy. In: V. Cílek u. a. (eds.): Střední Brdy. Př́ibram 2005, 179-200.

J. Soukal: Z musea novobenátecka. Náš kraj 15, 1936, 4.

S. Spors-Gröger: Germanische Herrschaftssitze nördlich und östlich des Schwarzwaldes. In: M. Geiberger/A. Stute/A. Hofmann (red.): Imperium Romanum. Römer, Christen, Alamannen - Die Spätantike am Oberrhein. Karlsruhe 2005, 210-218.

H. Steuer: Fürstengräber, Adelsgräber, Elitagräber: Methodisches zur Anthropologie der Prunkgräber. In: C. von Carnap-Bornheim/D. Krausse/A. Wesse (eds.): Herrschaft-Tod-Bestattung. Universitätsforschungen zur Prähistorischen Archäologie 139. Bonn 2006, 11-25. 
Svoboda 1965

Szameit 1997

Šach 1961

Šnajdr 1906

Tejral 2015

Tejral 2016

Tomasevic-Buck 1980

Tomasevic-Buck 1984

Trňáčková 1985

Tschumi 1930

Turek 1982

Tylecote/Gilmour 1986

Ulbert 1974

Ulrich/Heizmann 1890

Urbanová/Kostka/Korený 2010

Varsik 2017

Vích/Jílek 2016

Vích u. a. 2018

Vích u. a. 2020

Voss 2006

Voznesens'kal Nedopako/Pan'kov 1986

Wagner 1897

Wagner/Haug 1911

Waldhauser 1990

Waldhauser 1996

Waldhauser/Košnar 1997
B. Svoboda: Čechy v době stěhování národů. Monumenta archaeologica XIII. Praha 1965.

E. Szameit: Ein völkerwanderungszeitliches Werkzeugdepot mit Kleinfunden aus Niederösterreich. Ein Vorbericht. In: J. Tejral/H. Friesinger/M. Kazanski (Hrsg.): Neue Beiträge zur Erforschung der Spätantike im mittleren Donauraum. Spisy AÚ AV ČR Brno 8. Brno 1997, 233-248, 253-256.

F. Šach: Rádlo a pluh na území Československa. Část I. Nejstarší orební nářadí. Vědecké práce Zemědělského muzea ČSAZV 1961, 1961, 25-155.

L. Šnajdr: Nálezy u Přerova n. Labem. Památky archeologické 1904, 1906, 139-144. Tejral: Zum Problem der Feinschmiedeproduktion im Mitteldonauraum während des 5. Jahrhunderts nach Chr. Památky archeologické 106, 2015, 291-362.

J. Tejral: Die Metallgefässausstattung des Königsgrabes von Mušov in Mähren im Vergleich mit früh- und spätkaiserzeitlichen Elitengräbern. In: H. U. Voss/ N. M. Scheessel (eds.): Archäologie zwischen Römern und Barbaren. Zur Datierung und Verbreitung römischer Metallarbeiten des 2. und 3. Jahrhunderts n. Ch. im Reich und im Barbaricum - ausgewählte Beispiele (Gefässe, Fibeln, Bestandteile militärischer Ausrüstung, Kleingerät, Münzen). Teil I. Kolloquien zur Vor- und Frühgeschichte. Band 22. Frankfurt am Main - Bonn 2011, 271-307.

T. Tomasevic-Buck: Ein Depotfund in Augusta Raurica, Insula 42. Forschungen in Augst 4. Augst 1980.

T. Tomasevic-Buck: Ein Bronzedepotfund aus Augusta Raurica (Dorfstraße 1, Kaiseraugst, Kt. Aargau). Bayerische Vorgeschichtsblätter 49, 1984, 143-196.

Z. Trňáčková: Ein Hortfund von Metallgegenständen aus der späten Kaiserzeit und frühen Völkerwanderungszeit aus Mušov. Památky archeologické 75, 1985, $279-284$.

O. Tschumi: Grab, Haus und Herd in der Urzeit. Germania 14, 1930, 121-139.

R. Turek: Čechy v raném středověku. Praha 1982.

R. F. Tylecote/B. J. J. Gilmour: The Metallography of Early Ferrous Edge Tools and Edged Weapons. BAR British Series 155. Oxford 1986.

G. Ulbert: Straubing und Nydam. Zu römischen Langschwertern der späten Limeszeit. In: G. Kossack/G. Ulbert (Hrsg.): Studien zur vor- und frühgeschichtlichen Archäologie: Festschrift für Joachim Werner zum 65. Geburtstag. Münchner Beiträge zur Vor- und Frühgeschichte. Ergänzungsband 1. München 1974, 197-216.

R. Ulrich/A. Heizmann: Catalog der Sammlungen der antiquarischen Gesellschaft in Zürich II. Griechisch-Italisch-Römische Abtheilung. Zürich 1890.

K. Urbanová/M. Kostka/R. Korený: Neznámý známý hrob XIV z Prahy-Dejvic Podbaby. Archaeologica Pragensia 20, 2010, 361-392.

V. Varsik: Niekol'ko poznámok k výskytu spôn s hrotitou nôžkou na juhozápadnom Slovensku (skupina Almgren VI, 2). In: E. Droberjar/B. Komoróczy (eds.): Řimské a germánské spony ve střední Evropě. Archeologie barbarů 2012. Spisy AÚ AV ČR Brno 53. Brno 2017, 321-337.

D. Vích/J. Jílek: Hrob nebo depot? Nález z doby římské u Jevíčka (okr. Svitavy). Archeologické rozhledy 68, 2016, 363-380.

D. Vích/M. J. Biborski/M. R. Biborski/J. Jílek/J. Stępiński/J. Martínek: Nálezy mečů protohistorického období z Křenova na Svitavsku. Archeologické rozhledy 70, 2018, 526-553.

D. Vích/J. Jílek/J. Kmošek/M. J. Biborski/M. R. Biborski/J. Martínek: Soubor kovových předmětů z doby římské z Boršova na Moravskotřebovsku. Památky archeologické 111, 2020, 159-192.

H. U. Voss: Hagenow in Mecklenburg - ein frühkaiserzeitlicher Bestattungsplatz und Aspekte der römisch-germanischen Beziehungen. Bericht der RömischGermanischen Kommission 86, 2005, 19-59.

G. A. Voznesens'ka/D. P. Nedopako/S. V. Pan'kov: Čorna metalurgija ta metaloobrobka naselennja schidnojevropejs'kogo lisostepu za doby rannich slovjan ta Kijivs'koji Rusi. Kyjiv 1986.

E. Wagner: Karlsruhe, Grossherzogl. Sammlungen für Altertums- und Völkerkunde I. Westdeutsche Zeitschrift für Geschichte und Kunst 16, 1897, 325-326.

E. Wagner/F. Haug (Hrsg.): Fundstätten und Funde aus vorgeschichtlicher, römischer und alamannisch-fränkischer Zeit im Großherzogtum Baden. Band 2. Tübingen 1911.

J. Waldhauser: Problematika depotu laténských železných předmětů z Kolína (Příspěvek k metodice archeologické analýzy). Archeologické fórum 1, 1990, 74-83. J. Waldhauser: Keltové na Jizeře a v Českém ráji. Praha 1996.

J. Waldhauser/L. Košnar: Archeologie Germánu v Pojizeří a v Českém ráji. Praha 1997. 
Werner 1938

Wielowiejski 1985

Willer 2005

Willer 2006

Willmy 2008

Zav'jalov/Rozanova/Terechova 2012

Zeitlinger 1944

Zeman u. a. 2017
J. Werner: Die römischen Bronzegeschirrdepots des 3. Jahrhunderts und die mitteldeutsche Skelettgräbergruppe. In: E. Sprockhoff (Hrsg.): Marburger Studien. Darmstadt 1938, 259-267.

J. Wielowiejski: Die spätkeltischen und römischen Bronzegefäße in Polen. Bericht der Römisch-Germanische Kommision 66, 1985, 123-320.

F. Willer: Restaurierung und Experiment - Zu den römischen Sensen aus Dormagen. In: Von Anfang an. Archäologie in Nordhein-Westfalen. Köln 2005, 411, 412.

F. Willer: Beobachtungen zur antiken Herstellungstechnik. In: R. Petrovszky u. a. (eds.): Geraubt und im Rhein versunken. Der Barbarenschatz. Speyer 2006, 176-181.

A. Willmy: Schmieden, gießen, zieren, flicken. Das Metallhandwerk. In: D. Ade/ B. Rüth/A. Zekorn (Hrsg.): Alamannen zwischen Schwarzwald, Neckar und Donau. Stuttgart 2008, 116-119.

V. I. Zav'jalov/L. S. Rozanova/N. N. Terechova: Tradicii i innovacii v proizvodstvennoj kul'ture severnoj Rusi. Moskva 2012.

J. Zeitlinger: Sensen, Sensenschmiede und ihre Technik. Jahrbuch des Vereines für Landeskunde und Heimatpflege im Gau Oberdonau 91, 1944, 13-178.

T. Zeman u. a.: Střední Pomoraví v době řimské. Svědectví povrchové prospekce. Archaeologica Olomucensia II. Olomouc 2017.

\title{
Depoty kovových předmětů z mladší až pozdní doby římské v Čechách
}

\author{
Rastislav Korený - Petra Jánská - Jiří Hošek - Jan Jílek
}

Souhrn

Předmětem předkládané studie jsou zčásti nové a zčásti již dřive odkryté, ale dosud podrobně nezhodnocené depoty z doby římské ze středních Čech. Do první skupiny patří depot z Rosovic (okr. Př́íbram). Tento depot zásadně pomohl k přehodnocení a novému datování staršího nálezu z Let u Dobřichovic (okr. Beroun), který je dosud řazen do 6.-7. stol. Vůbec poprvé byl podrobně posouzen také depot z Benátek nad Jizerou (okr. Mladá Boleslav), dosud mylně datovaný vesměs do pozdně laténského období. Součástí příspěvku je též archeometalurgická analýza kos z Rosovic a dokumentace experimentu jejich výroby. Studie v širokém záběru zásadně doplňuje dosavadní soupisy depotů z území Čech doby římské, které již byly uveřejněny na jiných místech, zároveň také předkládá hypotézu o distribuci ř́mských dlouhých kos na českém území.

\section{Rosovice, okr. Příbram}

Kosy byly nalezeny s pomocí detektoru kovů 2. května 2015 v lesním porostu na mírně zvlněném plató jihozápadně od osady Trnová (obr. 1). Kosy byly uloženy v jámě o rozměrech přibližně $80 \times 30 \mathrm{~cm}$, první v hloubce 10 a druhá $25 \mathrm{~cm}$, s orientací SV - JZ. Jedna kosa ležela naplocho, se špičkou v hloubce $10 \mathrm{~cm}$ a ostřím natočeným k druhé kose, druhá kosa byla otočená s ostřím a rukojetí/trnem vzhůru (obr. 2). Jejich tvar odpovídá dlouhým kosám typu 4 podle třídění B. Hanemannové $(2014,193$, obr. 171).

Do této skupiny náleží 26 exemplářů z 16 lokalit, které lze datovat do průběhu 2.-4. stol. (obr. 4-6), byt๋ u některých probíhá ohledně datování diskuse.

Nejnověji se některým kosám tohoto typu věnovala A. Bartoli, která je datuje do 4. až 5. stol. (Bartoli 2017, 325, pozn. 5), což je podle současných poznatků nereálné a naopak odráží situaci, kdy kosy tohoto typu se už nejen nepoužívaly, ale navíc všechny známé kusy byly již deponovány.

Nejstarším exemplářem je celá kosa z kastelu Regensburg-Kumpfmühl (tabela 1). Z kastelu/vicu v Rainau-Buch, vile v Regensburg-Hartingu a kastelu ve Weißenburgu pochází osm nepoškozených kos. V prvním případě byl zánikový horizont obou studní, ve kterých byly kosy uloženy, dendrochronologicky datován k r. 254, na druhé lokalitě byla dřevěná studna vyhloubena r. 232 a zasypána v polovině 3. stol., kastel ve Weißenburgu zanikl v 1. 251/253. Významné je, že v prvních dvou případech byly kosy deponovány v jednom okamžiku a společně s další výbavou usedlosti (neboli $\mathrm{v}$ „živém kontextu“). Oba depoty tedy, do jisté míry, zakonzervovaly autentický obrázek o výbavě usedlostí. Tato data současně naznačují, že produkce kos tohoto typu byla s velkou pravděpodobností zahájena až ve druhém stol. Jejich výroba pak v této části hranice skončila patrně v souvislosti s pádem hornogermánsko-raetského limitu v r. 260. Dalšími 
chronologickými oporami jsou depot/hrob z Benkenu a depot (?) z Monatshausenu z 3. stol. Ovšem tyto soubory byly uloženy mimo sídliště (t. j. „živý kontext") a ve velmi redukovaném složení, což se týká i počtu kos - pouze po jednom kuse, byt’ se stále jedná o celé, či téměř celé exempláře. V dalších depotech se kosy nacházely už víceméně poškozené, opravované, či ve fragmentárním, př́íp. reutilizovaném stavu - data shrnujeme ve schématu „životního cyklu“ kos 4. typu (obr. 8).

Obě rosovické kosy byly podrobeny metalografickému průzkumu s cílem stanovit způsob jejich výroby a údržby. Bylo prokázáno, že čepele obou jsou z kvalitní oceli o zhruba eutektoidním obsahu uhlíku. Nebyly kaleny, byt’ ochlazení z kovacích teplot mohlo být poměrně rychlé. Jelikož ostř́i jedné z čepelí nese známky intenzivního tváření za studena, je zřejmé, že vysoká ostrost těchto kos byla dosahována občasným naklepáváním kladívkem a častým přebrušováním kamenným brouskem. Čepele byly kovářsky navařeny na řapy, jejichž materiál očividně nepodléhal přísnějšímu výběru. Lze shrnout, že rosovické kosy vyžadovaly stejnou údržbu, jakou vyžadují kosy současné.

Z hlediska zachování originálů do budoucna bylo přistoupeno k výrobě kopií kos z Rosovic, což znamenalo též experimentální ověření pracovní náročnosti a času nutného k vyrobení jedné kosy a funkční vyzkoušení a posouzení práce s uvedeným typem kos. Výroba jedné kosy trvala asi 30 hodin. V době římské, s ohledem na praxi kováře, zhotovení jedné kosy vyžadovalo asi 20 hodin.

\section{Lety u Dobřichovic, okr. Praha-západ}

Depot byl nalezen náhodně bez př́tomnosti archeologa, neznáme tedy přesně uložení, stav a počet předmětů při odkrytí, stav před jejich konzervací F. C. Friedrichem a nynější stav. V současnosti jsou totiž k dispozici pouze bronzové nádoby, železné předměty se nepodařilo dohledat a jsou zřejmě nezvěstné od roku 1967, kdy byl depot předán do Národního muzea (obr. 15; Lutovský 2005, 126; Lutovský/Slabina 2004, 30). Ke studiu byly proto k dispozici pouze nádoby, několik fotografií, kreseb železných předmětů a v současnosti velmi cenná kolekce dentakrylových odlitků jedenácti železných předmětů.

Depot byl odkryt při stavbě nového mostu přes Berounku a navazující komunikace (dnešní Pražská ulice) v letech 1936-1937; údajně př́mo vedoucím stavby (silnice?) p. Kratochvílem při stavbě silnice k novému mostu v roce 1936. Okolnosti nálezu jen nedokonale ve svém deníku zachytil F. C. Friedrich. Týž zachráněné předměty od Kratochvíla převzal a později konzervoval (Friedrich 1946, 40). Přesné místo nálezu však nebylo zaznamenáno. Přibližným vodítkem by mohlo být datum předání nálezu (9. července 1936). O tři dny dříve (tj. 6. července) byla uvedeného dne v prostoru „za vilou dr. Babičky“ porušena štítarská jáma (Lutovský/Slabina 2004, 30). Babičkova vila, dnes č. 65, se nachází v ̌̌evnické ulici. Objekt samotný stojí na svahu řiční terasy, svažující se přímo k Berounce. Depot byl tedy nalezen pravděpodobně na ploše terasy, vymezené ulicemi Pražskou, Řevnickou a př́íčnou bezejmennou uličkou (obr. 16). Hromadný nález jako první zveřejnil F. C. Friedrich, podle propozic J. Eisnera jej zhodnotil jako slovanský a datoval do 6.-7. stol. Teprve J. Bubeník zpochybnil provenienci předmětů a naznačil jejich datování do intervalu doby římské a (či spíše) do doby stěhování národů (Bubeník/Pleinerová/Profantová 1998, 128, s literaturou). Náznak obratu nahlížení na tento nález však byl kategoricky negován M. Beranovou (Beranová/Lutovský 2009, 123).

Depot obsahoval kuchyňské náčiní: vědro (typ Eggers 43, obr. 17: 1), mísovitý kotel (typ NE 16, obr. 17: 2), talíř/pánev (typ NE 24a), pánev (typ Den Boesterd 91), trojnožku, závěs kotle, dvě tyčinky s očkem, kroužek; nástroje a nářadí: nůžky, dlouhou kosu, tři srpy, radlici, dvě sekery, lžícovitý vrták, koželužskou kosu a předměty nejistého určení. Podrobněji si povšimneme několika z nich:

Menší z popsaných nádob (obr. 17: 3) náleží k talíŕo̊m/pánvím typu NE 24a (Künzl 1993, 253, 254, tab. 18:NE 24a). Větší nádoba se sklopeným dnem je pánví typu Den Boesterd 91 (Den Boesterd 1956, 33, tab. IV: 91). Její funkci dokládá bronzový nýt uprostřed dna a korozní stopy po železné trojnožce, na kterou byla pánev připevněná již zmíněným nýtem (obr. 17: 4). Množství exemplářů je doloženo z depotů z třetího stol. (podrobně Bienert 2007, 173, 174; Kapeller 2003, 54, tab. 1: 2-5). Právě s pánvemi souvisí železný předmět, který F. Friedrich popsal jako „závěs kotle“ a toto určení je dodnes tradováno (obr. 19: 2; Beranová/Lutovský 2009, obr. 25). Ve skutečnosti se jedná o dlouhou třínožku pánve (např. Haberstroh 2000, 100, 158, tab. 35:1). Velké pozornosti se mezi předměty z letského depotu dostalo částečně dochované kose. Nejpodrobněji se jí při různých příležitostech věnovala M. Beranová (např. Beranová/Kubačák 2010, 165). Klasifikovala ji jako krátkou kosu a datovala do 6.-7. stol. (srov. Henning 1986, 137, obr. 4; 2005, obr. 1.6; 2009, 162, obr. 7). Významnou roli v chybné klasifikaci a datování hrají některé dosud přehlížené prvky, které odkazují na původní tvar předmětu. Z výše uvedeného tedy vyplývá i její datování do 2.-3. stol.

\section{Hypotéza společného původu depotů z Rosovic a Let u Dobřichovic}

V depotech, které byly tezaurovány během 3. stol., figurují kosy 4. typu v setech zpravidla po třech kusech. Část z nich byla uložena $v$ okamžiku zániku daného místa (vily, kastelu), nebo v čase bezprostředně předcházejícím (t. j. $\mathrm{v}$ tzv. živém kontextu). Nabízí se tedy hypotéza, že kosy byly v kastelech či venkovských vilách užívány většinou v sérii tři kusů, podobně, jako byly v určitých logických celcích užívány např. soupravy dlát, kladiv, seker apod. Užití tohoto modelu na venkově by nebylo nijak zvláštní, nebot' veteráni se zde hojně usazovali, čímž docházelo k přenosu určitých zvyklostí a norem (Ployer 2006).

Hypotéza „,tř́ kusůđ byla proto testována na širším vzorku depotů od Porýní až k pannonské části limitu (tabela 3). Nebyly brány v potaz depoty, které byly uloženy mimo území Římské říše, či sporné depoty. Z přehledu plyne, že 
u nálezů s více jak jednou kosou dominuje varianta 3 kusů, což dovoluje na daném území předpokládat jistou normu ve výbavě ř́mských usedlostí, vil či dokonce kastelů v průběhu 2.-4. stol.

Předchozí výklad nás přivádí $\mathrm{k}$ problematice dálkových komunikací v prostoru Brd. Donedávna platila obecně představa, že dálková trasa z jižních Čech vedla na Berounsko a do Pražské kotliny údolím Litavky. V posledních letech díky podrobnému terénnímu průzkumu (Bolina/Klimek/Cílek 2018, 454-464) a novým detektorovým nálezům je možné tuto tezi významně zpochybnit. Dálková komunikace vedla z prostoru starého brodu přes Berounku v Letech (Halama 2006, 338, obr. 1; 11: 3), pokračovala přes Řevnici, přičemž jedna z tras pak vedla kolem polykulturního hradiště Pišták (John/Stolz 2012) přes Hřebeny na Kytín a dále na jih k Voznici a Dobříši.

Nyní již můžeme formulovat následující hypotézu o společném původu rosovických kos a kosy z Let. K tomu nás vedou tyto důvody:

1. Kosy 4. typu byly v průběhu 2.-3. stol. na území provincií Raetia a Noricum zpravidla užívány v sériích po třech kusech (doloženy čtyři případy, obecně pak sedm případů: tabela 3).

2. Mimo uvedené provincie je jejich výskyt zcela ojedinělý a omezuje se zpravidla na jeden, obvykle již poškozený/ nefunkční exemplář. Můžeme tedy odvodit následující:

Mimořádné nálezy provinciálních dlouhých kos v barbariku, stejného typu, nadto od sebe vzdálených po předpokládané komunikaci přes Hřebeny pouhých $18 \mathrm{~km}$, jsou z těchto hledisek velmi nápadné. Výklad, že jsou stopami různých, na sobě zcela nezávislých událostí, je sice možný, ale málo pravděpodobný, a to tím spíše, že by se jednalo o opakování již tak mimořádně vzácného jevu na velmi malém území.

Pravděpodobnější je vysvětlení, podle kterého všechny tři kosy mají společný původ v inventáři blíže neidentifikovatelné vily či vojenského tábora na území provincií Raetia a Noricum. Někdy v intervalu mezi polovinou 3 . a během 4. stol. se kosy společně s dalšími předměty dostaly na území barbarika (ovšem depot v Letech nemusí být ve finální podobě shodný s konvolutem předmětů, odvezených z provincií). Tam byly nejpozději ve 4. stol., nejprve poblíž pravěké stezky vedoucí přes Hřebeny zakopány dvě kosy, třetí kosa až s jistým časovým odstupem v prostoru brodu přes Berounku u předpokládaného sídliště z mladší doby římské (nap̌r. Vích u. a. 2020).

\section{Benátky nad Jizerou, okr. Mladá Boleslav}

Hromadný nález byl odkryt někdy na konci května, či v průběhu června roku 1936 během stavby nové silnice kolem tehdejšího dobytčího tržiště (tzv. Pucovka). Místo nálezu je uprostřed současné komunikace Na Kosince (obr. 30). Poloha se nachází na severním okraji města, v nadm. výšce $225 \mathrm{~m}$, asi $150 \mathrm{~m}$ od vodoteče. Podle údajů v inventární knize Muzea Benátek n. J., předměty nalezl pan Špitálský, který je (přímo?) předal J. Šturmovi, členu městské rady Nových Benátek. Posledně jmenovaný pak depot v témže roce odevzdal do sbírek místního muzea (Soukal 1936, 4).

Depot se skládá ze závěsného řetězu na kotel (typ Neupotz NE 10), tkacích mečíků (typ Benátky), kopí a lžícovitého vrtáku.

Tkací mečíky (typ Benátky) byly dosud považovány za meče (např. Kotýnek 2018, 27, 116, 117, 120, 123, tab. 11; obr. 22; 36). Funkčně se tento předmět pokusil poprvé zařadit J. Henning $(1985,588)$. Z Čech známe, kromě předmětů z Benátek, ještě dvě paralely z Karlovic - Čertovy ruky (tab. 4; Kotýnek 2018, 41, 120-123, kat. č. 58, 110). Lze shrnout, že nálezy tkacích mečíků typu Benátky se vesměs koncentrují v barbariku na území mezi Rýnem, Labem a Jizerou (obr. 33). Patrně někde $\mathrm{v}$ tomto prostoru probíhala $\mathrm{v}$ mladší a pozdní době římské jejich výroba a distribuce. Je pozoruhodné, že v depotech se vyskytly v párech (viz i literárně doložený exemplář z Osterburken, Wagner 1897, 325).

\section{Diskuse a interpretace}

Na depoty z Rosovic, Letů u Dobřichovic a Benátek nad Jizerou je nutné nahlížet z několika hledisek. Kličové body spojené s interpretací se týkají a) chronologie jednotlivých součástí nálezu, b) chorologie komponent a kulturně historických souvislostí a za c) uložení a lokalizace v krajině.

\section{a) Chronologie}

Rosovice

Dvě dlouhé kosy 4. typu byly podle analogických nálezů deponovány pravděpodobně v druhé polovině 3. až v průběhu 4. stol.

\section{Lety u Dobřichovic}

V případě vědra typu E 43 je nejvíce zástupců evidováno v úseku od poloviny 2. stol. po konec 3. věku. Podobně lze ohraničit také výskyt a datování železné třínožky. Třetí stol. je rovněž obdobím odkud známe poměrně značné množství talířů/pánví typu NE 24a/Den Boesterd 91. Významným datovacím prvkem je dlouhá kosa 4. typu, jejíž protějšky byly produkovány v 2.-3. stol. Obě sekery (bradatice) jsou doloženy zejména v 3.-4. stol. Z výše uvedeného lze sumarizovat, že k uložení depotu mohlo dojít od poloviny 3. věku až v průběhu celého 4. stol. - počátku 5. věku. 


\section{Benátky nad Jizerou}

Nálezové okolnosti depotu nejsou přesně známé, soubor tedy nemusí být kompletní. Pozoruhodným prvkem je závěs na kotel. Datovat jej můžeme od konce 1. stol. do počátku doby stěhování národů. Tvar lžícovitého vrtáku odkazuje spíše do mladší a pozdní doby římské (např. Gaitzsch a kol. 1984). Otázkou zůstávají tkací mečíky, kdy analogické nálezy jsou sice datovány do 4. - 5./6. stol., ovšem tzv. pozdní exempláře mají vesměs velmi nejisté nálezové okolnosti.

\section{b) Chorologie, vybavení římských kuchyní v barbariku a kulturně historické souvislosti}

V případě hodnocení depotů z mladší/pozdní doby římské může být jedním z východisek pro interpretaci i jejich artefaktuální složení. V případě celku z Rosovic složeném ze dvou dlouhých kos se nabízí úvaha o torzu původní provinciální sady zemědělského nářadí, která však v barbariku mohla postrádat smysl, a proto došlo k jejímu rozdělení. S ohledem na výskyt další identické kosy v regionu totiž v depotu z Letů u Dobřichovic nemůžeme vyloučit společný původ všech třech exemplářù, které však mohly být uloženy v různých časových úsecích. Více prostoru pro interpretaci poskytuje depot z Letů u Dobřichovic. Zemědělské nářadí je zde zastoupeno radlicí, kosou a srpy. Další řemeslné aktivity dokládají nůžky, zlomek lžičkovitého vrtáku a koželužský nástroj. Sekery nelze jednoznačně zařadit, nebot' na ně můžeme pohlížet i jako na součást výzbroje. K řemeslným nástrojům depotu z Benátek nad Jizerou spadá rovněž lžičkovitý vrták a dva tkalcovské mečíky (?). Zbraně pak zastupuje hrot kopí. Nářadí, nástroje a zbraně jsou doloženy v depotech v prostředí barbarika (srv. naposledy Půlpánová-Reszcyńska/Pưlpán/Ondráčková 2018; Vích u. a. 2018). Podobně jsou rovněž častou složkou provinciálních depotů (Gaitzsch u. a. 1984, tab. 1).

Z nářadí si speciální pozornost zasluhují právě tkalcovské mečíky, nebot’ ty kromě depotů (Benátky nad Jizerou, Osterburken), známe i z Karlovic-Čertovy Ruky s doklady aktivit od mladší doby kamenné do středověku (Jiř́k 2008, 164; Kotýnek 2018), jejíž interpretace není stále uspojivě vyřešena (naposledy Jiřík 2008, 172, 173).

Skladba kovových nádob v depotu z Letů u Dobřichovic ukazuje na součásti římsko-provinciálního kuchyňského vybavení (srv. např. Leconte 2013). Ze zastoupených typů vyčnívají zejména obě pánve/talíře a trojnožka, které v barbariku nepatří k častým nálezům. Součástí římského kuchyňského vybavení, pokud odmyslíme jednoduchá soudkovitá vědra, kotle a naběračky s cedníky typu E 161, je v mladší době římské až počátku doby stěhování národů v barbarské části střední Evropy známých jen několik.

Zajímavým jevem je však zastoupení vybraných nádob a součástí vybavení kuchyní v ostatních depotech středoevropského barbarika např́íc dobou římskou. Příklady vybavení kuchyní v depotech shrnul J. Henning (1985, 575, 589). Ke kuchyňskému vybavení z námi hodnocených celků je nutné připsat rovněž torzo závěsného řetězu z Benátek nad Jizerou a snad také fragment železného háku na maso z depotu v Letech.

Zdá se tedy, že předměty zastoupené v římskoprovinciálních kuchyních nebyly v středoevropském prostoru zcela neznámé. Do jisté míry o tom svědčí i nálezy (např. rošty, kotle, pánve typu NE 24a, závěsy kotlů) z bohatě vybavených hrobů barbarské elity. V hrobových kontextech jsou tyto záležitosti interpretovány jako významné statusové prvky (Steuer 2006, 14, 19, 22), které patřily k nedílné součásti ritualizovaných výbav některých bohatých hrobů již od pozdní doby laténské/časné doby římské, a to jak na území pod římskou správou a vlivem (např. Voss 2006, 25, obr. 4: 16), tak v barbariku (ke kotlům viz Voss 2006, 25). Aktuálně jsou zmíněné prvky hrobových výbav interpretovány jako předměty sloužící při pohřebních hostinách (k tomu podrobně Steuer 2006, 14, 19, 20).

Otázka vztahů mezi nálezy z depotů a hrobů je stále diskutována. N. Myrberg $(2009,135,136)$ předpokládala, že v pozdní době stěhování národů až vikingském období, byly zejména luxusní artefakty známé z hrobů a depotů pečlivě vybírány s ohledem na funkci a symboliku. Nelze tak vyloučit, že se může jednat o památky s vlastní historií; tzv. předměty paměti (např. Bradley 2017, 53, 54).

Druhý úhel pohledu je spojen s rituálními důvody. V případě depotů uložených na sídlištích pod podlahami zemnic, případně v sídlištních situacích je však tato interpretace obtížně uchopitelná (k tomu Roymans/Scheers 2012, 20), jakkoliv můžeme přemýšlet o obětích souvisejících s pomyslným užíváním daných sídlištních objektů, jakým může být výstavba objektu, jeho užívání a následné opuštění (Kolon 2015).

Zajímavé vysvětlení ukládání depotů v nebezpečných časech předložili N. Roymans a S. Scheers $(2012,19,20)$, kteří v př́ipadě deponování keltských zlatých mincí a drahocenností z caesarovského období ukázali, že samo uložení předmětů před nepřáteli mohlo být spojeno s rituálem směřujícím jak k záchraně společenstva, tak i vlastních artefaktů.

\section{c) Uložení a lokalizace v krajině}

Depot z Rosovic byl uložen do jámy s velikosti $80 \times 30$ a hloubkou 25 centimetrů, delší stranou orientované SV - JZ. Podle způsobu uložení, tak jak jej popsal a částečně fotograficky dokumentoval nálezce, lze uvažovat o možnosti, že kosy byly před uložením do země zabaleny do nějakého vaku organického původu, jeho přítomnost však nebyla potvrzena. Orientace ke světovým stranám také nemusela být náhodná (srov. Hrádečná: Půlpánová-Reszcyńska/Půlpán/ Ondráčková 2018, 577). Soudobé osídlení, a to ani v širším okolí, není známé. Místo nálezu je v nadmořské výšce 440 m, mimo vodní toky. Z kontextu nálezů z jiných období pravěku a konfigurace terénu je pravděpodobné, že předměty byly uloženy v blízkosti či v trase komunikace.

Detaily o formě uložení depotu z Benátek nad Jizerou neznáme. Pouze podle složení závěsného háku a (původně zcela?) zohýbaných tkacích mečíků lze soudit na obal, v kterém byly předměty původně uloženy. Depot byl uložen na rozhraní údolí a úbočí na severní straně kopce v nadm. výšce $225 \mathrm{~m}$. Místo bylo ve středověku a novověku změněno výstavbou města a zámku, přesto mu však nelze upřít jeho jistou exponovanost - nabízí poměrně široký rozhled po 
krajině v širším severním směru. Ačkoliv je od současné občasné vodoteče vzdálen asi 150 metrů, nedá se dle současné konfigurace terénu vyloučit, že v minulosti mohl být v jeho blízkosti pramen, či pramenná pánev.

Z hodnocených celků vyčnívá především depot z Letů u Dobřichovic. Předměty byly naskládány do dvou kovových nádob a uloženy do jámy. Př́tomnost látky či jiného obalu z organického materiálu nelze doložit. Obložení objektu kameny poukazuje na možnost, že se mohlo jednat např. o výrobní objekt, snad pec, ale tuto úvahu již nelze argumentovat.

Depot byl podle dostupných informací uložen pravděpodobně na ploše terasy. Samotná pozice nálezu vyvolává řadu otázek. Trvalo sídliště z časné doby římské (Halama 2006, 338, obr. 1) i ve 3.-4. stol., nebo byl sklad uložen do země až po opuštění osady (?). Důležité je situování nálezu do soutoku Berounky s potokem Kejná. Právě vazba k vodním tokům a soutokům je často jedním z důležitých argumentů pro rituální interpretaci depotů (Bradley 2017, např. 19, 169-172; Lutovský 2001, 156). Na základě výše nastíněných indicií můžeme uvažovat jako o tzv. rituálním depotu.

\section{Poděkováni}

Za dokumentaci dentakrylových kopií srdečně děkujeme Jiřímu Koštovi z Národního muzea. Podle dochovaných údajů byly dentakrylové kopie pořízeny p. Slabihoudkem někdy po roce 1967 pro účely prezentace letského nálezu v stálé expozici v hlavní budově Národního muzea. Později byla vyhotovena další sada pro stálou expozici v Lobkovickém paláci na Pražském hradě. Za možnost dokumentace měděných nádob děkujeme Elišce Wiesnerové a Luboši Rypkovi z Muzea města Ústí nad Labem; Jiřímu Koštovi, Viktorii Čistakovové, Luboši Rypkovi a Tomáši Zacharovi (Eberhard Karls Universität Tübingen) za podnětné diskuse a poskytnutí jinak nedostupné literatury. Za pomoc při lokalizaci Babičkovy vily v Letech a umožnění studia př́islušných archivních materiálů děkujeme paní Petře Flasarové, knihovnici v Obecní knihovně v Letech. Za možnost dokumentace depotu z Benátek srdečně děkujeme ředitelce Muzea Mladoboleslavska Kateřině Jeníčkové, vedoucí pobočky muzea v Benátkách nad Jizerou Marii Chupíkové a archeologovi Filipu Krásnému.

Obr. 1. Rosovice, místo nálezu depotu. Zhotovil P. Čechák a R. Korený.

Obr. 2. Rosovice, depot v momentě odkrytí druhé kosy. Foto nálezce.

Obr. 3. Rosovice, depot. Kreslil R. Korený.

Obr. 4. Mapa s nálezy kos 4. typu podle B. Hanemannové. 1 - Regensburg-Kumpfmühl; 2 - Lienz; 3 - Bregenz; 4 - Monatshausen; 5 - Stein; 6 - Sanzeno; 7 - Dellach-Gurina; 8 - Benken; 9 - Bad Urach - Runder Berg; 10 - Osterburken; 11 - Loka pri Žusmu; 12 - Lety u Dobřichovic; 13 - Rosovice; 14 - Rainau-Buch; 15 - Regensburg-Harting; 16 Weißenburg; 17 (?) - Bratislava-Rusovce.

Obr. 5. Kosy 4. typu. 1 - Regensburg-Kumpfmühl; 2 - Lienz; 3 - Bregenz; 4 - Monatshausen; 5 - Stein; 6 - Sanzeno (podle Garbsch 1993; Henning 1991a; Nothdurfter 1979; Pohanka 1986). Různá měřítka.

Obr. 6. Kosy 4. typu. 1-3 - Dellach-Gurina; 4 - Benken; 5 - Bad Urach - Runder Berg; 6-8 - Osterburken; 9 - Loka pri Žusmu; 10 - Lety u Dobřichovic (podle Ciglenečki 2000; Henning 1985; Jablonka 2001; Keller 1846-1847; Koch 1991; Ulrich/Heizmann 1890, upraveno). Různá měřítka.

Obr. 7. Kosy 4. typu. 1-3 - Rainau-Buch; 4-6 - Regensburg-Harting; 7, 8 - Weißenburg (Greiner 2010; Rieckhoff 1997; Schwarz 1967, upraveno). Různá měřítka.

Obr. 8. Kosy 4. typu a jejich výskyt v průběhu 1.-4. stol.

Obr. 9. První kosa. 1 - studovaný předmět a zpo̊sob jeho navzorkování; 2 - schématické nákresy vzorků (A1, B1 - neleptaný stav; A2, B2 - po naleptání nitalem; A3, B3 - po naleptání Oberhofferem; A4, B4 - rozložení popisovaných strukturních oblastí; A5, B5 - vyznačení hlavních svarů a zachycených strukturních oblastí); 3 - graf průběhu tvrdosti. Foto J. Hošek.

Obr. 10. První kosa. a - za studena tvářená perlitická struktura vzorku A, oblasti I; b - mírně nadeutektoidní perliticko-cementitická struktura ve vzorku A, oblasti II; c - řádkovitost struktury a část podélného svaru vzorku A, oblasti III; d - oblasti III a IV ve vzorku A; e - perlitická struktura s trochou feritu ve vzorku B, oblasti I. a, b, d, e leptáno nitalem; c - leptáno Oberhofferem. Foto J. Hošek.

Obr. 11. První kosa. Schématické nákresy vzorku C (C1 - neleptaný stav; C2 - po naleptání nitalem; C3 - po naleptání Oberhofferem; C4 - rozložení popisovaných strukturních oblastí; C5 - vyznačení hlavních svarů a zachycených strukturních oblastí); a - feritická struktura oblasti I; b - perlitická struktura oblasti III; c - nadeutektoidní perliticko-cementitická struktur oblasti IV. Leptáno nitalem. Foto J. Hošek.

Obr. 12. Druhá kosa. 1 - studovaný předmět a způsob jeho navzorkování; 2 - schématické nákresy vzorku A (A1 - neleptaný stav; A2 - po naleptání nitalem; A3 - po naleptání Oberhofferem; A4 - rozložení popisovaných strukturních oblastí; A5 - vyznačení hlavních svarů a zachycených strukturních oblastí); 3 - graf průběhu tvrdosti. Foto J. Hošek.

Obr. 13. Druhá kosa. Schématické nákresy vzorku B. B1 - neleptaný stav; B2 - po naleptání nitalem; B3 - po naleptání Oberhofferem; B4 - rozložení popisovaných strukturních oblastí; B5 - vyznačení hlavních svarů a zachycených strukturních oblastí. a - perlitická struktura vzorku A, oblasti II; b - feriticko-perlitická struktura vzorku B, oblasti III; c - makrofotografie vzorku B, oblasti II obklopené oblastí I. Leptáno nitalem (a, c, d). Foto J. Hošek.

Obr. 14. Postup výroby repliky kosy. Kreslila P. Jánská.

Obr. 15. Lety, fotografie depotu, nedat. (1967?). 1 - radlice s tulejí (?, podle Beranová/Lutovský 2009, upraveno).

Obr. 16. Lety. 1 - sídliště ze starší doby římské; 2 - předpokládané místo nálezu depotu (podle Halama 2006, doplněno). Zhotovil P. Čechák a R. Korený.

Obr. 17. Lety. Kovové nádoby. Kreslil R. Korený. 
Obr. 18. Lety. Kovové nádoby. 1-3 - talí̌r/pánev typu NE 24a; 4-pánev typu Den Boesterd 91; 5-8 - mísovitý kotel. Foto

R. Korený, upravil J. Jílek.

Obr. 19. Lety. 1 - závěs na kotel; 2 - železná třínožka; 3, 4 - pouta na kotle (podle Beranová/Lutovský 2009).

Obr. 20. Sarajevo-Stup. Část kuchyňské soupravy z římské vily, 3.-4. stol. (podle Busuladžić 2011).

Obr. 21. Železné třínožky s pánvemi (podle Greiner 2010).

Obr. 22. Lety. 1 - naběračka/klíč; 2 - vrták; 3 - koželužská kosa; 4 - nůžky. Kreslil R. Korený.

Obr. 23. Lety. 1 - kosa (a - reparační otvor; b - reparační otvor (část); c - štěpiny po zlomené rukojeti; d - hřbet; e - lišta; f - šikmý lom po zlomení koncové části rukojeti); 2, 3 - srpy; 4 - nůžky (fotografie podle Beranová/Lutovský 2009, upraveno).

Obr. 24. Lety. Kosa. Rekonstrukce. Kreslil R. Korený.

Obr. 25. Lety. 1 - radlice; 2 - dvojhrot; 3, 4- srpy. Kreslil R. Korený.

Obr. 26. Lety. Sekery. Kreslil R. Korený.

Obr. 27. Sarajevo-Stup. Římská vila. Sekery (podle Busuladžić 2014).

Obr. 28. Manching. Klíč (podle Jacobi 1974).

Obr. 29. Lety. 1 - klíč/šídlo (?); 2, 3 - plochá kování s očkem; 4 - trn z vidlí (?); 5 - náboj kola vozu (?); 6 - kroužek; 7, 8 plíšky (podle Bartošková 1986).

Obr. 30. Benátky nad Jizerou. Místo nálezu depotu. Zhotovil P. Čechák a R. Korený.

Obr. 31. Benátky nad Jizerou. 1 - závěs kotle; 2, 3 tkací mečíky; 4 - lžícovitý vrták; 5 - kopí. Kreslil R. Korený.

Obr. 32. Neupotz. Jednoramenný závěs na kotel, typ N 10 (podle Künzl 1993).

Obr. 33. Nálezy tkacích mečíků typu Benátky.

Obr. 34. Depoty železných předmětů z doby římské v Čechách. 1 - Rosovice (okr. Příbram); 2 - Lety u Dobřichovic (okr. Beroun); 3 - Benátky nad Jizerou (okr. Mladá Boleslav); 4 - Přerov nad Labem (?, okr. Nymburk); 5 - Opolany (okr. Nymburk); 6 - Hrádečná (okr. Chomutov). Zhotovil P. Čechák a R. Korený.

Tabela 1. Kosy typu 4, jejich parametry a nálezové kontexty.

Tabela 2. Přehled nálezů kos (různé typy) s kovadlinkami, kladívky typů 3 a 2 (podle Hanemann 2014) a brousky (zkratky: $\mathrm{D}=$ depot).

Tabela 3. Zastoupení kos ve vybraných depotech.

Tabela 4. Tkací mečíky a jejich parametry (celková délka, délka, šířka a profil čepele, délka a profil trnu, poměr délky čepele a trnu).

Übersetzung von Jana Kličová (Text), Jan Machula (Abb. 8 und Tab.)

Translated by Klára Posekaná

Mgr. Rastislav Korený, Ph.D.

Hornické muzeum Př́ibram, p. o.

Nám. Hynka Kličky 293

CZ - 26101 Příbram VI

koreny-r@muzeum-pribram.cz

Ing. Jiří Hošek, Ph.D.

Archeologický ústav Praha, v. v. i.

Letenská 4

CZ - 11801 Praha 1

hosek@arup.cas.cz

CZ - 60200 Brno
Petra Jánská

Ryšín 11

CZ - 27021 Pavlíkov

pj7772pj@gmail.com

PhDr. Jan Jílek, Ph.D.

Ústav archeologie a muzeologie

Oddělení klasické archeologie

Filozofická fakulta, Masarykova univerzita

Arna Nováka 1/1

Archeologické oddělení

Východočeské muzeum v Pardubicích

Zámek 2

CZ - 53002 Pardubice

mitridates@post.cz 